\title{
Summary and Conclusions of a Workshop on "Quantifying the Contribution of Flaming Residential Upholstered Furniture to Fire Losses in the United States”
}

William M. Pitts 
NIST Technical Note 1757

\section{Summary and Conclusions of a Workshop on "Quantifying the Contribution of Flaming Residential Upholstered Furniture to Fire Losses in the United States”}

William M. Pitts Engineering Laboratory Fire Research Division

http://dx.doi.org/10.6028/NIST.TN.1757

September 2012

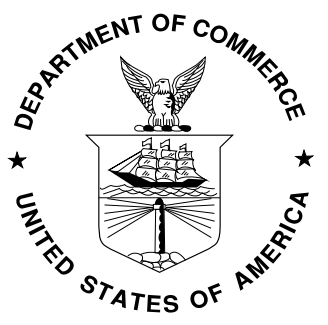

U.S. Department of Commerce Rebecca Blank, Acting Secretary

National Institute of Standards and Technology Patrick D. Gallagher, Under Secretary of Commerce for Standards and Technology and Director 
Certain commercial entities, equipment, or materials may be identified in this document in order to describe an experimental procedure or concept adequately. Such identification is not intended to imply recommendation or endorsement by the National Institute of Standards and Technology, nor is it intended to imply that the entities, materials, or equipment are necessarily the best available for the purpose.

National Institute of Standards and Technology Technical Note 1757

Natl. Inst. Stand. Technol. Tech. Note 1757, 134 pages (September 2012)

http://dx.doi.org/10.6028/NIST.TN.1757

CODEN: NTNOEF 


\section{ABSTRACT}

This report summarizes the presentations and discussions, lists major conclusions, and provides recommendations for specific next steps from a workshop entitled "Quantifying the Contribution of Flaming Residential Upholstered Furniture to Fire Losses in the United States" that was held at the National Institute of Standards of Technology on March 22-23, 2012. The workshop objective was "to identify approaches for quantifying the full contribution of flaming fires of modern residential upholstered furniture (RUF) to the Nation's fire losses and, therefore, the potential for reducing these losses”. The workshop consisted of three sessions including 1) presentations by experts on RUF fire behavior and the collection and analysis of United States fire statistics (primarily the National Fire Incidence Reporting System (NFIRS)), 2) an open, wide-ranging participant discussion addressing several specific topics with the aid of facilitators, and 3) a closing session where conclusions were listed and recommendations developed for a series of actions designed to improve the quantification of fire losses due to flaming RUF with characterized levels of uncertainty. Major workshops findings included 1) fires involving flaming RUF have the potential to grow very rapidly to high release rate levels capable of threatening civilians, firefighters, and property, 2) fires involving RUF are a major factor in current fire losses in the United States, contributing at much greater levels than their numbers would indicate, and 3) existing statistical analyses likely underestimate the full contribution of flaming RUF to fire losses. An approach based on a matrix analysis is recommended to improve estimates for the contribution of flaming RUF to fire losses in the short term. In addition, a series of longer-term steps designed to improve the accuracy of these estimates and reduce uncertainties in the values are suggested. These include 1) surveys of NFIRS practitioners to better understand how specific items are coded in NFIRS, 2) organize and carry out an NFIRS special study designed to provide targeted information concerning the role of flaming RUF in residential fires, and 3) perform probabilistic fire modeling to better understand the role of flaming RUF in fire growth and spread. Appendices to the report include the workshop announcement, attendees, agenda, and PowerPoint presentations; a copy of the NFIRS coding form; and a summary and conclusions from the first day presentations and discussion.

Key Words: fire losses; fire statistics; flaming fires; NFIRS; residential fires, residential upholstered furniture; workshop 


\section{Table of Contents}

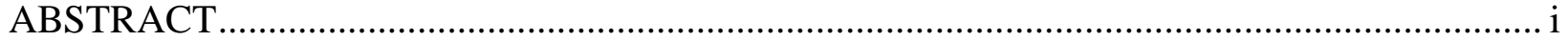

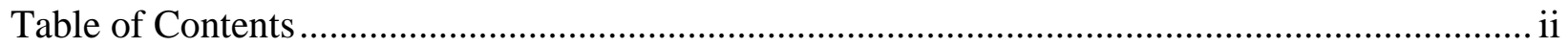

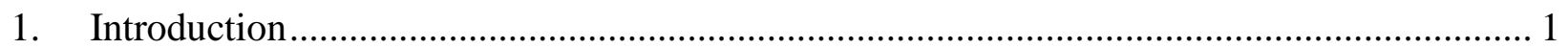

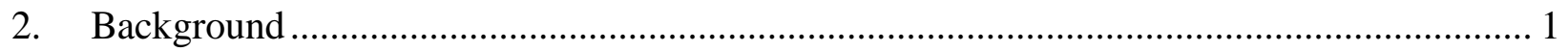

3. Workshop Organization .................................................................................... 2

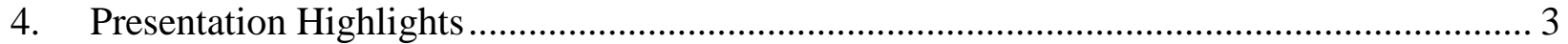

4.1. Anthony Hamins, NIST ………………………............................................... 3

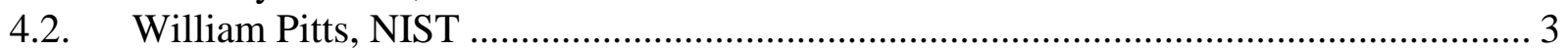

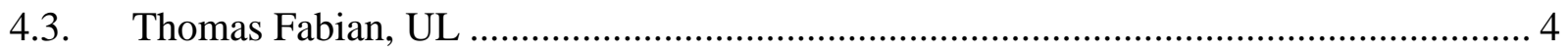

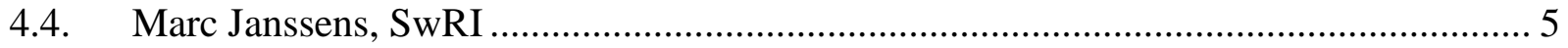

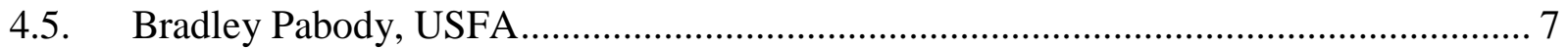

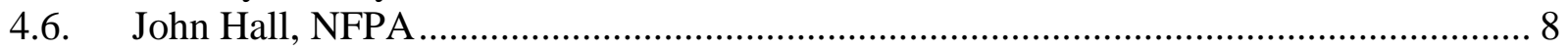

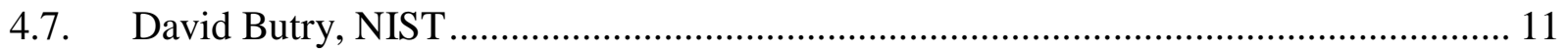

5. Open Forum Discussion........................................................................................... 12

5.1. Would decreasing the rate of fire growth and heat release in an enclosure significantly reduce residential fire losses within the room of fire origin? (Facilitator: Jason Averill)........ 12 5.2. Would decreasing the rate of fire growth and heat release in an enclosure significantly reduce residential fire losses at locations substantially removed from the room of fire origin? (Facilitator: Richard Gann) …………………………….................................................. 14

5.3. What are the relevant characteristics of residential fires involving flaming RUF contributing to fire losses? (Facilitator: Jason Averill)........................................................... 15

5.4. Is flaming RUF likely playing a significant role in residential fire losses? (Facilitator:

Richard Gann) ............................................................................................................... 16

5.5. Is it appropriate to differentiate fire losses inside and exterior to the room of fire origin with regard to the role of RUF in Residential Fire Losses? (Facilitator: Jason Averill) .......... 16 5.6. Do existing fire statistics and related analyses effectively capture contribution of flaming RUF to residential fire losses? .................................................................................. 17

5.7. Can existing fire statistics and extended analyses better capture contributions of flaming RUF to residential fire losses?............................................................................. 17

6. Summary of Presentations and Discussions and Identification of Approaches and Participants for Estimating Role of Flaming RUF in Fire Losses ............................................... 18

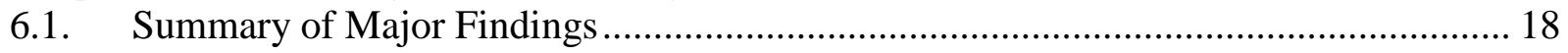

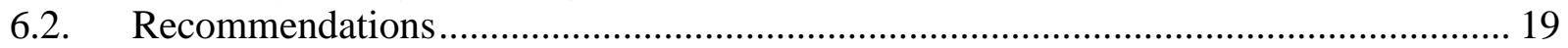

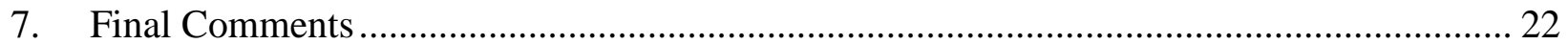

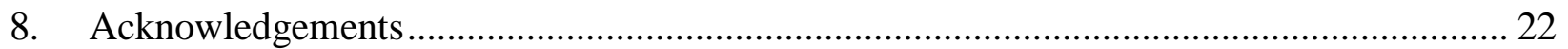

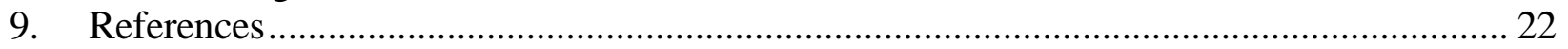

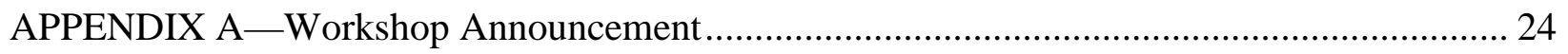

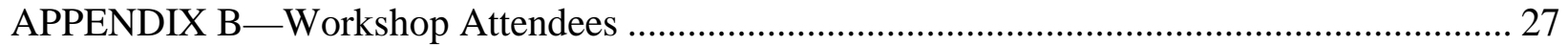

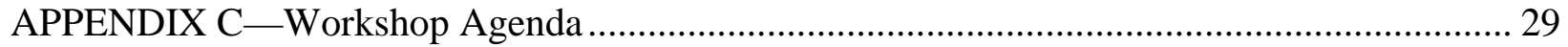

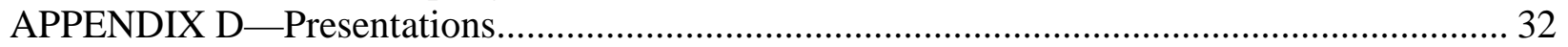

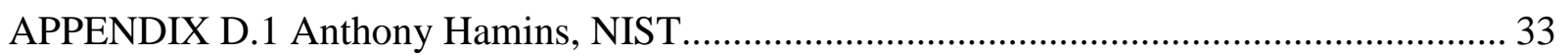

APPENDIX D.2 William M. Pitts, NIST ……………..................................................... 40

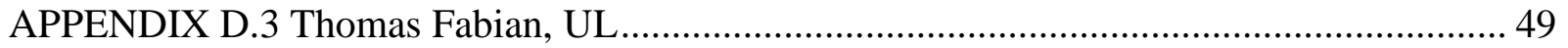

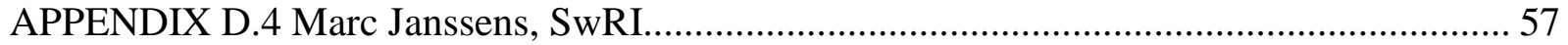




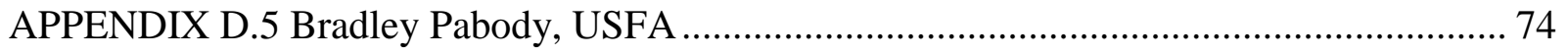

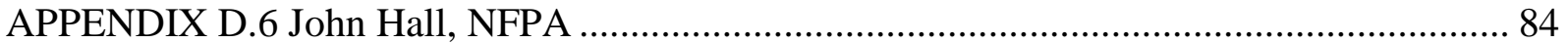

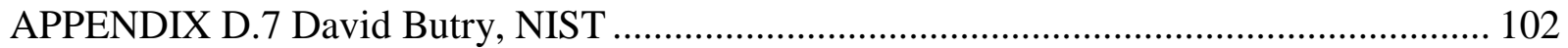

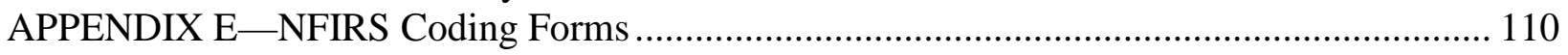

APPENDIX F-Summary of First-Day Presentations and Discussion.................................. 127 


\section{Introduction}

A workshop entitled "Quantifying the Contribution of Flaming Residential ${ }^{1}$ Upholstered Furniture to Fire Losses in the United States" was held at the National Institute of Standards and Technology (NIST) in Gaithersburg, MD on March 22-23, 2012. This report summarizes the presentations, discussions, conclusions, and outcomes of the workshop.

\section{Background}

The rationale for the workshop was discussed in the announcement. This document is included in Appendix A.

Briefly, a large fraction of the residential upholstered furniture (RUF) found in existing homes is believed to be capable of supporting rapidly growing flaming fires that can achieve sufficiently high heat release rates to ignite other nearby items and in some cases can induce flashover as a single burning item. Furthermore, this potential and the large size and mass of a typical RUF item mean that these items can be the principal contributors to the size and loss impact of the entire fire, even when a different item is the first item ignited. These diverse phenomena involve every aspect of RUF fire performance, except its susceptibility to smoldering ignition. For this reason, the term "flaming RUF" will be used throughout this report to refer to the propensity for RUF fires to grow rapidly to high peak intensities and thereby result in large, damaging fires.

Indications of the potential for RUF to contribute to fire losses is available in recent studies reported by NIST [1] and Underwriters Laboratories (UL) [2]. In the NIST study, fire growth was studied in rooms furnished with articles, including RUF, typically found in today's living rooms in order to characterize smoke detector response time and its implications for fire losses. One of the parameters characterized was the time to untenable conditions in the room. These times were compared with the results from a similar study carried out in the mid-1970s [3] and were found to have dropped from on the order of $17 \mathrm{~min}$ to around $3 \mathrm{~min}$. Changes in the materials used in RUF construction over this period were identified as a major, though not the only, factor in this dramatic decrease. The UL study included a comparison of fires in fully furnished rooms in which the only difference was the presence of RUF articles constructed from either materials commonly found in furniture today, (flexible polyurethane (FPUF) foam covered with polyester fabric), or so-called "legacy" materials (cotton fabric over cotton batting). This investigation found that the time to flashover in the room was reduced from just over 30 min to around 4 min when the legacy RUF was replaced with RUF incorporating FPUF and the plastic fabric.

There are a number of modes in which RUF can participate in fires in residences. These include: (1) RUF is the first item ignited, and the fire begins and ends in smoldering mode. (2) RUF is the first item ignited, and the fire begins in flaming mode. (3) RUF is the first item ignited and the fire begins in smoldering mode, but transitions to flaming mode. (4) RUF is the first item ignited, but the RUF fire also serves as a flaming heat source to ignite other items. (5) RUF is the first item ignited, and the RUF fire is either the principal or only contributor to the room going to flashover. (6) RUF is not the first item ignited, but another item serves as a flaming heat source to ignite RUF.

\footnotetext{
${ }^{1}$ The National Fire Protection Association (NFPA) makes a distinction between "home" and "residential" fires. Homes include one- and two-family homes (including manufactured housing) and multi-family housing or apartments. Residential includes homes, but it also includes hotels and motels, dorms, residential board and care or assisted living, rooming houses, etc. Most of NFPA's analyses, including analyses of upholstered furniture fires, refer to fires in homes and not all residential fires. Using these definitions, the workshop focus was home fires, even though the terms residential and home are used interchangeably in this report.
} 
Statistics for the United States indicate that fires in which RUF is the item first ignited are responsible for a significant fraction of civilian fire losses (deaths, injuries, property). The most frequently cited ignition source for these fires is smoking materials, which typically ignite smoldering fires that can later transition to flaming. As a result, fire prevention efforts for RUF have focused on limiting smoldering ignition. The proposed Consumer Product Safety Commission's (CPSC) draft standard 16 CFR Part 1634 [4] is the prime example of this approach. Efforts to limit the fire growth and maximum heat release rates of flaming RUF have received far less attention. It should be noted that such standards aimed at flaming furniture have been developed for residential mattresses (16 CFR Part 1633 [5]) and commercial and institutional upholstered furniture (California Technical Bulletin 133 [6]).

The following three hypotheses listed in the workshop announcement, if true, suggest that significant reductions in fire losses would occur if the fire development rates and maximum heat release rates of RUF articles were substantially reduced. The hypotheses are:

- A decreased rate of fire development inside a residential room containing RUF increases the time available for response or escape and can result in decreased fire losses (both property and human) inside the room of fire origin.

- Flashover development in the room of fire origin increases production of toxic gases and smoke and the likelihood of fire spread to other areas of the residence. This increases the potential for fire losses at locations substantially removed from the room of fire origin.

- Reducing the fire growth rate on and limiting the maximum heat release rate of RUF to levels insufficient to generate flashover or ignite nearby furnishings would substantially reduce financial and human fire losses in the United States.

Even though the fire behavior of flaming RUF suggests that it likely makes a significant contribution to the nation's fire losses, no authorative estimates of fire losses that include all and only the fires that we have here identified as "flaming RUF" are available. As a result, it is currently not possible to predict the potential for reducing fire losses by modifying RUF in such ways as to reduce its contribution to fire spread and growth in residences.

The workshop was organized specifically to evaluate the potential for estimating the contribution of flaming RUF to fire losses in the United States using currently available fire statistics and to identify future approaches for reducing uncertainties in such estimates.

The formal objective of the workshop was:

To identify approaches for quantifying the full contribution of flaming fires of modern RUF to the Nation's fire losses and, therefore, the potential for reducing these losses.

\section{Workshop Organization}

The approach adopted for the workshop was to bring together experts familiar with the collection and utilization of fire statistics, primarily the National Fire Incident Reporting System (NFIRS), and the fire behavior of flaming RUF with a goal of creating a synergy that would contribute to meeting the workshop objective. The final list of attendees is included in Appendix B of this report.

In order to prepare a foundation for later discussion, a series of presentations were solicited dealing with the fire behavior of flaming RUF and the description and use of NFIRS. The presenters and their talk titles are included as part of the workshop agenda provided in Appendix C. Note that due to a scheduling conflict, it was necessary for David Sheppard of the Bureau of Alcohol, Tobacco, Firearms and 
Explosives (ATF) to withdraw from the workshop, and this presentation was not presented. The allocated time for this presentation was absorbed into the other talks and discussion.

The afternoon session on the first day of the workshop was intended to provide a wide ranging discussion of the workshop topic involving all of the participants. A series of questions designed to satisfy the Workshop objective and address various aspects of the topic are listed in Appendix C. Facilitators aided in focusing the discussions and capturing the major thoughts and ideas discussed by the workshop participants.

The final half day session of the workshop was devoted to identifying approaches for meeting the workshop objective and suggesting a path forward. Even though the agenda indicates a series of stages to accomplish this, the workshop participants concurred that sufficient consensus had been achieved during the first day that it was be possible to work together and lay out an appropriate strategy without further deliberation. John Hall of the National Fire Protection Association (NFPA) led the discussion.

\section{Presentation Highlights}

The slides presented by the speakers are included in Appendix D. Major points from the presentations and related questions and discussion are summarized below.

\subsection{Anthony Hamins, NIST}

Anthony Hamins, Chief of the Fire Research Division of NIST, welcomed the workshop participants and provided an overview of NIST and the Engineering Laboratory. He emphasized the Fire Research Division's focus on measurement science and provided an indication of the breadth of the NIST research portfolio. The magnitude of the nation's fire problem and its impact on society was made clear by citing statistics on direct fire losses, both human and property, as well as indirect costs such as fire departments and insurance. The fire research efforts at NIST were discussed both in terms of a long-range vision and its current programs.

The magnitude of continuing fire losses in the United States was provided by considering statistics from 2008, which indicated that 2800 people died, 14,960 were injured, and direct property losses amounted to 16.6 billion dollars in structure fires. The importance of residential fires was emphasized, with $73 \%$ of all reported structure fires, $92 \%$ of civilian fire deaths, $86 \%$ of civilian fire injuries, and $68 \%$ of direct property losses due to such fires. The relative importance of residential upholstered furniture and mattresses to these losses was identified by noting that the numbers of deaths and injuries associated with fires when these items were reported as the item first ignited were substantially higher than when other items were identified as the first ignited.

\subsection{William Pitts, NIST}

William Pitts provided an overview of the workshop. As an example of the potential for RUF to be a serious fire problem, he showed heat release rate measurements and photographs from a NIST experiment in which a single sofa inside a small room (ISO 9705 [7]) was ignited with a small flame. For the initial $100 \mathrm{~s}$ following ignition, the fire grew slowly and remained relatively small. This was followed by a period of more rapid fire growth. Starting around $180 \mathrm{~s}$, the fire grew very rapidly, reaching a peak heat release rate of $2.5 \mathrm{MW}$ around $300 \mathrm{~s}$. The room became filled with flames and heavy smoke. The NIST Dunes 1 [1] and Dunes 2 [3] experiments and the recent UL studies of RUF flammability [2] discussed in the Background Section above were then summarized. It was noted that the roughly three to four minutes required for the development of untenable conditions and/or flashover in these studies were consistent with the time required for the single sofa to become fully involved in the NIST experiment. A short summary of previous research on RUF flammability was provided. 
Some statistics from the CPSC Proposed Rule 16 CFR Part 1634, Standard for the Flammability of Residential Upholstered Furniture, were summarized [4]. These indicated that during the period 20022004, 7800 reported residential fires, 540 civilian deaths, 870 civilian injuries, and \$250 million in property loss per year were attributed to fires in which RUF was identified as the item first ignited. Utilizing NFPA statistics for fires from 2003 [8], it was revealed that these values represented $1.9 \%$, $17 \%, 6.2 \%$, and $4.1 \%$, respectively, of the totals for residential fires. The statistic which stands out is that the $1.9 \%$ of total reported fires in which RUF was the item first ignited were responsible for $17 \%$ of fire deaths in residences, but the values for injuries and property losses are also markedly higher than might be expected based simply on the percentage of fires involving RUF as the item first ignited. This provides an indication that fires involving RUF have the potential to be much more damaging than fires originating in other ways. In other words, the risks of civilian injury and death and property loss are much higher when the item first ignited is RUF.

Statistics taken from a summary compiled by the NFPA for 2010 indicated that $92 \%$ of civilian structural fire deaths occurred in residences, the $4 \%$ of fires starting in a living room, family room, or den were responsible for $24 \%$ of the total civilian fire deaths, and similar enhancements in deaths, injuries, and property losses were associated with fires starting in a bedroom. [9] While not directly linked, these statistics suggest that the presence of RUF and bedding contribute to more serious fires. Smoking materials ignition of RUF or mattresses remained the leading cause of civilian fire deaths. Another interesting observation was obtained by normalizing fire losses by the number of reported fires per year and inspecting the trends over a period of time. This analysis revealed that even though the annual number of reported fires has dropped $55 \%$ since 1980, the number of civilian fire deaths and injuries per reported fire has remained essentially constant. Over the same period the number of firefighter deaths and injuries per reported fire increased significantly, as did the average property loss per fire in normalized dollars.

The number of RUF articles in households was identified as an important parameter for understanding the role of RUF in fire losses. Statistics taken from the CPSC Proposed Rule 16 CFR Part 1634 indicate that an average residence contained four articles in the early 2000s [4]. This number is consistent with two, more recent, studies of flammable contents in residences carried out in Canada $[10,11]$.

The purpose of the workshop, the hypotheses discussed earlier, and the workshop objective were then reviewed. The need to remain focused on the specific topic of the workshop was emphasized, since it was recognized that the general topic of RUF flammability is a wide-ranging topic of high current interest.

\subsection{Thomas Fabian, UL}

This presentation started with a review of fire statistics taken from a report by M. Ahrens of NFPA based on statistics from 2003-2008. [12] It was reported that $23 \%$ of civilian fire deaths and $10 \%$ of injuries were associated with the $4 \%$ of reported fires that occurred in a living room, family room, or den. The percentage of reported fires and fire deaths agree well with those listed above. It was also noted that $21 \%$ of fire deaths occurred in fires where RUF was the item first ignited. This value is somewhat higher than the value of $17 \%$ cited above based on the CPSC work. The similarity of these statistics to those for bedroom fires was noted.

A series of experiments was performed at UL in which RUF materials, mock-ups, and actual RUF were tested. A range of materials were used with a focus on the effectiveness of fire barriers. A single fabric, two flexible polyurethane foams (FPUFs), a single polyester wrap, and eleven barriers were used. Data were presented for mock ups and actual RUF that showed that the use of a barrier significantly slowed fire growth and reduced peak heat release rates (HRRs). Comparison of mock-ups and RUF constructed with either non-fire-retarded foam or FPUF meeting the California TB 117 standard [13] showed 
measurable reductions in peak HRRs for items containing foam meeting the standard, but the reductions provided only a marginal improvement in fire performance. Cone calorimeter measurements were characterized as having the capability to distinguish the fire performance of individual materials or groups of materials, but did not necessarily correlate with large scale experiments.

In a second phase of the effort, specially constructed RUF was positioned inside a room containing other identical furnishings. Three types of RUF were considered: contemporary (non-fire-retarded foam with polyester fabric and polyester wrap), contemporary with added fire barrier, and legacy (cotton batting and cotton fabric). As mentioned above, when the contemporary furniture was ignited, flashover was observed in around $4 \mathrm{~min}$. These times were comparable to those observed in the NIST experiment with used furniture. When the legacy furniture was tested, the time to flashover increased to about $34 \mathrm{~min}$. Replacing the polyester wrap in contemporary furniture with a cotton-based barrier increased the required time for flashover to roughly $21 \mathrm{~min}$.

In recently completed experiments, the effects of replacing contemporary RUF with contemporary RUF with an added fire barrier were investigated inside structures representing a one story ranch house and a two story colonial home with an open floor plan. The tenability at locations well removed from the fire room was considered. Using a measured temperature $1.5 \mathrm{~m}$ above the floor, i.e., face height, of $150{ }^{\circ} \mathrm{C}$ as a criteria, the time to untenability for an upstairs room in the two story structure was increased from $303 \mathrm{~s}$ to $1959 \mathrm{~s}$ when the fire barrier was added.

A participant asked whether there would have been similar changes in smoke detector response time when the RUF was changed. The answer was that smoke detectors responded early in all fires, so that available escape times were significantly increased when the time to untenability increased.

The times quoted for the development of flashover and untenability led the audience to discuss the period required for a fire department to reach a location following an alarm. For an urban fire department, Sean DeCrane, a Battalion Chief with the Cleveland Fire Department, indicated that the average time between the receipt of an emergency call and when firemen are prepared to enter a residence is 7 min to 9 min. This period includes response ( $4 \mathrm{~min}$ to $6 \mathrm{~min}$ ) and scene deployment ( $3 \mathrm{~min}$ to $4 \mathrm{~min}$ ) times. Times for rural departments will generally be longer. These response times have obvious implications given the rapid fire growth observed with the contemporary upholstered furniture.

There was some discussion of the effectiveness of various barrier types as well as the effectiveness of using high loft barrier materials to replace polyester wrap. Both advantages and drawbacks of this approach were mentioned.

\subsection{Marc Janssens, SwRI}

This presentation described an investigation funded by the Department of Justice that is aiming to improve and characterize uncertainties associated with different approaches for predicting the burning behavior of RUF during fire reconstructions. An important point was made that the information available describing the RUF can vary considerably from cases where duplicate articles of RUF are available for testing, to cases where only small samples of materials used to construct the article are available, to cases where little or no information is available concerning the RUF article. The modeling approaches adopted for these various cases may vary considerably. For instance, if a duplicate article or sufficient materials are available, the RUF can be tested at full scale either as a duplicate article or a partial mockup in order to directly determine its burning behavior. If only small material samples are available, they can be tested in small scale apparatuses, such as the cone calorimeter or microscale combustion calorimeter, with the results used as inputs for appropriate RUF fire models. If no information is available, models for generic 
RUF burning must be used. Uncertainties are expected to increase as the amount of information available concerning a RUF article decreases.

A number of existing models for flaming RUF were described. These included a model developed during the 1990s European project on Combustion Behavior of Upholstered Furniture (CBUF) [14], two simple models developed by Babrauskas during the 1980s [15], and the fire field model, known as the Fire Dynamics Simulator (FDS) [16], developed at NIST that has recently incorporated a fire spread and growth model.

A series of experiments were run to characterize the burning behavior of individual materials used in RUF as well as composites of these materials. Fire tests were run on small scale (cone calorimeter and microscale combustion calorimeter), intermediate scale (mock-ups), and full scale (RUF articles) in the open and inside a room. Material effects were investigated by considering two types of fabrics (non-fireretarded and fire-retarded cotton) and five types of fillings (low and high density untreated FPUF, foams meeting the Cal 117 [13] and BS 5852 (Ignition Source 5) [17] standards, and polyester fiber fill). Other parameters varied included the size of the flaming ignition source (gaseous fuel flames of match size or equivalent to several sheets of burning newsprint or pool fires involving on $50 \mathrm{~mL}$ or $100 \mathrm{~mL}$ of gasolene), the ignition location (seat, lower front, and rear), and the size of the RUF article (one, two, or three seats). A fractional factorial model was used to reduce the number of experiments required.

In addition, to supplement the controlled tests described above, a number of articles of used RUF were collected in sets of two or more items. This allowed the burning behavior of individual articles inside a room to be investigated, while materials taken from the same type of item were tested with appropriate small-scale fire tests.

Intense burning was observed during experiments involving mock ups and actual RUF. The primary effect of ignition fire size was to change the period required for a fire to fully involve an item. Due to the intense burning and relative independence from ignition source, it was noted that evidence of intense burning on upholstered furniture might be interpreted by an investigator as involving the use of accelerants when none were used.

A subset of the full-scale mockup tests was part of a fractional factorial experiment. Analysis of the data from these tests resulted in the following observations:

- The HRR time profiles of 3-seat sofas are sensitive to the ignition location on the top of the seat cushions where the ignition source is applied (e.g., side versus middle).

- The type of ignition source significantly affects the ignition delay, with smaller sources resulting in longer delays.

- Peak HRR is strongly affected by the padding material. As an example, the peak HRR was significantly lower for mockups containing CAL TB 117 foam as opposed to those with non-fireretarded foam.

- Ignition on the rear of upholstered furniture generally resulted in a shorter ignition delay, but a slower fire growth rate and lower peak HRR.

Note that the finding concerning non-fire-retarded and CAL TB 177 foams differs from the conclusion reached in the UL study, which indicated differences in fire development on items containing the two foam types were minor. The reason for the different conclusions remains unclear, even though it was suggested during discussion that the different volumes of the rooms used in the two studies could possibly provide an explanation. 
Comparisons of model predictions for peak HRR with the experimental findings showed variable levels of agreement, depending on the model used. The overall best agreement was found with the simple model of Babrauskas [15]. The CBUF models also did a reasonable job, but predictions were somewhat poorer. Predictions using FDS tended to fall well below the measured values of peak HRR.

The study also evaluated the ability of two fire models (the zone model CFAST [18] and the field model FDS) to predict temperature distributions within a room given an experimental fire growth curve. Both models yielded results that agreed well with experiment.

During questioning, Janssens noted that single items of burning RUF were insufficient to induce flashover in the test room. ${ }^{2}$ This conclusion seemed to be at variance with the NIST and UL experiments described above. The larger size of the SwRI room $(3.7 \mathrm{~m} \times 4.9 \mathrm{~m} \times 2.7 \mathrm{~m})$ was identified as the most likely reason for the difference.

\subsection{Bradley Pabody, USFA}

The presenter is the Chief of the National Fire Data Center (NFDC), which has the responsibility for developing and maintaining NFIRS. NFDC is part of the United States Fire Administration (USFA) in the Department of Homeland Security.

The presentation included an overview of the NFIRS system and the type of data collected. The system is voluntary, but over 23,000 fire departments in all 50 states participate. During 2010, over 1 million fires were logged into the system. Data is collected locally by the fire departments, forwarded to state fire offices for compilation, and then collected and collated by NFDC. The USFA collates the results and makes them available to the public through its website. The raw data are also provided to various organizations to allow additional analysis.

The system employs a standard form for inputting data. A copy of this form is included in Appendix E. NFIRS was started in 1975. Since then it has undergone five major revisions, and the current version is NFIRS 5.0 (there were 4.0 and 4.1 versions). NFIRS 5.0 has been in use since 1999. Preliminary planning is underway for the next version, NFIRS 6.0, but funding has not been approved, and no date for its introduction has been set. A number of initiatives are underway in the meantime to improve the handling and warehousing of data and improved web access and security.

NFIRS consist of 11 modules. The modules used vary with the type of incident. The modules are:

- The Basic Module (NFIRS-1) captures general information on every incident (or emergency call) to which the department responds.

- The Fire Module (NFIRS-2) is used to describe each fire incident to which the department responds.

- The Structure Fire Module (NFIRS-3) is used to describe each structure fire to which the department responds.

- The Civilian Fire Casualty Module (NFIRS-4) is used to report injuries or deaths to civilians or other emergency personnel (e.g., police officers, non-fire department/EMS personnel) that are related to a fire incident.

- The Fire Service Casualty Module (NFIRS-5) is used to report injuries and deaths of firefighters.

\footnotetext{
${ }^{2}$ Subsequent to the workshop, Marc Janssens reported that this conclusion was based on a criterion of flames extending from the doorway of the room. Later analysis utilizing different criteria for the onset of flashover indicated that flashover may actually have occurred in up to one third of their tests.
} 
- The EMS Module (NFIRS-6) is completed by fire departments that provide emergency medical services.

- The Hazardous Materials Module (NFIRS-7) is completed to report spills or releases of 55 gallons or more of hazardous materials or when special HazMat actions were taken.

- The Wildland Fire Module (NFIRS-8) is completed to report incidents that involve wildland or vegetation fires. The module is used in lieu of the Fire Module for wildland fire incidents.

- The Apparatus or Resources Module (NFIRS-9), a department-use module, is completed to report data specific to each piece of apparatus that responds to an incident. It includes information that can be used to calculate response time and time out of service.

- The Personnel Module (NFIRS-10), a department-use module, is completed to report the same information as on the Apparatus or Resources Module, but it also provides for tracking the personnel associated with that apparatus.

- The Arson Module (NFIRS-11) is completed to report additional information on fires that have been coded by the department as "intentionally set."

Additional information can also be included on the Supplemental Form (NFIRS-1S).

Questions and comments during the presentation revealed the following additional information. There is no obvious correlation between the quality of reports and how often a fire department prepares a report. Several comments were made concerning how variable responses by different people or fire departments filling out the forms can affect data collected by NFIRS. It is difficult to modify the forms once they have been completed. Since more serious fires often involve additional investigation, some information can be lost if the NFIRS report is not revised to include the updated findings. The question was raised concerning whether there have been studies on how well the forms are filled out. The general answer was "no," but it was noted that studies have shown that fires with sources coded as of "unknown source" provide data similar to fires coded as "known." It was also noted that some fire departments advocate classifying fires as "unknown" if there is any doubt at all.

The question was asked whether new items will be included in NFIRS 6.0. The answer was that this is likely. The USFA will work with fire service stakeholders, including local and state fire organizations, other federal agencies and non-governmental organizations on this task. It was pointed out that the task involves a large group of both researchers and data providers (fire departments) that must be convinced of the need for change, and this generally takes a great deal of effort and time. Contracts are used for system enhancements, and these costs must be included in the budget.

\subsection{John Hall, NFPA}

John Hall began his presentation by noting that data from NFIRS is crucial to the fire statistics community. Without it, there would be little knowledge of the fire situation in America. He did note that NFIRS is not designed for representativeness or randomness, like a true statistically designed survey, although NFIRS captures such a large percentage of all fires that it can be treated as statistically valid for purposes of estimating the share of fires or losses having certain defined characteristics. NFPA performs a statistical survey of fire departments, which is combined with NFIRS data to provide an improved statistical picture of fire in the country.

Numerous choices must be considered by analysts when using NFIRS data. There are questions concerning how information is coded. Examples include residential structure versus home structure and how confined fires ${ }^{3}$ are treated. As indicated earlier, very large fire incidents often involve separate

\footnotetext{
${ }^{3}$ Confined fires are those that do not spread beyond a non-combustible enclosure such as a cooking pot, chimney, or trash compactor.
} 
investigations. Other types of data that might be used in conjunction with NFIRS include statistics related to insured fire losses and death certificates.

Certain data elements from NFIRS can be associated with particular fire characteristics. Elements which can be related to prevention of ignition and fire growth were considered during the presentation. A focus was information provided relative to RUF.

Six elements were identified that may be associated with an ignition. These include "cause of ignition" $\left(\mathbf{E}_{1}\right)$, "area of fire origin" $\left(\mathbf{D}_{1}\right)$, "heat source" $\left(\mathbf{D}_{2}\right)$, "equipment involved in ignition" $\left(\mathbf{F}_{\mathbf{1}}\right)$, "item first ignited" $\left(\mathbf{D}_{3}\right)$, and "type of material first ignited" $\left(\mathbf{D}_{4}\right)$ Note: Bolded indices in parentheses refer to items in the "Fire" module of NFIRS (NFIRS-2). Utilizing the "item first ignited" element coded with upholstered furniture for the 2006-2010 timeframe to obtain annual estimates revealed that 6700 structure fires (2\%) were responsible for 480 civilian deaths (19\%), 840 civilian injuries (7\%), and 427 million dollars in property losses (6\%). These values were adjusted statistically using the NFPA survey of fire departments. Values in parentheses are percentages of total losses in residences. These percentages are similar to those cited earlier based on CPSC analysis, with the exception that the percentage of property losses attributed to this type of fire is $50 \%$ higher.

When "type of material first ignited" (NFIRS-2 $\left(\mathbf{D}_{4}\right)$ ) was considered, the code "fabric made of cotton, blend, rayon or wool" was cited in $72 \%$ of fires and $76 \%$ of fire deaths. An additional $14 \%$ of fires and $15 \%$ of deaths were attributed to "unknown fabric". The code "Plastic-coated fabric. Includes plastic upholstery fabric and other vinyl fabrics" was only chosen in $2 \%$ of fires and was associated with $2 \%$ of deaths. These results were questioned by a member of the audience since many upholstery fabrics contain large fractions of polyolefin or polyester thermoplastics. The answer provided was that firefighters filling out the form would be unlikely to be able to distinguish between the various types of upholstery fabrics.

The question of how upholstered furniture is being ignited was considered by combining the elements on "item first ignited" (NFIRS-2 $\left(\mathbf{D}_{3}\right)$ ) with "heat source" (NFIRS-2 $\left(\mathbf{D}_{2}\right)$ ). Statistics indicate that $28 \%$ of these fires and $58 \%$ of the associated deaths are attributed to lighted tobacco products. A wide range of other heat sources make up the remainder, with any given type representing a fraction of $10 \%$ or less.

Primary elements related to fire growth are "item first ignited" (NFIRS-2 $\left(\mathbf{D}_{3}\right)$ ), which includes a check box for cases where spread "was confined to object of origin," and "fire spread" (NFIRS-3 ( $\left.\mathbf{J}_{2}\right)$ ), which provides an indication of the farthest extent of fire spread. Recorded fires that were "confined to object of origin" represented $24 \%$ of reported fires and were responsible for $6 \%$ of deaths. Fires that were "confined to the room of origin," but not to the "object of origin," contributed $34 \%$ of fires and $25 \%$ of fire deaths. For fires in which fire spread (NFIRS-3 $\left(\mathbf{J}_{2}\right)$ ) extended beyond the room of origin (either coded as "confined to floor of origin," "confined to building of origin," or "beyond building of origin"), the corresponding values were $42 \%$ and $69 \%$, respectively. Note that the latter type of fire is viewed as the best indictor that flashover took place during a fire. The important role of flashover is evident in that it occurred in less than one-half of the reported fires, but was responsible for over two-thirds of fire deaths.

The question of the contribution of RUF to fire growth was discussed in terms of the "item contributing most to flame spread" (NFIRS-3 $\left(\mathbf{K}_{\mathbf{1}}\right)$ ), even though no specific values were provided. It was noted that fire growth and flame spread do not necessarily refer to the same fire behavior. It was concluded that while the "fire spread" element may not represent an adequate surrogate for cases where RUF is the primary second item burning, it is the best element available in NFIRS that can provide some information with regard to this important topic. 
Cross referencing the elements for cases where RUF was the "item first ignited" (NFIRS-2 ( $\left.\mathbf{D}_{3}\right)$ ) with cases where fires extended beyond the room of origin (NFIRS-3 $\left(\mathbf{J}_{2}\right)$ ) showed that $60 \%$ of these fires started on RUF and were responsible for $72 \%$ of the deaths outside of the room. A wide range of items, with none representing more than $6 \%$ of the total, made up the remainder of the items first ignited.

There are a number of relevant properties concerning the burning behavior of RUF that cannot be estimated using only data collected by NFIRS. These include:

- Details of the type and composition of RUF present in residences.

- Location of ignition points on RUF.

- High-fidelity estimates of fires where RUF is the primary source of heat release, but is not the item first ignited.

- Detailed scenarios that show when upholstered furniture is ignited and how important it is to the course of the fire.

Given the limitations of NFIRS data in providing as detailed picture of how RUF burns as desired, a number of potential approaches for increasing the amount of information available were considered. The first was to modify NFIRS to improve the depth of information relevant to RUF burning behavior collected. This approach was viewed as unrealistic due to the increased data collection burden and the lack of resources available for collecting such data. The use of other potential sources of data, such as detailed investigations and court cases, is limited because they are almost certainly non-representative and non-statistical.

In the past, the NFIRS Special Study option has been used locally when additional information was required about particular aspects of fires. In such studies, one or more fire departments voluntarily collect focused information over a finite time period. NFIRS 5.0 has additional special study fields, although no National studies have been conducted using this feature due to limitations of some commercial software programs that may not contain this feature. CPSC has conducted studies in the past by asking fire departments to alert their investigators anytime a fire occurred with a particular heat source, equipment involved in ignition, or item first ignited. The workshop participants viewed a special study as a viable approach to obtain statistically valid data concerning RUF fire behavior.

Another potentially useful option is to construct probabilistic models incorporating knowledge about the prevalence and types of RUF in residences combined with models of fire behavior. Such models could provide insights concerning the contribution of RUF to fire losses.

The following provides a summary of the implications of this presentation for the workshop topic.

- For fires that spread beyond the room of origin, RUF serving as a secondary fuel package appeared to increase the number of fires in which RUF played a critical role by $69 \%$, as compared to only considering cases in which RUF was identified as the item first ignited.

- The number of fire deaths was apparently increased by $39 \%$ compared to cases where RUF was only considered as the item first ignited.

- The above does not consider unclassified furniture. If the majority of such cases actually involved RUF, the increase in RUF contribution drops to $52 \%$ for number of fires and $36 \%$ for deaths.

- For fires with burning confined to the room but beyond the object of origin, secondary ignitions of RUF add $48 \%$ to the number of fires and $31 \%$ to deaths, not including unclassified furniture.

In more layman terms:

- Secondary ignitions of RUF add significantly to the number of fires and losses as compared to cases when RUF is recognized as the item first ignited. 
- The quantitative increase in losses is currently subject to a fair degree of uncertainty.

- The uncertainty might be reduced through additional analysis and probabilistic modeling.

Several questions and comments were made in conjunction with this presentation. One participant wondered for cases in which RUF was a major factor in a fire loss, but was not the "item first ignited," how likely was it to be identified as the "item contributing most to flame spread?" The speaker did not have an opinion. It was suggested that the cost of answering this question would likely be prohibitive.

The speaker was asked whether it was possible to determine the degree of human and property losses associated with fires that did not transition to flaming, e.g., ignition of a smoldering fire in RUF by a cigarette. The answer was that fire losses associated with this type of fire are very low percentages of the total losses. There was general agreement among the participants that this was the case. The implication of this conclusion is that fires that initiate as smoldering fires should be included in the totals of fires where flaming RUF plays an important role in fire losses.

The question concerning how well the fabrics identified as a "type of material first ignited" captured the actual type of fabrics involved was discussed further. The general consensus was that there is not likely to be useful information to identify the actual type of fabric (e.g., cellulosic, thermoplastic, leather, etc.) being coded.

A participant asked whether it is possible to identify whether a RUF item was only damaged or completely destroyed. The answer was that NFIRS does not provide this level of detail.

\subsection{David Butry, NIST}

This presentation discussed the use of NFIRS for performing economic analyses. A brief introduction to the economic theory of minimizing the sum of costs of protection and losses was provided. This analysis allows the most efficient amount of protection to be provided as long as the dependence of losses on the amount of protection is known. For any economic analysis dealing with fire, data on cost and losses are required.

The presenter provided a short introduction to the NFIRS system, before describing how such data can be used in economic analysis related to fire. NFIRS data can be used to measure the components of fire risk e.g., likelihood of fires, death, injuries and property losses, to understand factors related to ignition, e.g, item first ignited, and to understand factors related to losses, e.g., presence of smoke alarms. Information related to costs of fire protection and mitigation is more limited in NFIRS.

An example of a NIST economic analysis related to fire was provided. The goal was to describe the effectiveness of sprinklers in reducing fire deaths in single- and two-family homes and to convert the results to economic savings. A significant challenge was to isolate the effectiveness of sprinklers from confounders such as smoke alarm technology, distance to fire department, structure age, family income, family ages, etc. NFIRS fire incidence data was used to control for differences between sprinklered and non-sprinklered residences. It was demonstrated that sprinklers reduced fire deaths and associated property losses after confounding influences such as the presence or absence of smoke detectors and housing and family differences were accounted for.

The topic of RUF and NIFRS was considered next. The two items in the NFIRS fire module, "item first ignited" (NFIRS-2 $\left(\mathbf{D}_{3}\right)$ ) and "item contributing most to flame spread" (NFIRS-3 $\left(\mathbf{K}_{\mathbf{1}}\right)$ ) refer directly to RUF. The second tracking item is considered only when the associated box indicating "check only if no flame spread OR if same material first ignited OR if unable to determine" is not checked. The "item first ignited" was reported $91 \%$ of the time for reported non-confined residential fires during the 2002-2009 
time frame. During this period, RUF was listed as the "item first ignited" $2 \%$ of the time. "Item contributing most to flame spread" is not a required field and was completed for only $28 \%$ of reported fires. Even with these limitations, RUF was identified on this item for $1 \%$ of reported fires. This would seem to suggest that, at a minimum, RUF as a second or later item ignited made a significant contribution to fire growth in roughly half as many fires as when it was the "item first ignited." Data for individual years indicated that this ratio remained roughly constant over the 2002-2009 time period.

Several questions were raised concerning how to interpret the data supplied by NFIRS. These include:

- Do "Item First Ignited" and "Item Contributing Most to Flame Spread" account for all (most) of the fires involving RUF?

- Do other ways exist to identify fires involving RUF?

- Is it difficult to determine if RUF was involved?

- Is under-reporting likely?

- Are fires that spread beyond the room of origin 'special' or 'different' than those that don't?

- Are there factors that affect both flame spread and the likelihood RUF is involved?

- Are ‘bad' fires more likely to contain an "Item Contributing Most to Flame Spread”?

The potential for performing economic analyses related to fires involving RUF was considered. One approach would be to simply report the number of fires and losses (deaths, injuries, property) where RUF was identified as having a major role. This approach has the advantage that it is straightforward to accomplish, but ignores the potential for the confounding effects of other factors. A second approach would be to develop statistical approaches which could account for confounding effects, thus establishing causal effects and providing a better understanding of RUF risks. Two downsides of this approach are that a researcher would need to develop a baseline for comparison, and the outcome would not directly provide national estimates.

During the follow-up questions a member of the audience pointed out that the initial economic model discussed can be very sensitive as to how it is mathematically described. There was also a question concerning whether or not society generally seeks to balance sum of costs of protection and losses, or if other factors may come into play. The speaker agreed that both of these questions would have to be addressed in any future economic modeling.

\section{Open Forum Discussion}

An open forum discussion involving all workshop attendees took place during the afternoon of the first day of the workshop. The series of questions included in the agenda (see Appendix C) were used to provide a framework for the discussion. Facilitators led the discussions. The following summarizes the major topics discussed and conclusions and suggestions that were made during the open forum.

\subsection{Would decreasing the rate of fire growth and heat release in an enclosure significantly reduce residential fire losses within the room of fire origin? (Facilitator: Jason Averill)}

Dan Gottuk of Hughes Associates asked the question, “What is significant?” The general consensus was that the answer depends on the amount of fire losses associated with this type of fire. Various statistics described above suggest a large fraction of losses occur in fires which are confined to a single room. It seems reasonable to expect that reducing the rates of fire growth and heat release would reduce these losses in a meaningful way.

John Hall of NFPA noted that NFIRS contains very little information about fire spread and growth within the room of origin. The data element "Item First Ignited" (NFIRS-2 $\left(\mathbf{D}_{3}\right)$ ) indicates where initial fire development occurred, but there is little beyond this. The check box associated with "Type of material 
contributing most to flame spread" can provide an indication that a fire was localized to the item first ignited, but it can also mean that the item contributing the most to flame spread was the initial item ignited or that it was not possible to identify the material contributing most to flame spread. The next indication of fire spread and growth does not occur until the fire leaves the room of origin as identified in "Fire Spread" (NFIRS-3 $\left(\mathbf{J}_{2}\right)$ ). Reported property losses provide little additional detail about losses inside the room of origin. Additional information that might aid in assessing the answer to this question includes condition, activities, and proximity of people injured in such fires. Again, such information is unavailable. The lack of relevant information means that NFIRS provides little direct help in answering the posed question. It was suggested that engineering analysis combined with sensitivity analysis, of the type discussed during John Hall’s presentation, might provide some insight.

NFPA has released a report by Marty Ahrens entitled Home Fires that Began with Upholstered Furniture [19] which summarizes much of the NFIRS data related to fires involving RUF based on data from 2005 to 2009. Examples of information from this report include analyses indicating $18 \%$ of the deaths involved people impaired by alcohol and/or drugs (Fig. 6 in report) and that around half of victims associated with fires started by smoking materials were found in the vicinity of the RUF (Fig. 14 in report). She noted that several types of information that could aid analyses of this type, such as at-risk populations, physical vulnerabilities of victims, and ignition behaviors of the RUF, are not available.

There was a wide ranging discussion of the effects of room characteristics on the recorded statistics. Recall that earlier experiments suggested that development of flashover with RUF burning seemed to depend on room size. Actual room sizes in residences can vary substantially. Think in terms of studio apartments compared with large living room and bedrooms in detached homes. No indication of such variations is available in NFIRS beyond type of residence. There are also uncertainties in how rooms may be coded. Many modern homes have large connected areas that can contain a kitchen, dining room, and living room, hallway, etc. These areas are essentially one single large room. Such areas are not distinguished from compartmented rooms.

The presence of medical oxygen was identified as another type of confounding variable. The role of oxygen in accelerating fires and contributing to losses is not generally captured in NFIRS. The consensus was that its contribution is likely underestimated and increasing over time.

It is clear that a great deal of information that could be useful in understanding fire spread and growth in a room containing RUF is not captured by NFIRS. One approach for obtaining this information would be through the special study option of NFIRS discussed earlier by John Hall. Marty Ahrens suggested that a one page check-box questionnaire that was carefully designed with five to ten simple questions would be appropriate. Sean DeCrane of the Cleveland Fire Department indicated that they frequently see fires involving RUF that are limited to a single room. Such fires had been responsible for several close calls during the past year. He believes that his department would be happy to participate in such a focused study. John Hall indicated that a study of this type could be performed over a period of roughly one year in cooperation with fire departments that were willing to participate. The selection of participating fire departments and the design of the research questions would need to be done carefully to ensure that the number of responses to a given question would be on the order of the hundreds required to provide meaningful statistics.

Several questions were raised above as to how specific NFIRS items are coded in the field. These questions included: What is coded as "Upholstered sofa, chair, vehicle seats" in "Item First Ignited" (NFIRS-2 $\left(\mathbf{D}_{3}\right)$ ) and "Item Contributing Most to Flame Spread" (NFIRS-3 $\left(\mathbf{K}_{\mathbf{1}}\right)$ )? What is coded as "Furniture, utensils, other" in "Item First Ignited" (NFIRS-2 $\left(\mathbf{D}_{3}\right)$ )? Are fires ignited on coverings or pillows coded as RUF or something else? How is "Area of fire origin" coded when there are multi-use areas connected together? What fabrics are really present when coded as "Fabric, fiber, cotton, blends, 
rayon, wool, finished goods. Includes yarn and canvas. Excludes fur and silk" or "Plastic-coated fabric. Includes plastic upholstery fabric and other vinyl fabrics." in the "Type of material first ignited"

(NFIRS-2 $\left.\left(\mathbf{D}_{4}\right)\right)$ ? These questions introduce the possibility of uncertainties in the statistical values derived from the NFIRS database.

An approach for reducing these uncertainties was discussed. It involved showing groups of fire investigators pictures of fire scenes and asking them to assign codes to specified questions based on what they observe. Such a survey might be done informally at assemblies of investigators by projecting the pictures and asking for a show of hands or more formally utilizing an internet survey. It was pointed out that such studies would not only provide important information for reducing uncertainties in fire statistics related to RUF, but would also prove valuable to developers of the next generation of NFIRS (Version 6.0).

\subsection{Would decreasing the rate of fire growth and heat release in an enclosure significantly reduce residential fire losses at locations substantially removed from the room of fire origin? (Facilitator: Richard Gann)}

It was pointed out that more than half of fire deaths and economic losses are associated with fires coded as extending beyond the room of origin in the "Fire spread" (NFIRS-3 ( $\left.\mathbf{J}_{2}\right)$ ) item.

Marty Ahrens noted that the earlier discussion concerning open areas is relevant for this question as well.

The point was raised that, as written, the subject question does not provide an indication of whether the extended space was sealed or not. This was viewed as having an important influence on the development of untenable conditions.

Dick Gann raised the question of whether or not it was possible to develop untenable conditions outside the room of origin without involvement of RUF in the fire. There was no consensus concerning an answer.

The current version of NFIRS provides little information on the relationship of victim proximity to a fire and the likelihood of death or injury. Older data does provide some information.

The importance of fire growth rate was noted by Sean DeCrane. He noted that for a rapidly growing fire on the first floor of a multistory residence, very little time would be available for people on higher floors to escape. In this context, the findings of the most recent study at UL were reviewed. Tom Fabian reported that times to untenable conditions were increased from five minutes for fires involving contemporary furniture to 25 minutes when a fire barrier was added to the contemporary furniture. The importance of early detection in both scenarios was again noted.

John Hall noted that the discussion was pointing towards the value of scenario based modeling in understanding the role of RUF in fire losses. Marc Janssens added that appropriate modeling could greatly expand the database available for describing these types of fires.

Dick Gann suggested that a good data question for a special study would be aimed at determining how often firefighters find items of RUF still flaming when they arrive at residential fires.

Tom Fabian reiterated that the recent UL study completed in January considered tenability time at locations outside of the room and included soft furnishings in the fire loads. 
Jason Averill briefly discussed a recent study on "Residential Fireground Field Experiments" which considered the effects of firefighter crew size on multiple measures of firefighter effectiveness. [20] This study found that 12 min to 13 min were required between the time of a 911 call and when water was applied to a fire. This time is comparable to the time for a slowly developing fire to reach flashover, but is much longer than the times reported above for RUF-fueled fires to develop untenable conditions. It should be mentioned that when rooms including upholstered furniture fires were burned as part of this study, measured times to untenable conditions inside the fire room varied from roughly $150 \mathrm{~s}$. to $250 \mathrm{~s}$.

Sean DeCrane emphasized the need to consider the burning behavior of multiple items. He again pointed out the short amount of time available for firefighters to reach a residence before conditions become untenable outside the room of fire origin.

Tom Fabian returned to the subject of rapid fire development inside the enclosure by noting that only a small fraction of upholstered items have natural fiber fabrics. This implies that ignition by small open flames is relatively simple. Fast fire growth will follow.

The question was raised of whether or not the degree of ventilation plays a role in fire growth. The group was unable to answer the question. John Hall thought that it was possible. Dick Gann pointed out that no information on ventilation in real fires is available. He noted that the discussion was related to the earlier discussion on what defines a room.

John Hall summarized the discussion by noting that it provided additional justification of the need for a focused special study on the characteristics of flaming RUF fires.

\subsection{What are the relevant characteristics of residential fires involving flaming RUF contributing to fire losses? (Facilitator: Jason Averill)}

Jason Averill began the discussion by asking this question: Do people in a room of fire origin die from burns and people outside the room of fire origin die from smoke inhalation? John Hall replied that the statistics cannot be broken down this way. Some additional analysis, perhaps a special study would be needed to address this question.

This led to a discussion of smoldering versus flaming. Again, it appears to be impossible to differentiate with current information available in NFIRS. Dan Gottuk reiterated that the majority of fire losses are associated with flaming fires.

At this point, John Hall suggested a change in terminology from "smoldering" versus "flaming" to "prevention" versus "mitigation." The latter terms are based on current and possible future approaches for limiting fire losses. Current and proposed regulations for RUF are aimed primarily at preventing smoldering ignition. Future attempts to reduce the fire spread rate and maximum heat release rate of flaming RUF would be an example of mitigation once a fire was ignited.

Jason Averill pointed out that rapid fire development not only has implications for people in the residence, but also the firefighters who respond to the fire. Sean DeCrane seconded this by noting that the firefighters on the fire ground most often lose their lives as the result of cardiovascular problems or trauma associated with the fire. The probabilities of both types of event increase with fire size. He noted that a rapidly developing fire has ripple effects that increase the chances for firefighter losses. 


\subsection{Is flaming RUF likely playing a significant role in residential fire losses? (Facilitator: Richard Gann)}

The discussion returned to the role of RUF in residential fire losses. Tom Fabian emphasized that RUF has always played a large role in fire losses and continues to do so. John Hall, based on his experience and discussions during the workshop, concluded that RUF as a second item ignited contributes to fire losses in meaningful way. Jason Averill questioned whether we are capturing its effect fully. The general answer was yes, but with caveats. Marty Ahrens noted that RUF is the most important "Item first ignited" in residential fire deaths. She feels that values currently derived from NFIRS may be underestimated.

\subsection{Is it appropriate to differentiate fire losses inside and exterior to the room of fire origin with regard to the role of RUF in Residential Fire Losses? (Facilitator: Jason Averill)}

Directly addressing the question posed, John Hall stated that it is possible to differentiate inside and outside the room of fire origin and that it is important to do so. He emphasized the point made earlier that it is more difficult to isolate the role of burning RUF inside a room due to the lack of data elements in NFIRS that capture fire behaviors between the ignition of "item first ignited" and fires which propagate beyond the room of origin. He once again noted that earlier versions of NFIRS included elements which could help address this limitation.

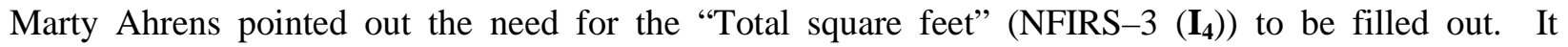
frequently is not. This value would be useful in determining the relative roles of fires inside and outside the room of origin on fire losses.

Dick Gann recommended that fire losses inside and outside the room of fire origin continue to be differentiated. John Hall agreed, but emphasized the need for different approaches to better understand what takes place inside the room of fire origin. An NFIRS special study is one example of such an approach.

Sean DeCrane emphasized the need to understand what is meant when a fire is coded as having moved beyond the room of fire origin. He feels that there may be some ambiguity in NFIRS coding. The group recognized this as another question to be explored using the approach of polling NFIRS responders discussed earlier.

Dick Gann pointed out that there is an extensive database of fire measurements inside rooms including such parameters as temperatures, toxic gas concentrations, and radiant heat fluxes. It should be possible to get a good idea of tenability criteria using these measurements. John Hall noted that the presence of people is crucial to such analyses. Once appropriate models are developed, their outputs can be compared with the existing statistics in order to determine how accurately they are capturing real-world observations.

Marc Janssens noted that the recent experimental series at SwRI had generated data for 85 room fires spanning heat release rates from $100 \mathrm{~kW}$ to $3 \mathrm{MW}$. These should provide an ideal database to serve as the basis for a study of the type suggested above. Dick Gann added that he did not think many people would be left inside a room by the time a fire had reached the $100 \mathrm{~kW}$ level.

John Hall asked what would be the technical feasibility of carrying out such a study and would it help improve the understanding of the role of RUF in fire losses. He answered his own question in the affirmative by noting the importance of the type of fires under discussion. He felt that the modeling approach provided a viable way forward. 


\subsection{Do existing fire statistics and related analyses effectively capture contribution of flaming RUF to residential fire losses?}

John Hall started the discussion by indicating the answer to the question is "no." Tom Fabian asked if it was possible to provide a positive answer using existing NFIRS data. The answer was yes, with a caveat. With the existing data it is necessary to integrate over the less severe fires that do not emerge from the origin of fire room.

The discussion at this point returned to prevention versus mitigation. Mitigation refers to actions that address fires that were not prevented. Characterizing fires in this way is consistent with the way the Center for Disease Control characterizes hazards.

Dan Gottuk reiterated that flaming combustion is primarily responsible for the hazard of residential fires. Significant fire losses due to a smoldering fire alone require extraordinary circumstances. John Hall raised the counterpoint that an extended smoldering period can cause a build-up of toxic products in the vicinity of the fire so that when the fire transitions to flaming, the time required for untenable conditions to develop, near or far from the fire, will be reduced. Tom Fabian also noted that higher levels of carbon monoxide and cyanide per unit mass loss are generated during smoldering combustion. Note that mass loss rates for smoldering fires are generally orders of magnitude lower than those for flaming fires.

\subsection{Can existing fire statistics and extended analyses better capture contributions of flaming RUF to residential fire losses?}

John Hall indicated that the answer to this question is "yes," but with reservations. Teasing out the role of flaming combustion will require extended approaches for analyzing the existing NFIRS data and an improved understanding of what is actually being captured in the existing data. The type of study suggested earlier in which the personnel actually generating NFIRS data are polled to better understand how various items are being coded is an example of the latter.

At this point, John Hall suggested a specific approach for analyzing NFIRS data designed to isolate the contribution of flaming RUF to fire losses. He proposed that a series of $2 \times 2$ matrices be used to assess the contribution of RUF to the various types of fire loss (deaths (NFIRS-4 (C,H)), injuries (NFIRS-4 $(\mathbf{C}, \mathbf{H})$ ), and property (NFIRS-1, $\left(\mathbf{G}_{2}\right)$ ) for fires "confined to room of origin" and fires which spread beyond the room of origin, (NFIRS-3 $\left(\mathbf{J}_{2}\right)$ ). An example of such a matrix is shown below:

$\mathrm{N}_{\mathrm{yy}}, \mathrm{N}_{\mathrm{yn}}, \mathrm{N}_{\mathrm{ny}}$, and $\mathrm{N}_{\mathrm{nn}}$ represent the amounts of losses due to fires matching (y subscript) and not

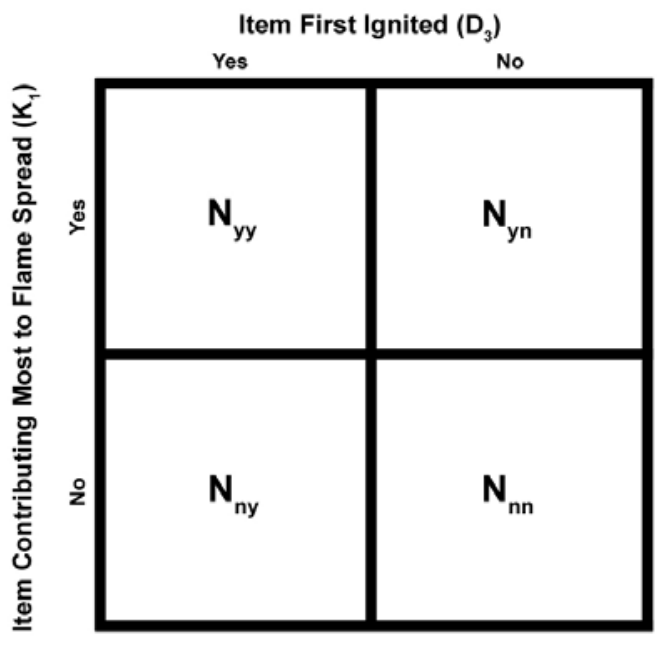


matching (n subscript) each cell's criteria. The matrices isolate losses where both conditions were true $\left(\mathrm{N}_{\mathrm{yy}}\right)$, one condition was true $\left(\mathrm{N}_{\mathrm{yn}}\right.$ and $\left.\mathrm{N}_{\mathrm{ny}}\right)$ and neither condition was met $\left(\mathrm{N}_{\mathrm{nn}}\right)$.

The total amount of losses where RUF was a primary contributor for a given type of fire loss will equal $\mathrm{N}_{\mathrm{yy}}+\mathrm{N}_{\mathrm{yn}}+\mathrm{N}_{\mathrm{ny}}$, while the amount of losses in fires where RUF contributed most to flame spread but was not identified as the first item ignited will equal $\mathrm{N}_{\mathrm{ny}}$. Summing together the results for fires isolated to and those spreading beyond the room of fire origin will provide the total losses associated with flaming RUF.

At this point, the discussion turned back to the potential for reducing fire losses once the actual contribution of flaming RUF to fire losses was quantified. The question was asked whether quantifying the contribution of RUF was sufficient along with the rhetorical question of whether it would not be better to just eliminate RUF as an issue. The answer was that in the absence of a realistic analysis of the actual contribution of RUF, it is not possible to estimate the effectiveness of various mitigation approaches for reducing fire losses.

Based on the presentations and discussions, the workshop participants agreed that limiting the development of flaming RUF fires provides the greatest opportunity for further reducing the nation's fire losses. In addition to the current losses associated with RUF as the "item first ignited," a significant fraction of current losses occur when RUF is the second (or higher) item ignited. For the particular case of residential fire deaths, participants estimated the annual numbers attributable to RUF as second item ignited would turn out to be in the 100s. Dan Gottuk asked how flaming RUF stacks up compared to mattresses, for which flaming behavior has now been regulated. John Hall answered that first- and second-item ignitions of RUF contribute to a comparable or larger fraction of fire losses as mattresses and bedding.

\section{Summary of Presentations and Discussions and Identification of Approaches and Participants for Estimating Role of Flaming RUF in Fire Losses}

The purpose of the final session of the workshop on the morning of the second day was to develop recommendations for estimating the total contribution of flaming RUF to fire losses and identifying potential organizations to perform the studies.

\subsection{Summary of Major Findings}

The session was opened by William Pitts, who presented a short summary of major points that were identified from the presentations and discussions on the first day. The slides used for this summary are included in Appendix F. The following conclusions are based on these slides with some additional points added:

- Recent studies confirm the potential for rapid flaming fire growth on RUF to cause significant fire losses in residences.

- Statistics show that fires involving RUF are many times more likely to result in property loss, injury, and particularly fatalities than expected based simply on their percentage of all fires.

- Times required for RUF-fueled fires to grow to dangerous levels are shorter than or on the same order as those required for fire departments to be notified and respond (implications for both human and property losses and fire fighter safety).

- Consensus that losses due to smoldering-only RUF fires are small and nearly negligible (losses occur following transition to flaming).

- Statistics suggest that flaming ignition of RUF occurs in a number of ways that in total represent a significant but not dominant source of fire losses involving RUF.

- Direct measures are not available describing RUF as a second (or higher) item ignited, but there may be approaches for estimating losses due to such burning. 
- There is justification for breaking down statistics into losses inside the room of fire origin and outside the room of fire origin.

- Statistics describing the role of RUF inside the room of fire origin are somewhat limited due to a lack of information concerning fire growth within the room (events between ignition and fire leaving the room are not well captured by NFIRS).

- Statistics concerning the role of RUF on losses external to the room of fire origin appear to have a firm foundation.

- An analysis estimating the total contribution of RUF to fire losses utilizing the existing NFIRS database was suggested utilizing the matrix approach discussed on p. 16.

- Approaches for filling in some data gaps and uncertainties in NFIRS data were suggested.

- Informal questioning of people filling out NFIRS form to clarify how coding is being performed in the field.

- Targeted NFIRS special study using a one page data sheet.

- Probabilistic modeling of fire spread and growth in rooms based on fire experiments using existing fire models offers an approach for better understanding the role of RUF in fire losses.

- There is a continuing need for estimates of the numbers and characteristics (etc., fabric, polyurethane foam, fiber fill, barrier fabrics) of RUF items currently in residences.

- "Prevention” versus "mitigation” provides an alternate framework for discussing the contribution of RUF to fire losses.

\subsection{Recommendations}

As mentioned earlier, even though the workshop schedule (Appendix C) called for a systematic discussion building towards formulation of approaches for quantifying the full contribution of flaming fires of RUF to the nation's fire losses, the participants felt that sufficient progress had been made during the first day such that only a shortened single discussion was necessary in order to formulate recommendations. John Hall of NFPA acted as the facilitator for this session.

The final recommendations of the workshop participants closely follow suggestions made during the presentations and open forum discussions.

\section{1) Estimate fire losses (deaths, injuries, and property) utilizing the matrix approach discussed on p. 16.}

The first recommendation is to use the NFIRS database to provide estimates for the annual fire deaths, injuries, and property losses in residential fires where flaming RUF played a crucial role as identified by its NFIRS coding as "Item first ignited" (NFIRS-2, $\left(\mathbf{D}_{3}\right)$ ) and/or "Item contributing most to flame spread" (NFIRS-3, $\left(\mathbf{K}_{\mathbf{1}}\right)$ ). This analysis will be accomplished using the matrix approach described on p. 16. Careful attention will be paid to cases where the box in element $\mathbf{K}$ of NFIRS-3 is checked, since this element has the potential to introduce uncertainty into the analysis. The analysis will be repeated for various "Area of fire origin" (NFIRS-2, $\left(\mathbf{D}_{1}\right)$ ) and cases where fires are "Confined to room of origin" (NFIRS-3 ( $\left.\mathbf{J}_{2}-2\right)$ ) and where fires spread beyond the room of origin (NFIRS-3 $\left(\mathbf{J}_{2}-3,4\right.$, or 5$)$ ).

Summation over all of the elements will provide overall estimates for fire losses where flaming RUF played a pivotal role. Considering individual classes will allow statistics to be broken out in terms of initial ignition condition (smoldering versus flaming), role of flashover (losses in room of origin versus losses outside of room) and location of the RUF.

Implementation of this recommendation was viewed by the practitioners as being relatively straightforward and as falling within their current duties. Researchers from NFPA and USFA committed 
to performing these analyses shortly after this report becomes available. Researchers at CPSC and NIST have expertise in this area and could effectively contribute to a joint effort.

From the presentations and discussions, it became evident that while completion of Recommendation 1) will provide much improved estimates for the contribution of flaming RUF to fire losses, the values will still be subject to significant uncertainties due to questions as to how the relevant NFIRS items are being coded in the field and limitations based on the specific information that is collected by NFIRS.

Three approaches were recommended to reduce these uncertainties. The first is designed to address questions that arose as to how certain NFIRS items are coded by surveyors in the field.

\section{2) Survey groups of people responsible for coding NFIRS forms to determine how items are coded when presented with pictures or descriptions of various conditions.}

This information will be utilized to better understand what the NFIRS responses of field practitioners actually represent. The surveys could range from questioning of groups at appropriate meetings to more formal internet surveys based on email lists of people known to fill out NFIRS forms and participants in training classes at the National Fire Academy.

A number of items and responses were suggested for examination. These include:

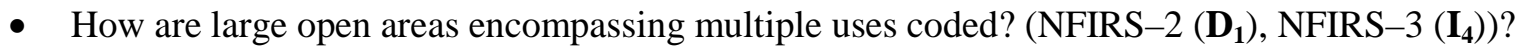

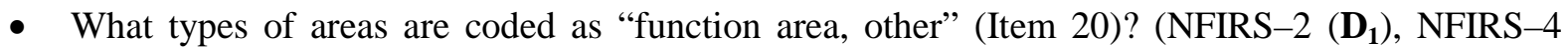
$\left.\left(\mathbf{M}_{5}\right)\right)$ ?

- What range of items are identified as being "upholstered furniture” (Item 21)? (NFIRS-2 ( $\mathbf{D}_{3}$ ), NFIRS-3 $\left.\left(\mathbf{K}_{\mathbf{1}}\right)\right)$ ?

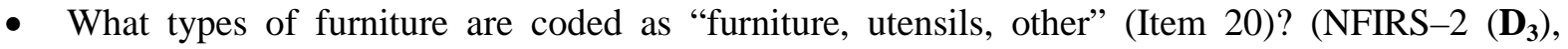
NFIRS-3 $\left.\left(\mathbf{K}_{\mathbf{1}}\right)\right)$ ?

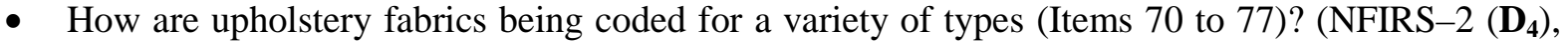
NFIRS-3 $\left.\left(\mathbf{K}_{2}\right)\right)$ ?

- What conditions result in the associated box for NFIRS-3 (K) being checked?

- Are fires where coverings/pillows are responsible for "Item first ignited" (NFIRS-2 $\left(\mathbf{D}_{3}\right)$ ) or "Item contributing most of flame spread" (NFIRS-3 $\left(\mathbf{K}_{\mathbf{1}}\right)$ ) coded as "upholstered furniture (Item 21) or something else?

- What observations do coders use to determine that a fire has moved beyond the room of origin?

- Do respondents “observe" or "infer”?

- How often do respondents complete NFIRS forms?

Surveys of this type will not only serve to reduce uncertainties in estimates of fire losses due to RUF in residences, but will also provide valuable feedback to the NFIRS development team with regard to the current questionnaire (Version 5) as well as guidance for the development of Version 6.

Participants recognized that organizing a study of this type would represent a major undertaking requiring institutional support, significant time and financial resources, and cooperation among a variety of organizations. It was evident that such an undertaking requires additional planning and coordination between potential participating organizations. It is recommended that planning for a study of this type be started as soon as possible. Potential participants include NIST, NFPA, USFA, and CPSC, as well as organizations that can aid in identifying and obtaining cooperation of NFIRS coders to participate in the survey.

\section{3) Organize an NFIRS Special Study Focused on RUF Fire Behavior in Room of Fire Origin}


The second approach for reducing uncertainties in fire loss estimates is to utilize the NFIRS provision for special studies designed to address specific questions concerning fires recorded by the survey. The participants recommended that such a special study be designed and carried out to better understand the role of flaming RUF in the room of fire origin. As discussed earlier, the existing NFIRS database provides few insights concerning fire behavior between the time an item is ignited inside a room and the fire spreads beyond the room of origin.

It was suggested that a single page containing five to ten carefully formulated questions be developed for incorporation into the NFIRS questionnaire. This additional page would ask for observations aimed at developing a better understanding of flaming RUF behavior during residential fires. Potential points that could be addressed by the special study include:

- Specific details concerning RUF, e.g., pillow and coverings, type of upholstery fabric, size, general configuration.

- Did flaming RUF occur?

- Area of RUF burning when fire department arrived.

- Area of RUF burned when fire was extinguished.

- Where was RUF ignited?

- Were there signs of flashover in the room?

- What were the ventilation conditions in the room of origin?

- If fires were fatal, were deaths due to burns or smoke inhalation (broken out by inside and outside of room of fire origin)?

The participants felt that a one-year period would be sufficient for the study, assuming the active participation of a sufficient number of fire departments to ensure statistically meaningful samples.

The development and performance of an NFIRS Special Study is a major undertaking. As for the more informal survey discussed above, a great deal of planning and cooperation between multiple organizations would be required. The questionnaire must be developed carefully and tested prior to the study. Due to the extra burden and training associated with a Special Study, a premium is placed on identifying fire departments willing to participate in the study. The workshop participants recognized the large commitment of organizational resources would be required to make such an effort successful. Nonetheless, the participants strongly recommended that a Special Study be organized because of the unique opportunity it offers to advance the understanding of the role of flaming RUF in fire losses. Participants noted that CPSC has extensive experience in organizing NFIRS Special Studies. Additonal organizations that could make invaluable contributions include USFA, NFPA, NIST, the International Association of Fire Fighters, and the International Association of Fire Chiefs.

\section{4) Probabilistic Modeling of RUF Room Fires Incorporating Experimental Observations}

The third approach identified for limiting uncertainties associated with estimates of fire losses due to flaming RUF is to combine existing model(s) of fire behavior with experimental results for the burning behaviors of RUF to investigate the role of RUF in fire spread and growth and the development of untenable conditions. This approach is designed to better understand the burning behavior of RUF inside a room of fire origin as well as the likelihood of fire spread beyond the room of origin.

Using this modeling approach, it would be possible to study the importance of key parameters over a wide range. These parameters include such intrinsic RUF properties as fire growth rate and maximum heat release rate. Properties related to the room of fire origin such as dimensions, volume, other contents, and ventilation conditions will also be varied parametrically. Some fire models include the capability to ignite 
nearby items, thus it will be possible to investigate the role of RUF in igniting nearby items as well as fire spread to RUF from nearby burning items.

This type of modeling requires an extensive database of flaming RUF to serve as inputs. The recent studies from UL, SwRI, and NIST described in this report along with earlier published studies can serve as the basis for such a database. All three organizations are committed to making their experimental findings available to the research community.

The modeling effort necessary to understand the behavior of RUF in residential fires is likely to require an extended period and involve strong interactions between experimentalist and modelers. Prior to the workshop, NIST researchers had in place a plan for a scoping study designed to investigate the potential of the CFAST software [18] to provide a better understanding of the contribution of RUF to fire losses. This study will be carried out during the next few months. It should provide a good indication of what progress can be expected using this approach.

\section{Final Comments}

The objective of the workshop, to identify approaches for quantifying the full contribution of flaming fires of modern RUF to the nation's fire losses, was met. When the approach outlined above is fully implemented, it will provide a vastly improved quantification of the role of RUF in residential fire losses. The data generated by the study would also provide valuable input to the developers of NFIRS.

Research discussed during the workshop reinforced the widely held perception that the potential for rapid flaming fire spread and growth on RUF is likely playing a large role in current fire losses in residences and is likely the largest single factor for fire fatalities. Statistics showing the unusually high number of fire deaths associated with fires starting in rooms typically containing RUF and the high losses in fires where RUF is cited as the "Initial item ignited" and/or the "Item contributing most to flame spread," when combined with experiments showing the rapid fire spread and growth possible on contemporary RUF provide strong evidence for the important role of RUF. The implications for civilian and firefighters losses are evident.

\section{Acknowledgements}

The success of the workshop was the direct result of the active participation and contributions of all of the attendees. The organizers wish to thank everyone for their hard work and dedication. We recognize that every person and organization in attendance invested time and money to spend a day and a half at NIST. It is our hope that you found the workshop as useful and informative as it was for us. We look forward to working together with you and your organizations as we move forward to implement the recommendations generated formulated by the workshop participants.

\section{References}

[1] R. W. Bukowski, R. D. Peacock, J. D. Averill, T. G. Cleary, N. P. Bryner, W. D. Walton, P. A. Reneke, E. D. Kuligowski, Performance of Home Smoke Alarms Analysis of the Response of Several Available Technologies in Residential Fire Settings, National Institute of Standards and Technology Technical Note 1455-1, Gaithersburg, MD, December 2007 Revision, 396 pp.

[2] Upholstered Furniture Flammability, World Wide Web Summary of Project, http://www.ul.com/global/eng/pages/offerings/industries/buildingmaterials/fire/fireservice/upholstere d/, Underwriters Laboratories, Northbrook, IL.

[3] R. W. Bukowski, T. E. Waterman, and W. J. Christian, Detector Sensitivity and Siting Requirement for Dwellings. Final Technical Report, National Bureau of Standards Government Contractors Report GCR 75-51, Gaithersburg, MD, 1975, 337 p. 
[4] Standard for the Flammability of Residential Upholstered Furniture; Proposed Rule, 16 CFR Part 1634, Consumer Product Safety Commission, Federal Register 71 (50), 13471-13523 (March 4, 2008).

[5] Standard for the Flammability (Open Flame) of Mattress Sets; Final Rule, 16 CFR Part 1633, Consumer Product Safety Commission, Federal Register 73 (43), 11701-11752 (March 15, 2006).

[6] Flammability Test Procedure for Seating Furniture for Use in Public Occupancies, State of California, Department of Consumer Affairs, Bureau of Home Furnishings and Thermal Insulation, Technical Bulletin 133, North Highlands, CA, January 1991, 29 pp.

[7] Fire tests - Full-scale room test for surface products, International Organization for Standardization ISO 9705: 1993(E), Geneva, Switzerland, 1996.

[8] M. J. Karter, Jr., United States fire loss for 2003, NFPA Journal, 66-71 (November/December 2004).

[9] The U. S. Fire Problem, National Fire Protection Association, Quincy, MA, http://www.nfpa.org/itemDetail.asp?categoryID=953\&itemID=23071\&URL=Research\%20\&\%20Re ports/Fire\%20statistics/The\%20U.S.\%20fire\%20problem.

[10] A. C. Bwalya, An extended survey of combustible contents in Canadian residential living rooms, National Research Council Canada Research Report No. 176, Ottawa, Ontario, November, 2004, $30 \mathrm{pp}$.

[11] A. C. Bwalya, G. D. Lougheed, A. Kashef, and H. H. Saber, Survey results of combustible contents and floor areas in Canadian multi-family dwellings, National Research Council Canada Report NRCC-50593, Ottawa, Ontario, January 2010, 21 pp.

[12] M. Ahrens, Home structure fires, National Fire Protection Association, Quincy, MA, March 2010.

[13] Requirements, test procedure and apparatus for testing the flame retardance of resilient filling materials used in upholstered furniture, Bureau of Home Furnishings and Thermal Insulation, Technical Bulletin 117, North Highlands, CA, January 1991, 8 pp.

[14] B. Sunström, ed., CBUF-Fire safety of upholstered furniture-the final report on the CBUF research programme, European Commission Measurements and Testing Report EUR 16477 EN, Interscience Communications Limited, London (1995).

[15] V. Babrauskas, Upholstered furniture heat release rates-measurements and estimation, Journal of Fire Sciences 1, 9-32 (1983).

[16] K. B. McGrattan, S. Hostikka, J. E. Floyd, H. R. Baum, R. G. Rehm, Fire Dynamics Simulator (Version 5) Technical Reference Guide, National Institute of Standards and Technology Special Publication SP 1018, Gaithersburg, MD, October 2007, 100 pp.

[17] Methods of Test for Assessment of the Ignitability of Upholstered Seating by Smouldering and Flaming Ignition Sources, British Standards Institution, BS 5852:2006, London, England, March 2006.

[18] W. W. Jones, R. D. Peacock, G. P. Forney, P. A. Reneke, CFAST: Consolidated Model of Fire Growth and Smoke Transport (Version 6). Technical Reference Guide, SP-1026, National Institute of Standards and Technology, Gaithersburg, MD, April 2009 revision, 117 pp.

[19] M. Ahrens, Home fires that began with upholstered furniture, National Fire Protection Association, Quincy, MA, August 2011, 94 pp.

[20] J. D. Averill, L. Moore-Merrell, A. Barowy, R. Santos, R. Peacock, K. A. Notarianni, and D. Wissoker, Report on Residential Fireground Field Experiments, National Institute of Standards and Technology Technical Note 1661, Gaithersburg, MD, April 2010, 104 pp. 


\section{APPENDIX A-Workshop Announcement}




\section{Workshop on Quantifying the Contribution of Flaming Residential Upholstered Furniture to Fire Losses in the United States}

Background. Modern residential upholstered furniture (RUF) and particularly the flexible polyurethane foam (FPUF) most often used as cushioning material are frequently cited as playing a dominant role in fire growth in residences. Fire tests have shown that modern RUF can be responsible for rapid fire growth to intense levels, especially due to the prevalence of FPUF in the cushioning. NIST showed that the burning of modern RUF led to untenable conditions in about 3 minutes. Underwriters Laboratories found similar flashover times of about 4 minutes.

Appropriately, the regulatory focus on RUF in the United States has been on scenarios that are prevalent in the compiled fire loss statistics as tracked by the National Fire Incident Reporting System (NFIRS). Since these statistics have indicated that the largest cause of fire deaths is from cigarette ignition of soft furnishings (RUF and beds), much effort has been focused on limiting smoldering ignition.

There has been less focus on and less success in limiting the consequences of flaming RUF. There are similar products whose contributions to fire hazard are regulated: 16 CFR Part 1633 caps the allowable heat release rate from residential mattresses. California TB 133 caps the allowable heat release rate from upholstered furniture for public occupancies.

A principal impediment to limiting the consequences of flaming RUF is the absence of authoritative estimates of the losses from these fires. This, despite RUF having been shown to be capable of being the principal contributor to rapid fire growth and spread in rooms, even if it is not the first item ignited. Such quantification is crucial in order to understand the potential benefits of developing and implementing approaches that effectively slow fire growth on and limit the maximum heat release rates from RUF.

This workshop is designed to identify approaches for and to stimulate efforts to develop this quantification. The results of this workshop will guide NIST research efforts and also serve to nurture cooperative efforts with members of the wider research community.

Hypotheses. The following hypotheses are provided as means for investigating and guiding efforts to quantify the contribution of RUF to residential fire losses:

-A decreased rate of fire development inside a residential room containing modern RUF increases the time available for response or escape and can result in decreased fire losses (both property and human) inside the room of fire origin.

-Flashover development in the room of fire origin increases production of toxic gases and smoke and the likelihood of fire spread to other areas of the residence. This increases the potential for fire losses at locations substantially removed from the room of fire origin.

-Reducing the fire growth rate on and limiting the maximum heat release rate of RUF to levels insufficient to generate flashover or ignite nearby furnishings would substantially reduce financial and human fire losses in the United States.

Workshop Objective. The purpose of the workshop is to identify approaches for quantifying the full contribution of flaming fires of modern RUF to the Nation's fire losses and, therefore, the potential for reducing these losses. The small group of invited participants will consist of experts in fire statistics and building fire dynamics. The program for this one-and-one-half day workshop will consist of:

a.Short introductory presentations on fire statistics, RUF characteristics in modern American residences (including a brief overview of materials, sources, and industry practices), RUF fire 
behavior, relevant structure fire dynamics, and current efforts to reduce the contribution of RUF (and mattresses) to flaming fire development.

b.Identification of approaches for estimating the contribution of RUF flaming fire behavior to fire losses utilizing existing fire incidence data.

c.Identification of modest additions to fire incident reports that would improve the quality of these estimates in future years.

d.Development of an action plan for quantifying the contribution of modern RUF to the existing fire problem in the United States.

\section{Workshop Details.}

The workshop will take place over one and a half days on March 22-23, 2012 at the National Institute of Standards and Technology campus in Gaithersburg, MD. The first session will start at 8:30 a.m. on Thursday morning and we will wrap up by 4:30 p.m. A la carte lunches at your own expense will be available in the NIST cafeteria. An informal dinner will be arranged Thursday evening for those wishing to join the group. On Friday, we will once again begin at 8:30 a.m. and conclude the workshop by noon.

NIST is closed to the general public at this time. In order to attend the workshop it is necessary to preregister. Preregistering is easy. Please email your full name and affiliation to the Fire Research Division Secretary, Wanda Duffin-Ricks (wanda.duffin-ricks@nist.gov, 301-975-6863) by Friday, March 16 ${ }^{\text {th }}$ and indicate you will be attending the Residential Upholstered Furniture workshop.

On the day of the workshop, badges can be picked up at the visitor center located at the NIST main gate at W. Diamond Ave. and Bureau Drive. Photo identification must be presented to receive your badge. Directions to NIST, site maps, and additional information are available on the WEB at www.nist.gov.

The workshop will be held in the Fire Research Division Conference Room, which is Room B245 in Building 224. To reach Building 224 from the visitor center, after passing through the guard's station you will come to a "T." Turn right onto North Drive. Take your first left onto West Drive You will see the new NIST "Net-Zero Energy Home” on your left. Building 224 is the second general purpose laboratory building on your left after you pass the house. Ample parking is available in the lots in front of the building. Building 224 is secured and requires an employee badge for entry. You should be met at the door in the morning if you arrive on time. If you arrive and no one is present, there is a phone in the lobby which you can use to call x6863 or x6859. Someone will come to escort you in.

The closest major hotel to NIST is the Holiday Inn, Gaithersburg, located at 2 Montgomery Village Ave on the corner of North Frederick Ave and Montgomery Village Ave 1.5 miles from NIST. We have arranged a special rate of $\$ 119 /$ night with the Holiday Inn. Reservations may be made by calling the Hotel directly at 301/948-8900. In order to receive the special rate, you must identify your group affiliation, "NIST/Upholstered Furniture Fire Loss," at the time of the reservation. Reservations must be received by Wednesday, March 7, 2012. Any reservations received after the cut-off date will be accepted on a space and rate availability basis. The Holiday Inn Gaithersburg participates in the "Smoke Free” program. Smoking is not permitted in any guest rooms, restaurants, lounges, meeting rooms and public space. Should this program be violated, the Hotel reserves the right to charge a $\$ 250.00$ recovery fee. A shuttle is available to and from NIST with times to be determined. 
APPENDIX B-Workshop Attendees 


\begin{tabular}{|c|c|c|c|c|}
\hline First Name & Last Name & Sponsor/Company & E-mail addresses & Telephone Number \\
\hline Thomas & Fabian & UL & thomas.fabian@us.ul.com & $847-417-5646$ \\
\hline John & Hall & NFPA & ¡hall@nfpa.org & $617-984-7460$ \\
\hline Marc & Janssens & SwRI & mjanssens@swri.org & $210-522-6655$ \\
\hline Bradley & Pabody & USFA & brad.pabody@dhs.gov & $301-447-1340$ \\
\hline James & Heeschen & USFA & jim.heeschen@dhs.gov & $301-447-1180$ \\
\hline Marty & Ahrens & NFPA & mahrens@nfpa.org & $617-984-7463$ \\
\hline Bob & Luedeka & PFA & rluedeka@pfa.org & $865-657-9840$ \\
\hline David & Miller & CPSC & dmiller@cpsc.gov & $301-504-7323$ \\
\hline Douglas & Thomas & NIST & douglas.thomas@nist.gov & $301-975-4918$ \\
\hline Anthony & Hamins & NIST & anthony.hamins@nist.gov & $301-875-6598$ \\
\hline Rick & Davis & NIST & rick.davis@nist.gov & $301-975-5901$ \\
\hline Jason & Averill & NIST & averill@nist.gov & $301-975-2585$ \\
\hline Dick & Gann & NIST & rggann@nist.gov & $301-975-6866$ \\
\hline Bill & Pitts & NIST & william.pitts@nist.gov & $301-975-6486$ \\
\hline David & Butry & NIST & david.butry@nist.gov & $301-975-6138$ \\
\hline William & Grosshandler & NIST & william.grosshandler@nist.gov & $301-975-6850$ \\
\hline Chuck & Smith & CPSC & clsmith@cpsc.gov & $301-504-7701$ \\
\hline Rik & Khanna & CPSC & rkhanna@cpsc.gov & $301-987-5208$ \\
\hline Shivani & Mehta & CPSC & smehta@cpsc.gov & $301-987-2025$ \\
\hline Linda & Fansler & CPSC & Ifansler@cpsc.gov & $301-987-2059$ \\
\hline Andrew & Lock & CPSC & alock@cpsc.gov & 301-987-2099 \\
\hline Lisa & Scott & CPSC & $\overline{\text { Iscott@cpsc.gov }}$ & $301-987-2064$ \\
\hline Dan & Gottuk & Hughes Associates, Inc. & dgottuk@haifire.com & $410-737-8677$ \\
\hline Sean & DeCrane & Cleveland Div. of Fire & rovloc93@aol.com & $216-224-6150$ \\
\hline Michael & Hawthorne & Chicago Tribune & mhawthorne@tribune.com & $312-222-3315$ \\
\hline Kathy & Butler & NIST & kathryn.butler@nist.gov & $301-975-6673$ \\
\hline Amanda & Robbins & NIST & amanda.robbins@nist.gov & $301-975-6551$ \\
\hline Tony & Putorti & NIST & anthony.putorti@nist.gov & $301-975-8615$ \\
\hline Nathan & Marsh & NIST & nathan.marsh@nist.gov & $301-975-5441$ \\
\hline Rick & Peacock & NIST & richard.peacock@nist.gov & $301-975-6664$ \\
\hline Bob & Chapman & NIST & robert.chapman@nist.gov & $301-975-2723$ \\
\hline Jonathan & Kent & CPSC & jkent@cpsc.gov & $301-987-2485$ \\
\hline George & Robbins & Fairfax Cty. Fire \& Rescue & george.robbins@fairfaxcounty.gov & $703-246-4741$ \\
\hline
\end{tabular}


APPENDIX C—Workshop Agenda 
AGENDA

\title{
Workshop on Quantifying the Contribution of Flaming Residential Upholstered Furniture to Fire Losses in the United States
}

\author{
NIST \\ Building 224/Room B245 \\ March 22-23, 2012
}

Thursday Morning, March 22, 2012

Background Presentations and Discussion

8:30Anthony Hamins, Welcome

8:45William M. Pitts, "Introduction and Background to Workshop Topic"

9:15Tom Fabian, "Residential Upholstered Furniture Flammability"

9:45 Marc Janssens, "Reducing the Uncertainty of Quantifying the Burning Rate of

10:15Break

Upholstered Furniture in Fire Investigations"

10:30 David Sheppard, “An Investigator's View of the Role of Upholstered Furniture in Fire Scene Investigations"

11:00Brad Pabody, "NFIRS Overview"

11:30 John Hall, "How NFPA Measures Fire Problems and Safety Strategies with Special Attention to Upholstered Furniture"

12:00 David Butry, "The Use of NFIRS in Economic Analysis"

12:30Lunch

Thursday Afternoon, March 22, 2012

Open Forum Discussions

1:30 Would decreasing the rate of fire growth and heat release in an enclosure significantly reduce residential fire losses within the room of fire origin? (Leader: Jason Averill)

1:55 Would decreasing the rate of fire growth and heat release in an enclosure significantly reduce residential fire losses at locations substantially removed from the room of fire origin? (Leader: Richard Gann)

2:20 What are the relevant characteristics of residential fires involving flaming RUF contributing to fire losses? (Leader: Rick Davis)

2:45 Is flaming RUF likely playing a significant role in residential fire losses? (Leader: Richard Gann)

3:10 Break

3:30 Is it appropriate to differentiate fire losses inside and exterior to the room of fire origin with regard to the role of RUF in Residential Fire Losses? (Leader: Jason Averill)

3:55 Do existing fire statistics and related analyses effectively capture contribution of flaming RUF to residential fire losses? (Leader Rick Davis)

4:20 Can existing fire statistics and extended analyses better capture contributions of flaming RUF to residential fire losses? (Leader Richard Gann)

4:45 Summary of Presentations and Forum Discussions (William M. Pitts) 
5:00 Adjourn

6:15 Dinner at Buca di Beppo Italian Restaurant, 122 Kentlands Boulevard, Gaithersburg MD 20878

Friday Morning, March 23, 2012

Identify Approaches and Participants for Estimating Role of Flaming RUF in Fire Losses

8:30 Brief Recap and Introduction to Session (William M. Pitts)

8:45 Identify Approaches for Estimating Contribution of Flaming RUF to Fire Losses within the Room of Fire Origin Using Available Fire Statistics (Leader: Jason Averill)

9:30 Identify Approaches for Estimating Contribution of Flaming RUF to Fire Losses at Locations Removed from the Room of Fire Origin Using Available Fire Statistics (Leader: Richard Gann)

10:15 Break

10:45 Identify Limitations in Existing Fire Statistics and Provide Suggestions for Improvement (Leader: Rick Davis)

11:30 Gauge Interest and Develop Working Group to Improve the Quantification of the Contribution of Flaming RUF to Residential Fire Losses (Discussion Leader: William M. Pitts)

12:15 Wrap-up and Final Comments (William M. Pitts)

12:30 Adjourn 


\section{APPENDIX D-Presentations}




\section{APPENDIX D.1 Anthony Hamins, NIST}

Welcome 


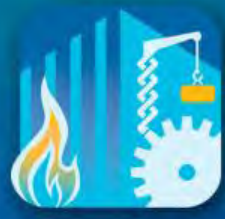

\title{
Workshop on Quantifying the
} Contribution of Flaming Residential Upholstered Furniture to Fire Losses in the United States

\author{
Anthony Hamins \\ March 22-23, 2012 \\ Fire Research Division, NIST
}

NIT

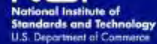

\section{NIST: Basic Stats and Facts}

- Non-regulatory agency within the U.S. Department of Commerce

- 2800 federal employees, 2600 associates and facilities users/year

- Four labs \& two centers

- Physical Measurement Laboratory

- Material Measurement Laboratory

- Engineering Laboratory

- Information Technology Laboratory

- Center for Nanoscale Science and Technology

- NIST Center for Neutron Research

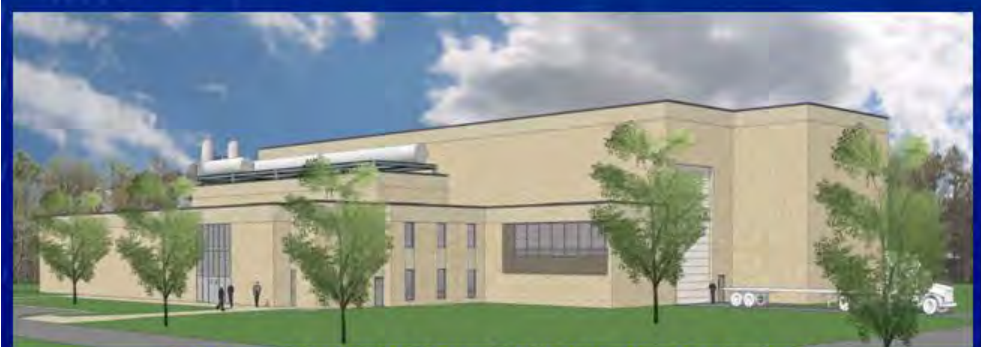

Expanded National Fire Research Lab

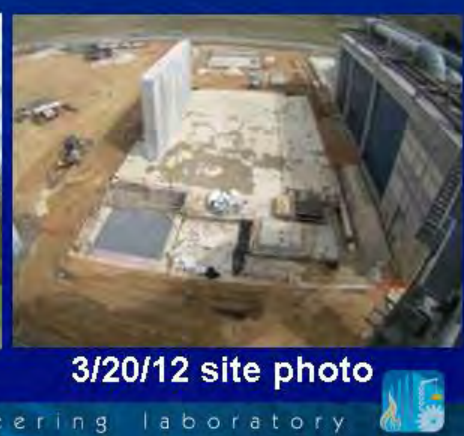

engineering 


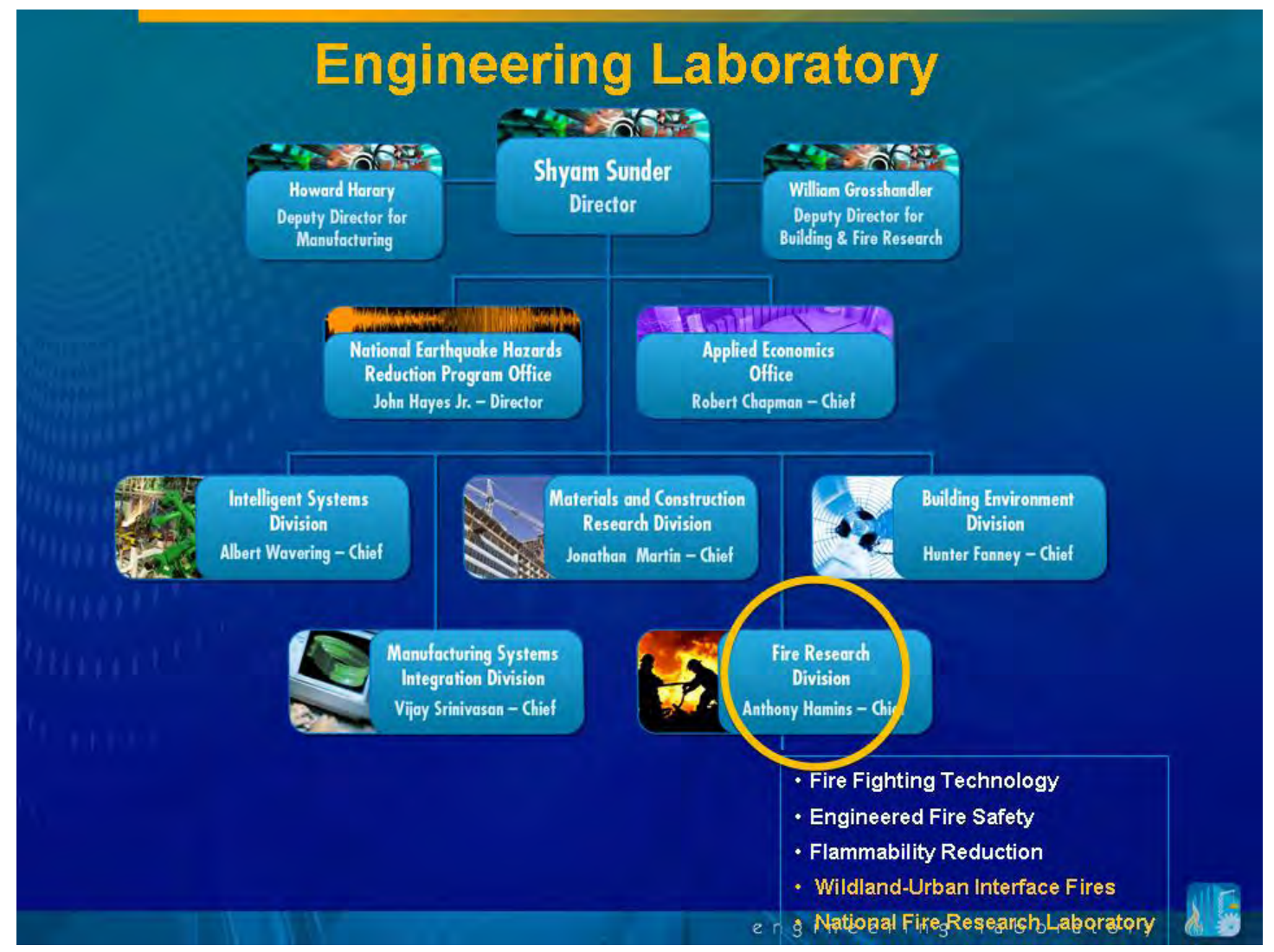

\section{Engineering Laboratory Mission}

To promote U.S. innovation and industrial competitiveness in areas of critical national priority by anticipating and meeting the:

- measurement science and

- standards

needs for technology-intensive manufacturing, construction, and cyber-physical systems in ways that enhance economic prosperity and improve the quality of life. 


\section{Scope of Measurement Science}

\section{Measurement science research and services include:}

- development of performance metrics, measurement and testing methods, predictive modeling and simulation tools, knowledge modeling, protocols, technical data, and reference materials and artifacts

- conduct of inter-comparison studies and calibrations

- evaluation of technologies, systems, and practices, including uncertainty analysis

- development of the technical basis for standards, codes, and practices-in many instances via testbeds, consortia, standards and codes development organizations, and/or other partnerships with industry and academia

\section{What is the Problem?}

3,320 fatalities $\& 16,705$ injuries: Civilian 105 fatalities \& 79,700 injuries: Firefighters in line of duty

\section{Estimated 2008 U.S. Total Cost of Fire: \$362 B (2.5\% GDP)\#}

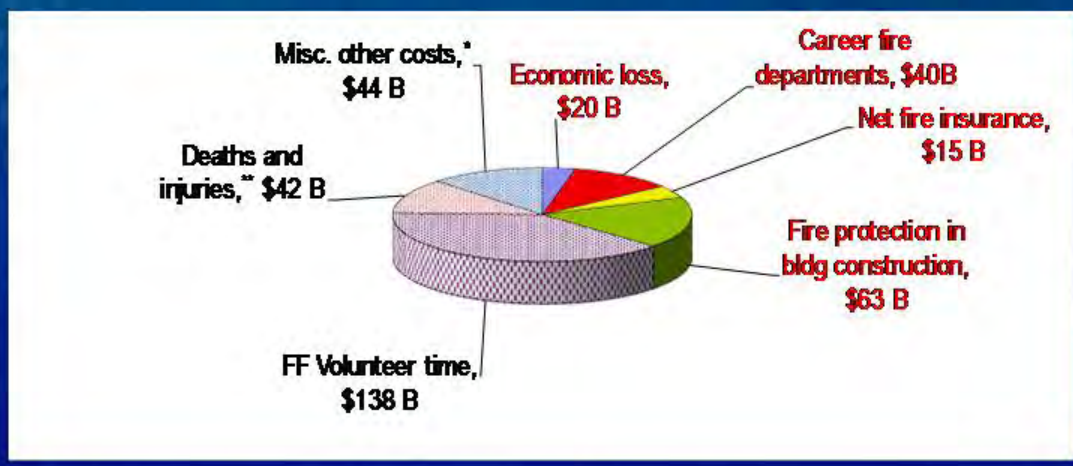

\# Hall, J.R., The Total Cost of Fire in the United States, NFPA, February 2011 (derived from USFA's NFIRS) ${ }^{*}$ industrial fire brigades, training programs, fire testing, fire retardants, maintaining/complying with product standards ${ }^{* *}$ CPSC model: \$6 M/death, \$0.2 M/njury 


\section{Fire Research at NIST}

\section{Long-term vision:}

Remove unwanted fire as a limitation to life safety \& economic prosperity in the United States.

- Save people's lives from fires,

- Help firefighters do their jobs better and more safely,

- Reduce the economic impact of fire,

- Help save people's homes from structural fires and wildfires,

- Promote U.S. exports by furthering sound international fire safety standards,

- Advance U.S. commerce by developing \& bringing fire safe products to market.

\section{Fire Research at NIST}

- Technology-centric research strategy supporting the technical basis for standards, codes, guidelines, models, software decision-tools, standard reference materials..

- Research prioritization based on:

- Mission alignment

- Analysis of greatest impact (problem size, potential reach)

- Consideration of cost-effective and implementable solutions

- Stakeholder input

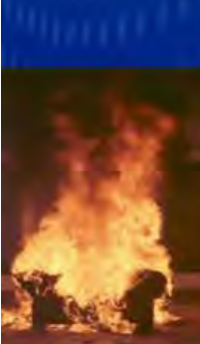

materials

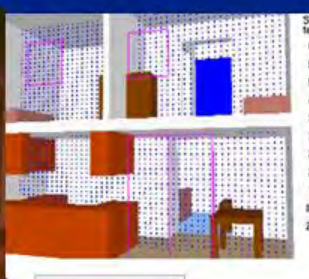

models

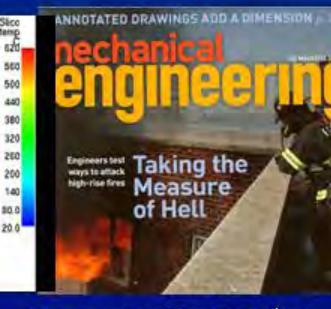

measurements

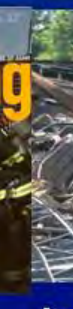

investigations standards 


\section{Fire Research Programs}

Reduced Fire Risk in Communities:

- Enable the development and implementation of advanced technologies and tactics to improve fire service safety and effectiveness

-Enable improved standards, codes, and technologies to increase the fire resistance of Wildland-Urban Interface (WUI) communities

\section{Reduced Fire Risk in Buildings:}

-Enable the manufacture of cost-effective fire-safe materials and products

-Enable effective fire protection technologies

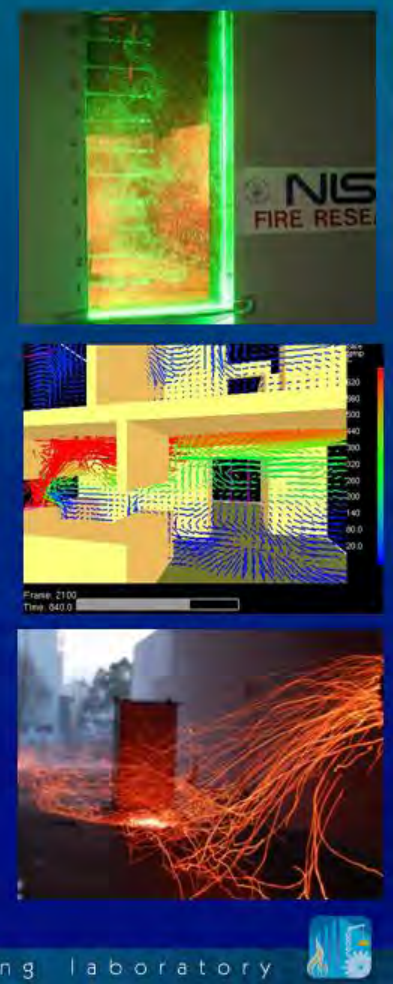

\section{What is the Problem?}

2008 Fire losses by Type (Butry/NFIRS)

\begin{tabular}{lcccc}
\hline Fire Type & Reported Fires & Deaths & Injuries & Property Loss (\$ B) \\
\hline Structure Fires & 515,000 & 2,900 & 14,960 & 16.6 \\
Wildland Fires & 364,000 & 18 & 257 & 2.8 \\
Vehicles \& Outside Fires & 572,000 & 402 & 1,488 & 1.8 \\
\hline Total & $1,451,000$ & 3,320 & 16,705 & 21.2 \\
\hline
\end{tabular}

Home fires (2005-2009) dominate structure fire losses (NFPA/NFIRS)

$.73 \%$ of all reported structure fires

$.92 \%$ of civilian structure fire deaths

$.86 \%$ of the civilian structure fire injuries

- $68 \%$ of direct structure fire property loss 


\section{What is the Problem?}

\begin{tabular}{|c|c|c|c|c|}
\hline $\begin{array}{c}\text { First Item Ignited } \\
\text { Fires in Residences }(2003-06)^{*}\end{array}$ & Fires & Deaths & Injuries & Property Damage (\$ B) \\
\hline Upholstered furniture & 7,400 & 590 & 900 & 0.4 \\
\hline Mattress/bedding & 11,200 & 380 & 1390 & 0.4 \\
\hline Thermoplastics & 29,400 & 280 & 1160 & 0.7 \\
\hline $\begin{array}{l}\text { Structural member, component or } \\
\text { insulation }\end{array}$ & 32,500 & 240 & 620 & 1.3 \\
\hline Other furniture or utensils & 6,000 & 170 & 500 & 0.2 \\
\hline Confined cooking fire/materials & 134,900 & 130 & 3670 & 0.3 \\
\hline Interior wall covering & 8,200 & 120 & 340 & 0.3 \\
\hline Subtotal of Above Categories & 229,600 & 1,910 & 8560 & 3.6 \\
\hline Totals & 378,600 & 2850 & 13,090 & 6.1 \\
\hline
\end{tabular}

Beyond the first item ignited, what is the total contribution of flaming residential upholstered furniture (RUF) to fire losses? 


\section{APPENDIX D.2 William M. Pitts, NIST}

Introduction and Background to Workshop Topic 


\title{
Workshop on
}

\author{
NIST \\ March 22-23, 2012
}

Welcome and Thank You

Organizer: William M. Pitts

1. Overview of RUF Burning Behavior

2. Overview of Selected Fire Statistics

3. Number of RUF Articles in Residences

4. Workshop

Background

Guiding Hypotheses

Objective

Organization and Schedule 


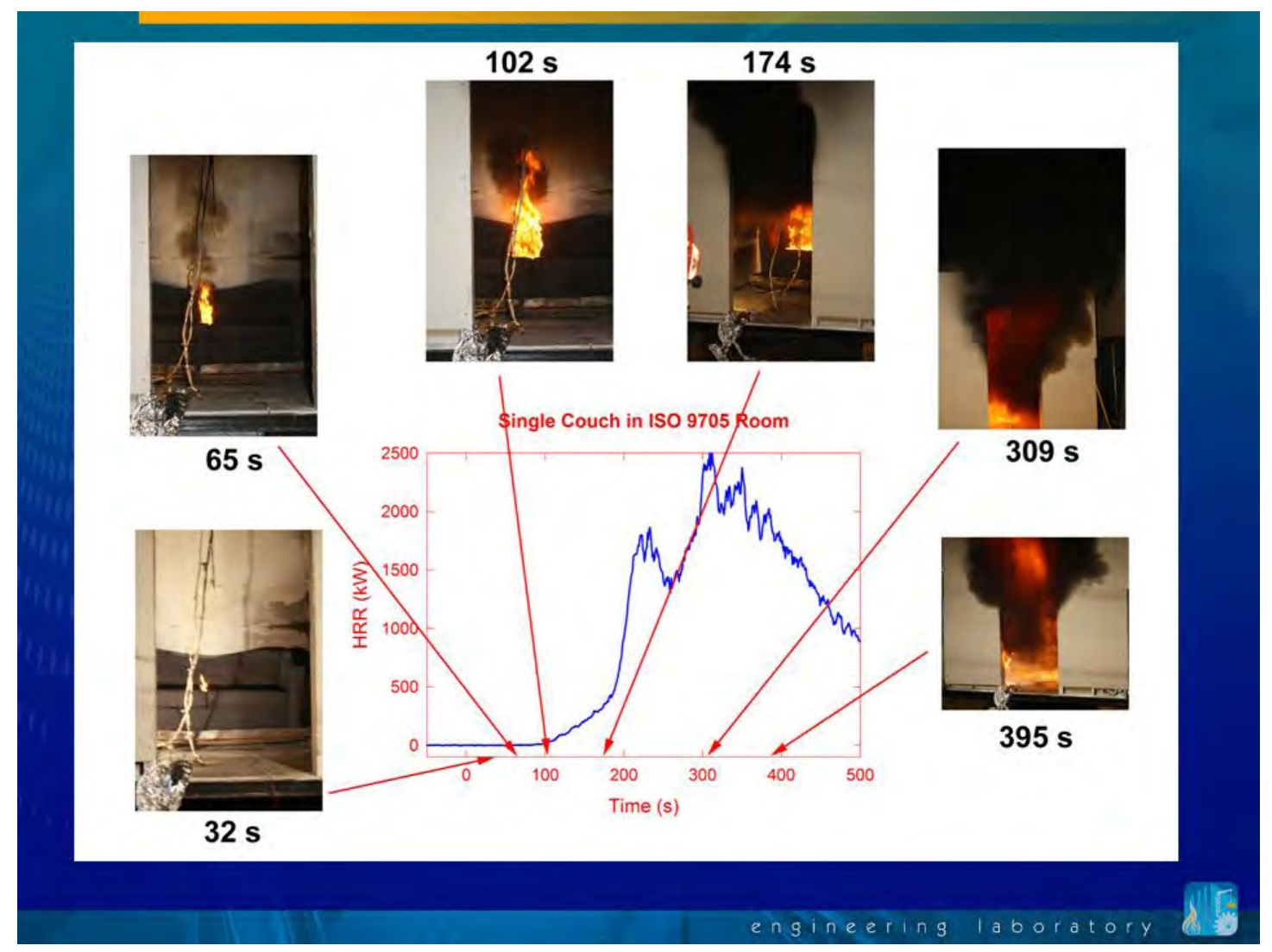

"When PCFs [primary combustible furnishing] are the first-ignited item, they are known to give rise to rapidly developing fires due to the flammability of the polyurethane foam (PUF) that is the dominant combustible constituent most often used in their manufacture." 
The NIST Dunes II study (Bukowski et al., 2004) reported that average times required to develop untenable conditions inside a residential room were reduced from the 17 minntics measured during Dunes I (Bukowski et al., 1975) using typical furniture from that period to the identified during Dunes II $(2004,2007)$ utilizing modern furniture. Material changes in RUF construction over the 1975 to 2004 period was identified as a major contribution to this dramatic decrease.

Underwriters Laboratory directly compared fire development in rooms containing RUF constructed with FPUF cushioning and microsuede fabric with rooms containing RUF produced with cotton batting cushioning and cotton fabric (chosen to represent legacy construction materials). They reported that flashover times with the legacy RUF were 34 minutes, which were reduced to 4 minutes when the modern materials were used.

CPSC, NIST, CBHF, BRANZ, University of Canterbury, many others

Years of work from 1980s onward

CBUF - Combustion Behavior of Upholstered Furniture EU Project, 1995

Upholstered Furniture Flammability Research Study

UL, study of furniture flammability dependence on a range of furniture material characteristics

Characterization of Fires in Multi-suite Residential Dwellings NRC Canada, on-going, focus on development of design fires, survey of combustible contents, single-item burning in room

- Burning Rate of Upholstered Furniture

- SwRI, focus on prediction of HRR for burning RUF for forensic analysis 
During period 2002-2004 upholstered furniture was the first item to ignite in an average 7,800 residential fires attended by the fire service annually compared with 402,000 fires reported in 2003 (NFPA). These fires resulted in an average of 540 deaths, 870 injuries and $\$ 250$ million in property loss each year compared with totals of 3,165 deaths, 14,075 injuries and $\$ 6,074,000,000$ in financial losses for 2003 (NFPA).

of reported fires

of fire deaths

$6.2 \%$ of injuries

$4.1 \%$ of property losses

- Fire departments responded to 369,500 home structure fires which resulted in 13,350 civilian injuries, 2,640 civilian deaths, and $\$ 6.9$ billion in direct damage.

- $92 \%$ of all civilian structure fire deaths resulted from home structure fires.

- Kitchens are the leading area of origin for home structure fires $(37 \%)$ and civilian home fire injuries $(36 \%)$.

- Only $4 \%$ of home fires started in the living room, family room, or den; these fires caused $24 \%$ of home fire deaths.

- $8 \%$ of reported home fires started in the bedroom. These fires caused $25 \%$ of home fire deaths, $21 \%$ of home fire injuries, and $14 \%$ of the direct property damage.

- Smoking is a leading cause of civilian home fire deaths.

- Almost two-thirds (62\%) of reported home fire deaths resulted from fires in homes with no smoke alarms or no working smoke alarms. 
Fire losses (2008) *

\begin{tabular}{ccccccc}
\hline Year & $\begin{array}{c}\text { Reported } \\
\text { Fires }\end{array}$ & $\begin{array}{c}\text { Civilian } \\
\text { Deaths }\end{array}$ & $\begin{array}{c}\text { Civilian } \\
\text { Injuries }\end{array}$ & $\begin{array}{c}\text { Firefighter } \\
\text { Deaths }\end{array}$ & $\begin{array}{c}\text { Firefighter } \\
\text { Injuries }\end{array}$ & $\begin{array}{c}\text { Core Cost of Fire } \\
\text { (\$ B In 2008 dollars) }\end{array}$ \\
\hline 1980 & $3,000,000$ & 6,505 & 30,200 & 138 & 98,070 & $\$ 74$ \\
1990 & $2,250,000$ & 5,195 & 28,600 & 108 & 100,300 & $\$ 86$ \\
2000 & $1,750,000$ & 4,045 & 22,350 & 103 & 84,550 & $\$ 102$ \\
2008 & $1,349,000$ & 3,320 & 16,705 & 105 & 79,700 & $\$ 138$ \\
\hline
\end{tabular}

Normalized Fire losses (2008) *

\begin{tabular}{ccccccc}
\hline Year & $\begin{array}{c}\text { Reported } \\
\text { Fires/1000 } \\
\text { people }\end{array}$ & $\begin{array}{c}\text { Civilian } \\
\text { Deaths/1000 } \\
\text { fires }\end{array}$ & $\begin{array}{c}\text { Civilian } \\
\text { Injuries/1000 } \\
\text { fires }\end{array}$ & $\begin{array}{c}\text { Firefighter } \\
\text { Deaths/1000 } \\
\text { fires }\end{array}$ & $\begin{array}{c}\text { Firefighter } \\
\text { Injies/1000 } \\
\text { fires }\end{array}$ & $\begin{array}{c}\text { Core Cost of } \\
\text { Fire per capita } \\
\text { (In 2008 dollars) }\end{array}$ \\
\hline 1980 & 13.2 & 2.2 & 10.1 & 0.46 & 32.7 & $\$ 326$ \\
1990 & 9.0 & 2.3 & 12.7 & 0.48 & 44.6 & $\$ 344$ \\
2000 & 6.2 & 2.3 & 12.8 & 0.59 & 48.3 & $\$ 382$ \\
2008 & 4.8 & 2.3 & 11.5 & 0.72 & 54.9 & $\$ 454$ \\
\hline
\end{tabular}

* Statistics derived from analysis of 2008 USFA fire statistics published by NFPA

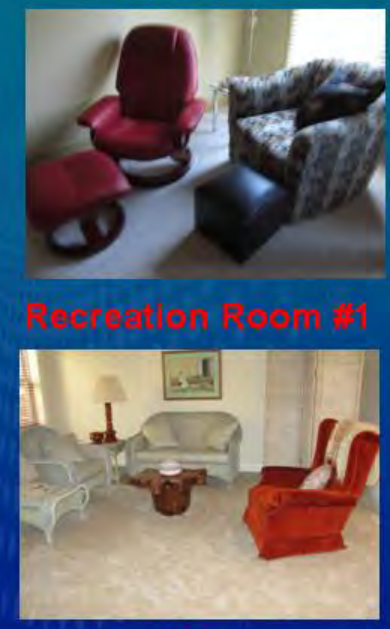

Family Room

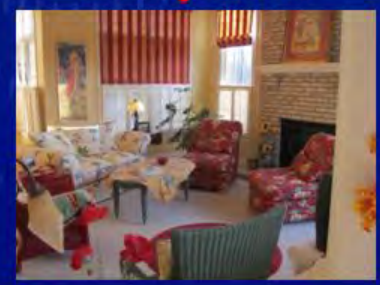

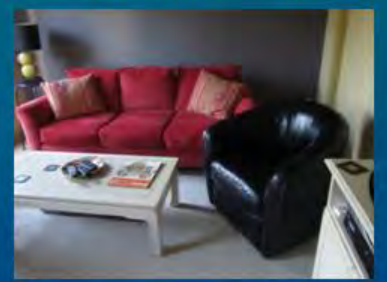

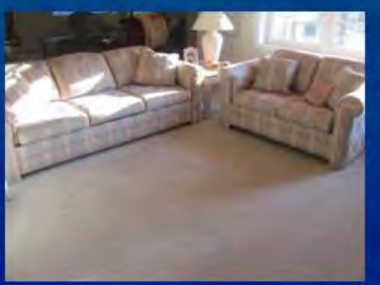

Living Room

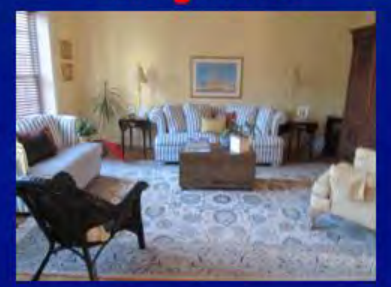

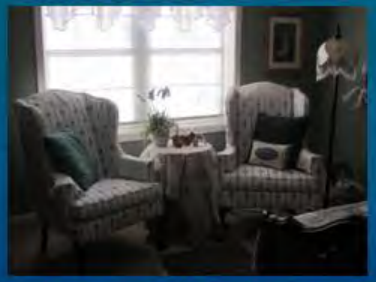

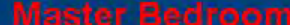

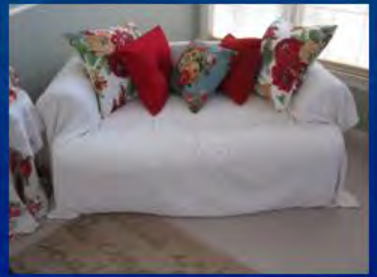

17 Articles in 6 Rooms 
Furniture articles primarily intended for indoor use in residences; constructed with an upholstered seating area, comprised of a contiguous upholstered seat and back or $\operatorname{arm}(\mathbf{s})$

Based on the assumption that the expected life of a piece of upholstered furniture is 16 years, the average number of upholstered items in household use during 2002-2004 was about 447 million pieces

Number of households in US in 2003 was 111 million (US census)

Four pieces of RUF per household

Bwalya et al. (NRCC-50593)

\begin{tabular}{|c|c|c|c|c|c|}
\hline & Mean & Standard & & & - Mean FL (ALS) \\
\hline Room & $\begin{array}{c}\text { FLD } \\
\left(\mathrm{ALJ} / \mathrm{m}^{2}\right)\end{array}$ & $\begin{array}{c}\text { Deviation } \\
\left(\mathrm{AL} / \mathrm{m}^{2}\right)\end{array}$ & $\begin{array}{c}95^{\mathrm{B}} \\
\text { Percentile }\end{array}$ & $\begin{array}{l}\text { Sample } \\
\text { Size }\end{array}$ & \\
\hline Kitchen & 807 & 123 & 940 & 515 & $7,908(2)^{4}$ \\
\hline $\begin{array}{l}\text { Secondary } \\
\text { bedroom }\end{array}$ & 594 & 146 & 846 & 129 & : $6,237(5)$ \\
\hline $\begin{array}{l}\text { Primary } \\
\text { Bedroom }\end{array}$ & 534 & 125 & 753 & 347 & s.864 (1) \\
\hline Living Room & 412 & 127 & 610 & 397 & $7.251(3)$ \\
\hline Dining Room & 393 & 132 & 576 & 292 & 3.812 (6) \\
\hline $\begin{array}{l}\text { Basement Living } \\
\text { Room }\end{array}$ & 288 & 96 & 450 & 130 & $6,682(4)$ \\
\hline
\end{tabular}

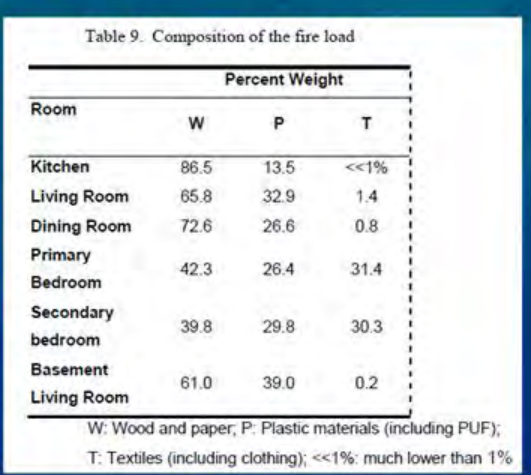

T: Textiles (including clothing); $<1 \%$ : much lower than $1 \%$

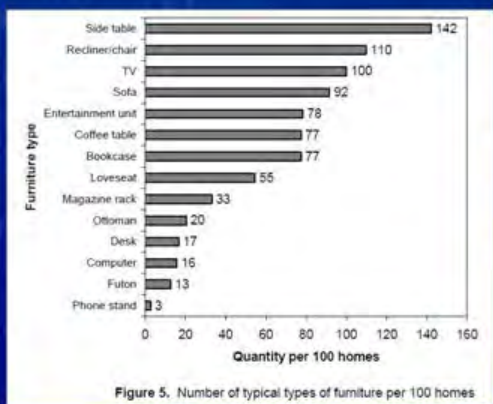

Bwalya (An Extended Survey of Combustible Contents in Canadian Residential Living Rooms, NRCC Research Report No. 176)

Works out to 2.9 RUF articles per room 
RUF is widely regarded as playing a central role in fire losses due to rapid fire growth and high heat content

Existing approaches seek to limit ignition, primarily by smoldering sources, e.g., CPSC 16 CFR 1634, UFAC, NFPA 260

Fire hazard on RUF, once ignited, is not controlled Statistics focus on RUF as first item ignited

Contribution of flaming combustion to flashover development not quantified

Few efforts in US to limit RUF HRR (contrast with BS5852, CPSC 1633 for mattresses)

A decreased rate of fire development inside a residential room containing modern RUF increases the time available for response or escape and can result in decreased fire losses (both property and human) inside the room of fire origin.

Flashover development in the room of fire origin increases production of toxic gases and smoke and the likelihood of fire spread to other areas of the residence. This increases the potential for fire losses at locations substantially removed from the room of fire origin

Reducing the fire growth rate on and limiting the maximum heat release rate of RUF to levels insufficient to generate flashover or ignite nearby furnishings would substantially reduce financial and human fire losses in the United States. 
To identify approaches for quantifying the full contribution of flaming fires of modern RUF to the Nation's fire losses and, therefore, the potential for reducing these losses.

Furniture Flammability is a broad topic with many facets. We are all aware of the intense interest in the broad topic, but, please remember, this is int a workshop on furniture flammability. The burning behaviors of the existing furniture stock and residential fires are necessarily incorporated to aid in identifying means for estimating the contribution of flaming RUF to fire losses. The workshop topic is complex and all of the time available will be required to adequately address it. Try to limit your deliberations to this topic. If necessary, moderators will attempt to redirect discussions back on topic. Please be understanding.

This Morning

Background Talks

RUF Burning Behavior: Fabian, Janssens, xxxx

Fire Statistics: Pabody, Hall, Butry

This Afternoon

Open Forum Discussions

Leaders: Averill, Gann, Davis

Tomorrow Morning

- Identify Approaches and Participants for Estimating Role of Flaming RUF in Fire Losses

- Leaders: Averill, Gann, Davis, Pitts 


\section{APPENDIX D.3 Thomas Fabian, UL}

Residential Upholstered Furniture Flammability 


\section{Residential Upholstered Furniture Flammability}

NIST Flaming Residential Upholstered Furniture Workshop

March 22, 2012

Gaithersburg, MD

Thomas Fabian, Ph.D.

Underwriters Laboratories

\section{Leading areas of origin in USA Home Structure} Fires: 2003-2007

Fact: $21 \%$ of home fire

deaths resulted from fires

beginning with upholstered

furniture.

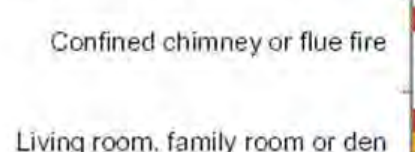

Living room, family room or den

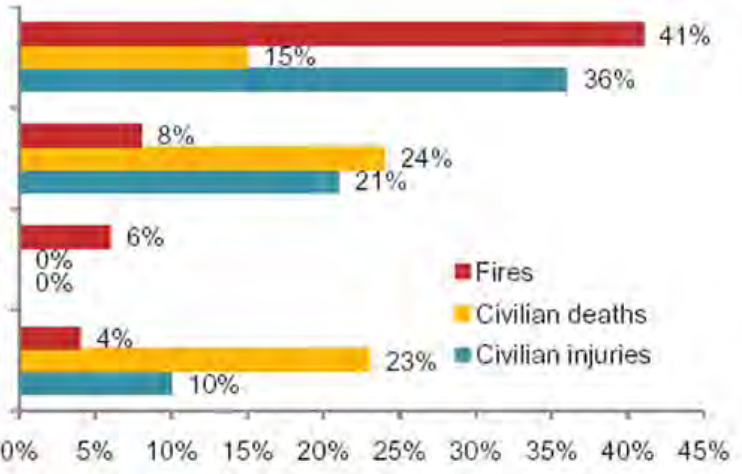

- M Ahrens, "Home Structure Fires", NFPA, March 2010 


\title{
Upholstered Furniture Flammability
}

\author{
"Demonstration of Concept" to \\ verify if commercially available \\ fire resistance technologies can \\ retard and/or reduce fire growth

\section{Scales of Testing} \\ -Material \\ -Mock-up \\ •Full chairs \\ www.ul.com/FireService
}

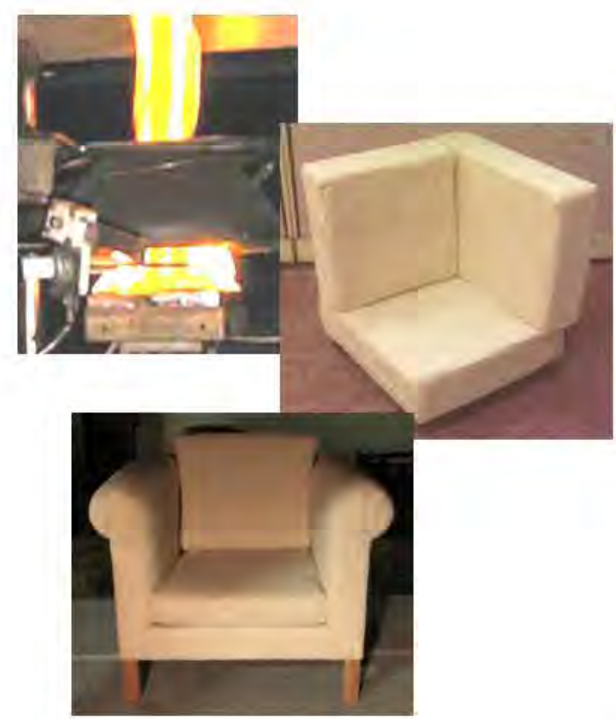

(14)

\section{Upholstered Furniture Flammability Materials}

Cover Fabric (1)

- Beige, polyester microsuede

Foam (2)

- Polyurethane foam $\left(29.6 \pm 0.6 \mathrm{~kg} / \mathrm{m}^{3}\right)$

- TB117 Fire retardant polyurethane foam $\left(27.6 \pm 0.6 \mathrm{~kg} / \mathrm{m}^{3}\right)$

Polyester Wrap (1)

- Polyester wrap (1 oz smooth bond)

\section{Fire Barrier (11)}

Chemistries: para-aramids, cotton, rayon, blends, and elastic Physical form: flat/high-loft, woven/non-wovens, plain weave/knits, single/multi-layer 


\section{Upholstered Furniture Flammability}

Mock-up Level Tests: PU-W-C vs. PU-W-FB1-C

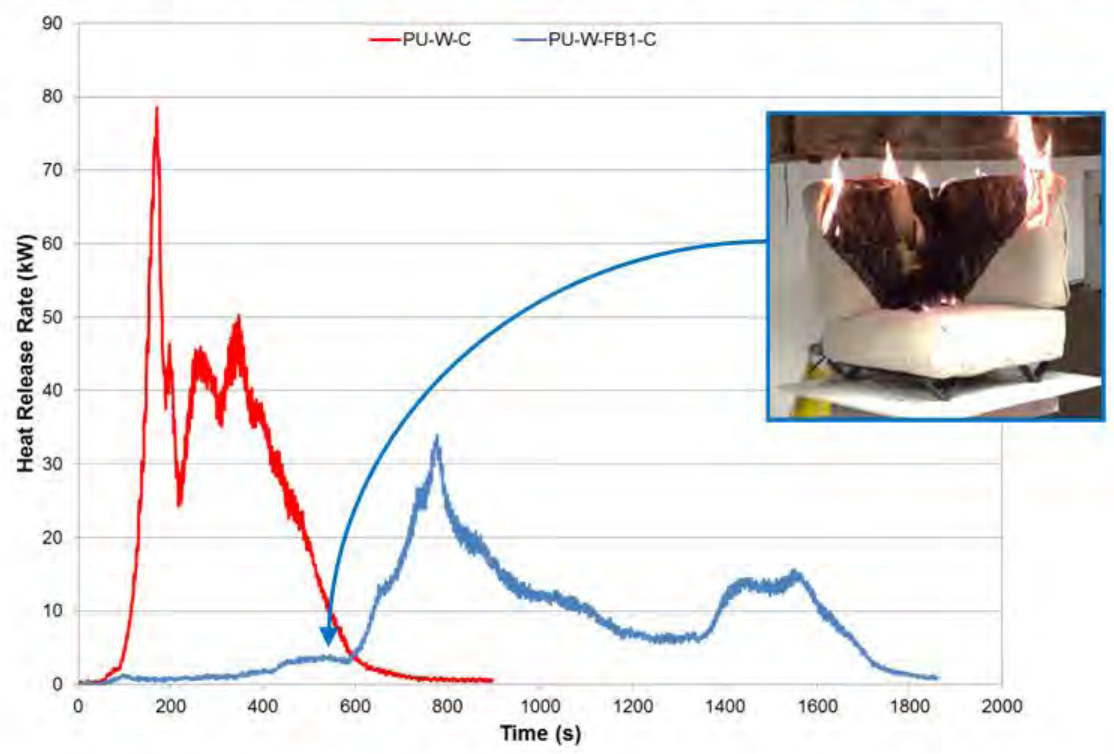

(U)

\section{Upholstered Furniture Flammability}

\section{Furniture Tests}

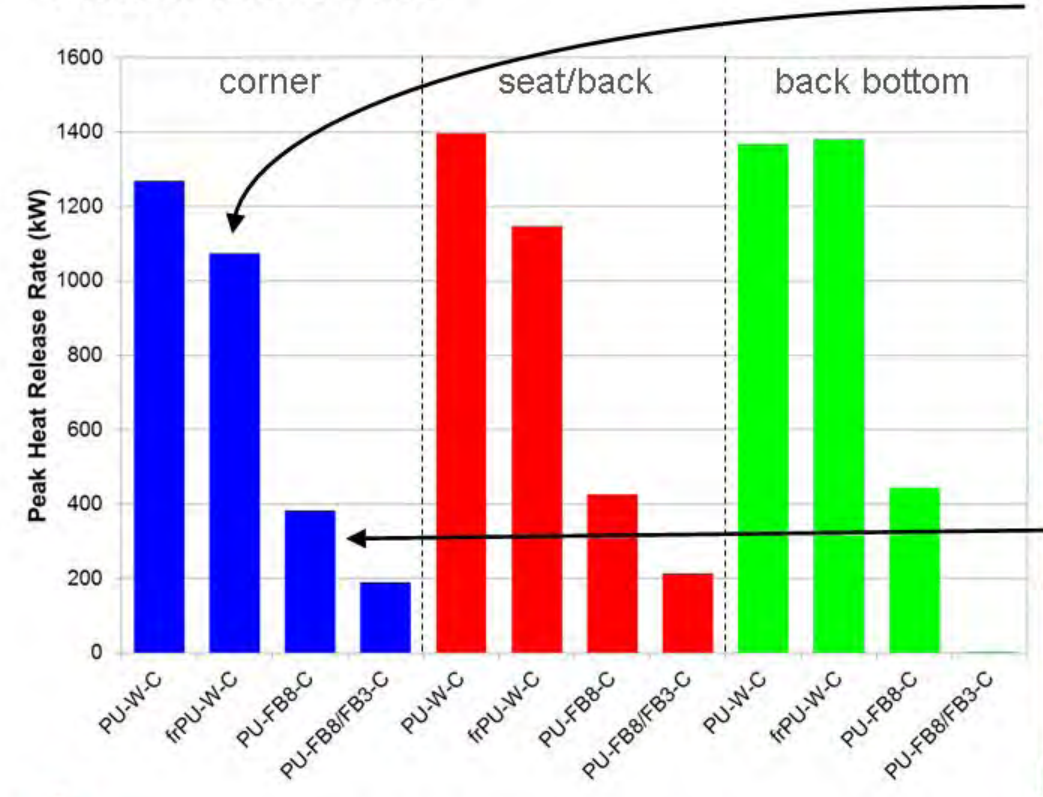

(U.)

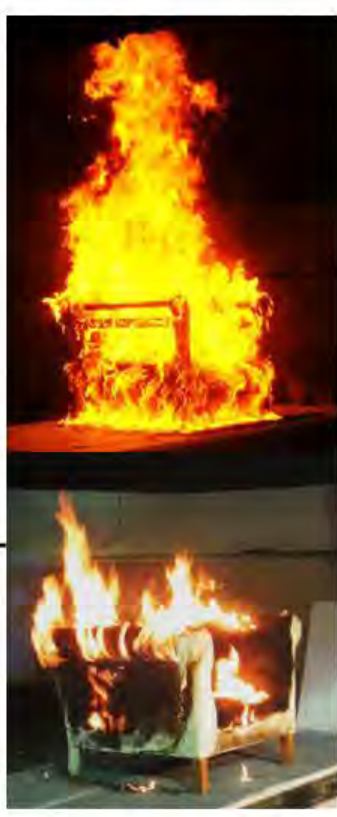

14 


\section{Upholstered Furniture Flammability Mitigation Summary}

All approaches exhibited some level of reduced ignitability/flammability.

\section{Approach 1: TB117 FR foam substitution for PU foam}

-Reduced burn duration on cone calorimeter tests

-Reduced HRR on mock-up tests

-Reduced furniture PHRR when cushions were ignited (1.3 vs. 1.1 MW)

Approach 2: FR barrier inclusion or poly-wrap substitution

-Reduced HRR on cone calorimeter and mock-up tests

-FR barrier substitution for poly-wrap reduced furniture PHRR by $\sim 3 \mathrm{X}$

Approach 3: FR barrier substitution for poly-wrap + covered sides

-Reduced PHRR from 1+ MW to $200 \mathrm{~kW}$

-Ignition of back did not propagate

(U1)

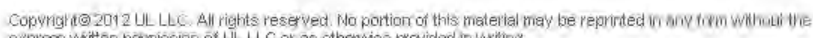

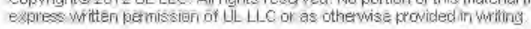

\section{Upholstered Furniture Flammability Project Test Summary}

Cone calorimeter tests are "simple" tests that differentiated the combustibility of individual materials and combinations of materials.

$\Rightarrow$ Potential for material substitution tests

Mock-up level calorimeter tests increased sample complexity and subsequent combustion behavior by virtue of larger sample size, 3 dimensional geometry, and construction elements such as seams.

$\Rightarrow$ Potential for subordinate design tests

Full-scale furniture calorimeter tests further increase sample complexity and subsequent combustion behavior by virtue of larger sample size and furniture design.

$\Rightarrow$ End product evaluation tests 


\section{Upholstered Furniture Flammability Phase 2: Living Room Fire Experiments}

How does fire growth initiated on upholstered furniture using commercially available fire resistance technology compare to legacy and contemporary furniture?

\section{Furniture Variations}

-Contemporary

-Contemporary w/ barrier

-Legacy

www.ul.com/FireService

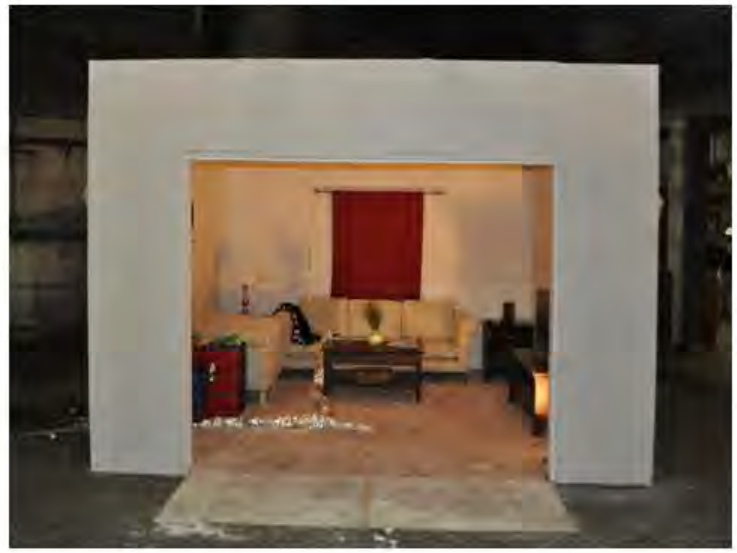

\section{Living Room Fire Tests: Summary}

- "Modern" upholstered furniture has reduced time to flashover by 30 minutes (34+ vs. $4+$ minutes)

- Replacing the polyester wrap around foam (cushions, arms) with a cotton-based FR barrier (green?) lengthened time to flashover from 4+ minutes to $21+$ minutes

$\Rightarrow$ Minimal impact on furniture construction process

- Further improvement could be made by encasing the upholstered furniture frame with flat barrier

$\Rightarrow$ Some impact on furniture construction process 


\section{Upholstered Furniture Flammability Phase 3: Tenability Experiments}

What is the impact of upholstered furniture on tenability and safe egress time?

2 Furniture Variations

-Contemporary

-Contemporary w/ barrier

2 Residential Structures

$\cdot 1,200 \mathrm{ft}^{2}$ ranch

$\cdot 3,200 \mathrm{ft}^{2}$ open floor 2 story
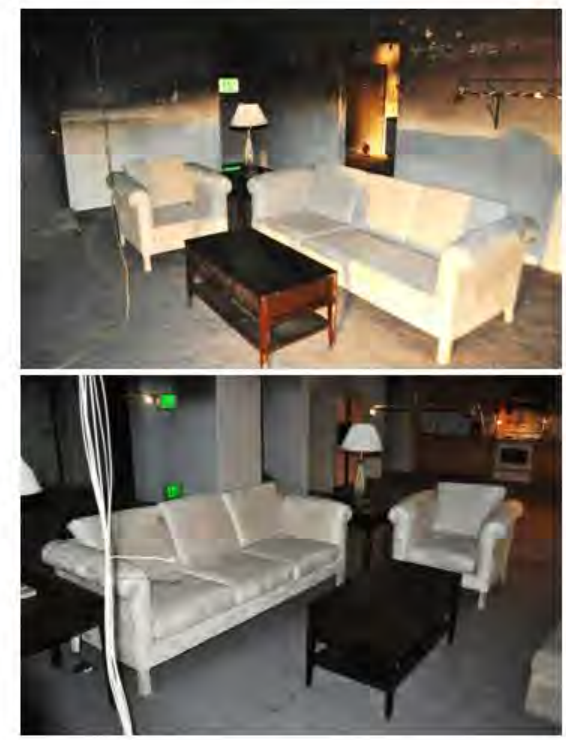

\section{Upholstered Furniture Flammability Phase 3: Tenability Experiments}

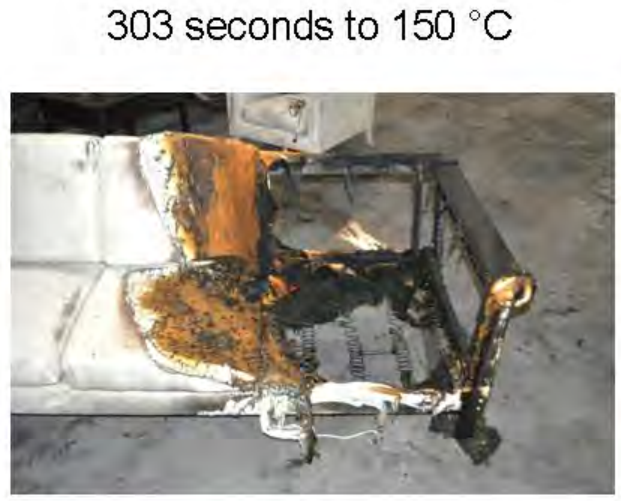

no barrier
1959 seconds to $150^{\circ} \mathrm{C}$

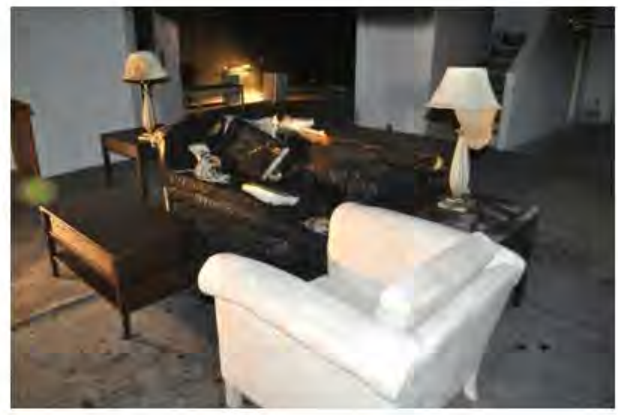

with barrier 


\section{Questions and Discussion}

\section{Thomas.Fabian@us.ul.com}

http://www.ul.com/fireservice

\section{Upholstered Furniture Flammability}

\section{Furniture Tests}

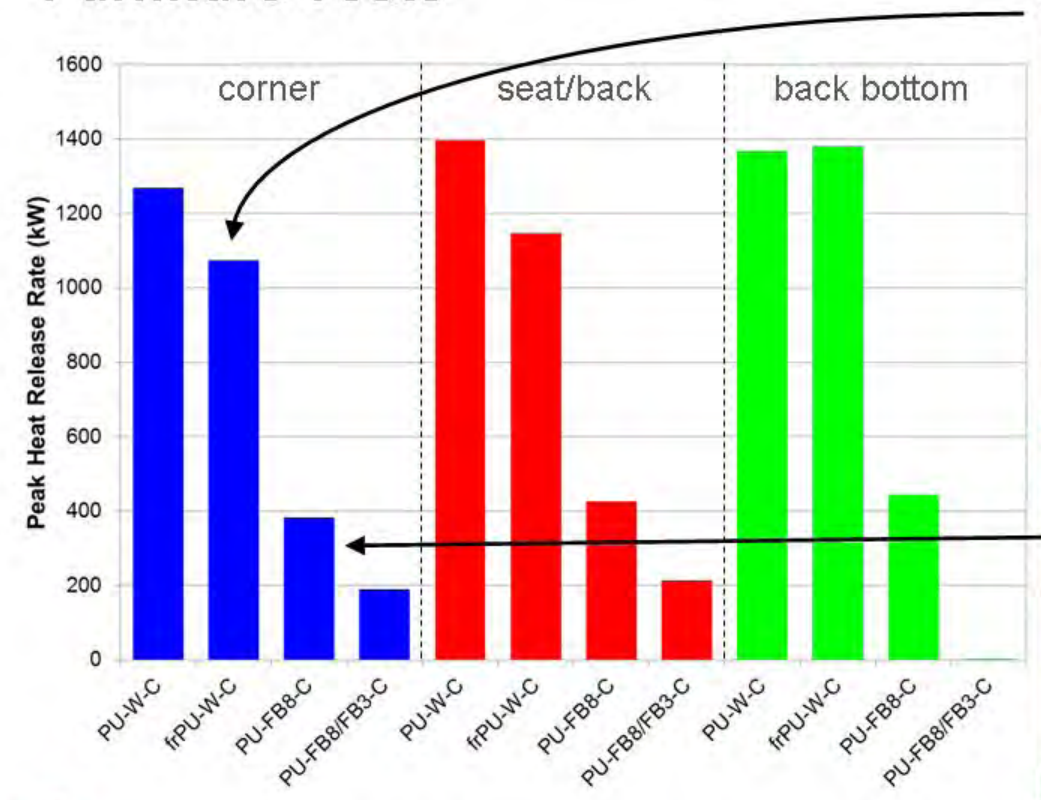

(14)

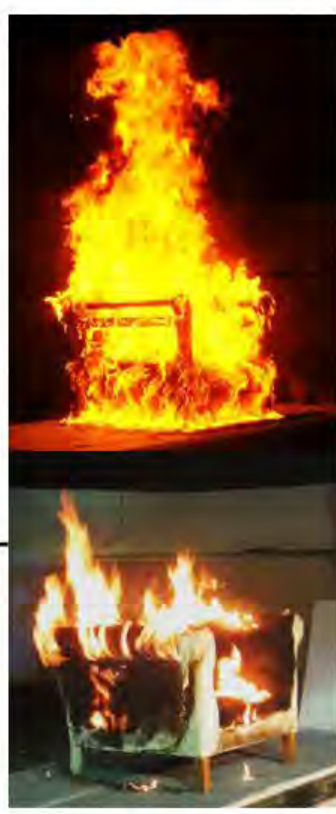

14 


\section{APPENDIX D.4 Marc Janssens, SwRI}

Reducing the Uncertainty of Quantifying the Burning Rate of Upholstered Furniture in Fire Investigations 
Workshop on Quantifying the Contribution of Flaming Residential Upholstered

Furniture to Fire Losses in the United States, NIST, March 22-23, 2012

\section{Reducing the Uncertainty of Quantifying the Burning Rate of Upholstered Furniture in Fire Investigations}

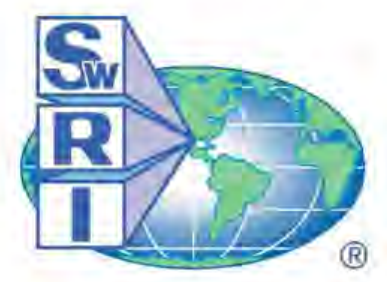

Marc L. Janssens, PhD, FSFPE

Senior Engineer

Southwest Research Institute

6220 Culebra Road, San Antonio, TX

\section{DISCLAIMER}

The following presentation summarizes partial results from SwRI Project No. 15998. This project is supported by Award No. 2010DN-UX-K221, awarded by the National Institute of Justice, Office of Justice Programs, U.S. Department of Justice. The opinions, findings, and conclusions or recommendations expressed in this presentation are those of the author and do not necessarily reflect those of the Department of Justice. 


\section{OUTLINE}

- Introduction

- Methods for Estimating Furniture Heat Release Rate

- Furniture Calorimeter Testing

- Mathematical Models Based on Bench-Scale Test Data

- Research Plan

- Parametric Study on Mockups $\Rightarrow$ Evaluate and Refine Models

- Validation Used Furniture

- Results

- Conclusions

\section{INTRODUCTION (1)}

- Upholstered furniture is often involved in residential fires, either as the first item ignited or as part of the fuel load

$\Rightarrow$ Residential fire reconstruction very often requires reliable estimates of upholstered furniture burning rates

- This is true regardless of whether a CFD code, a zone model, or another type of analysis is used

- The goal of this project is to develop guidelines for arson investigators on how to best estimate the burning rate of upholstered furniture 


\section{INTRODUCTION (2)}

- Uncertainty of the burning rate estimates depends on the extent of testing that can be performed

- Under ideal circumstances identical items as those involved in the fire are available for laboratory testing

- This is usually not the case and it is more likely that enough specimens are available for small-scale testing

- ASTM E 1354 Cone Calorimeter

- ASTM D 7309 Microscale Combustion Calorimeter

- In the worst case no undamaged materials can be recovered from the fire scene $\Rightarrow$ Database

\section{ESTIMATING HRR OF FURNITURE Furniture Calorimeter Testing (1)}
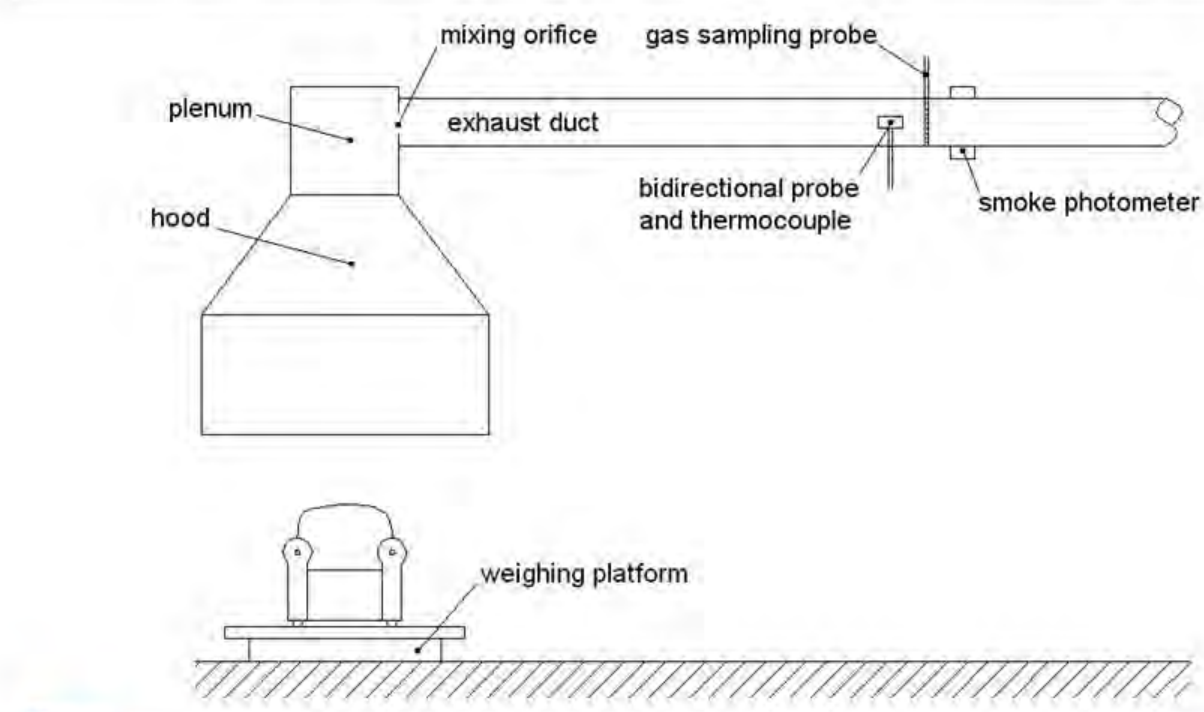

Southwest Research Institute - Fire Technology Department 


\section{ESTIMATING HRR OF FURNITURE Furniture Calorimeter Testing (2)}

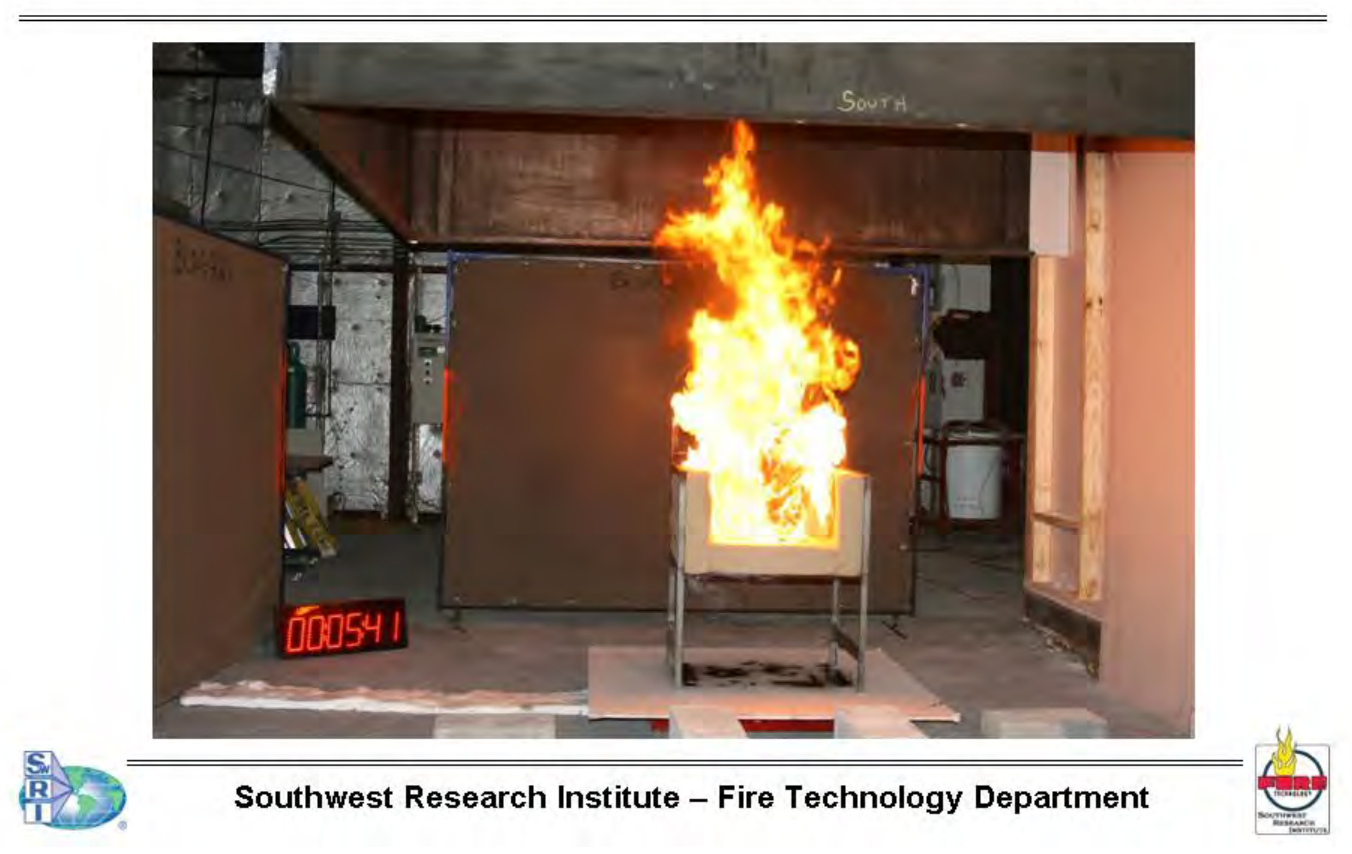

\section{ESTIMATING HRR OF FURNITURE Based on Cone Calorimeter Data (1)}

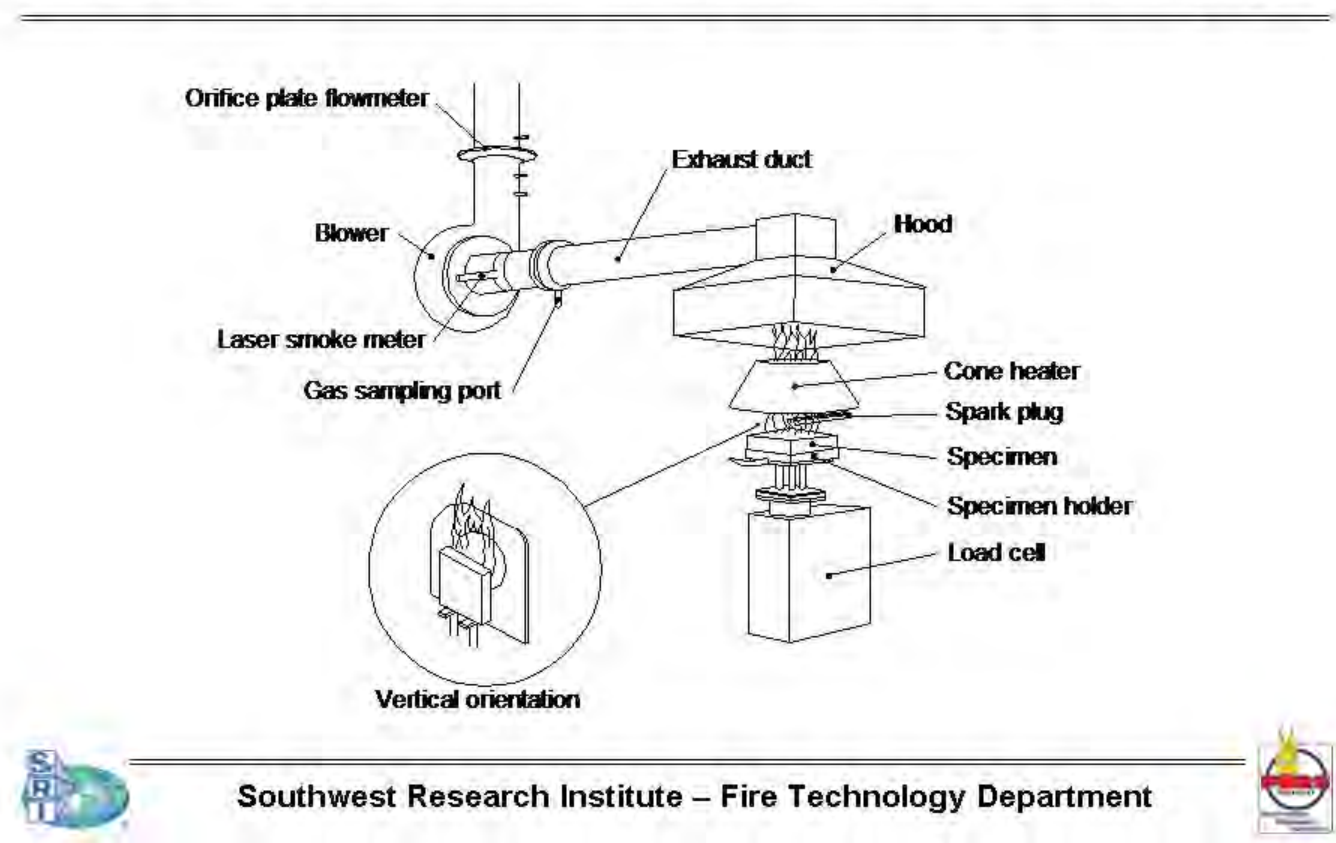




\section{ESTIMATING HRR OF FURNITURE Based on Cone Calorimeter Data (2)}

- ASTM E 1354, NFPA 271 and ISO 5660 Parts $1 \& 2$

- $100 \times 100 \mathrm{~mm}$ specimen size

- Maximum $50 \mathrm{~mm}$ thick $\Rightarrow$ Limitation

- Irradiance can be set at 0 to $100 \mathrm{~kW} / \mathrm{m}^{2} \Rightarrow$ Which Level(s)

- Pyrolyzates ignited with electric spark

- Specimen placed on load cell (mass loss)

- Heat and smoke release measured in duct

- ASTM E 1474 for upholstered furniture components

\section{ESTIMATING HRR OF FURNITURE Based on Cone Calorimeter Data (3)}

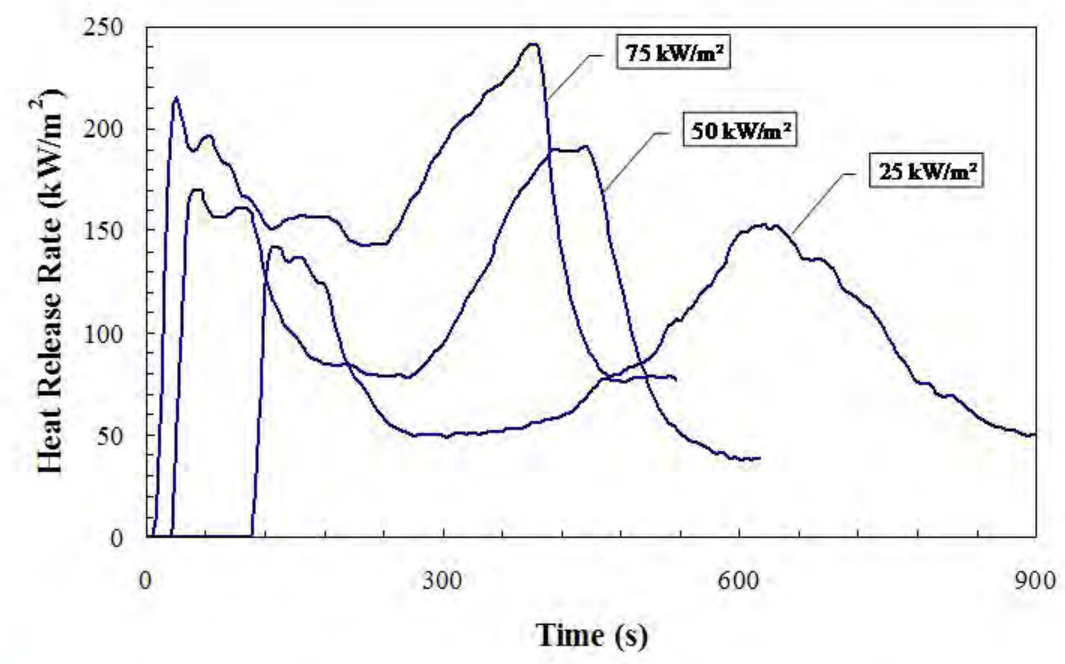

Southwest Research Institute - Fire Technology Department

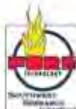




\section{ESTIMATING HRR OF FURNITURE ASTM E 1474 Specimen Preparation (1)}

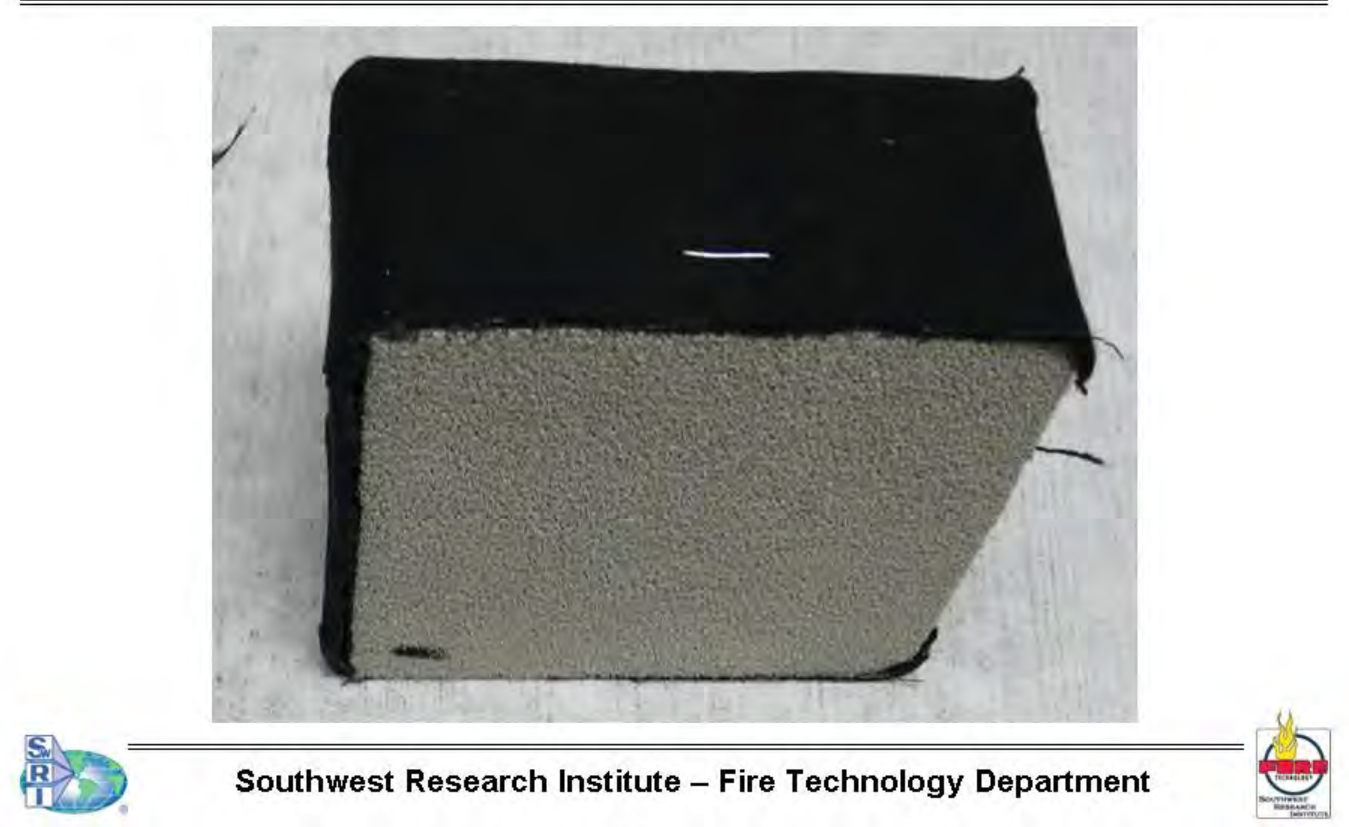

\section{ESTIMATING HRR OF FURNITURE ASTM E 1474 Specimen Preparation (2)}

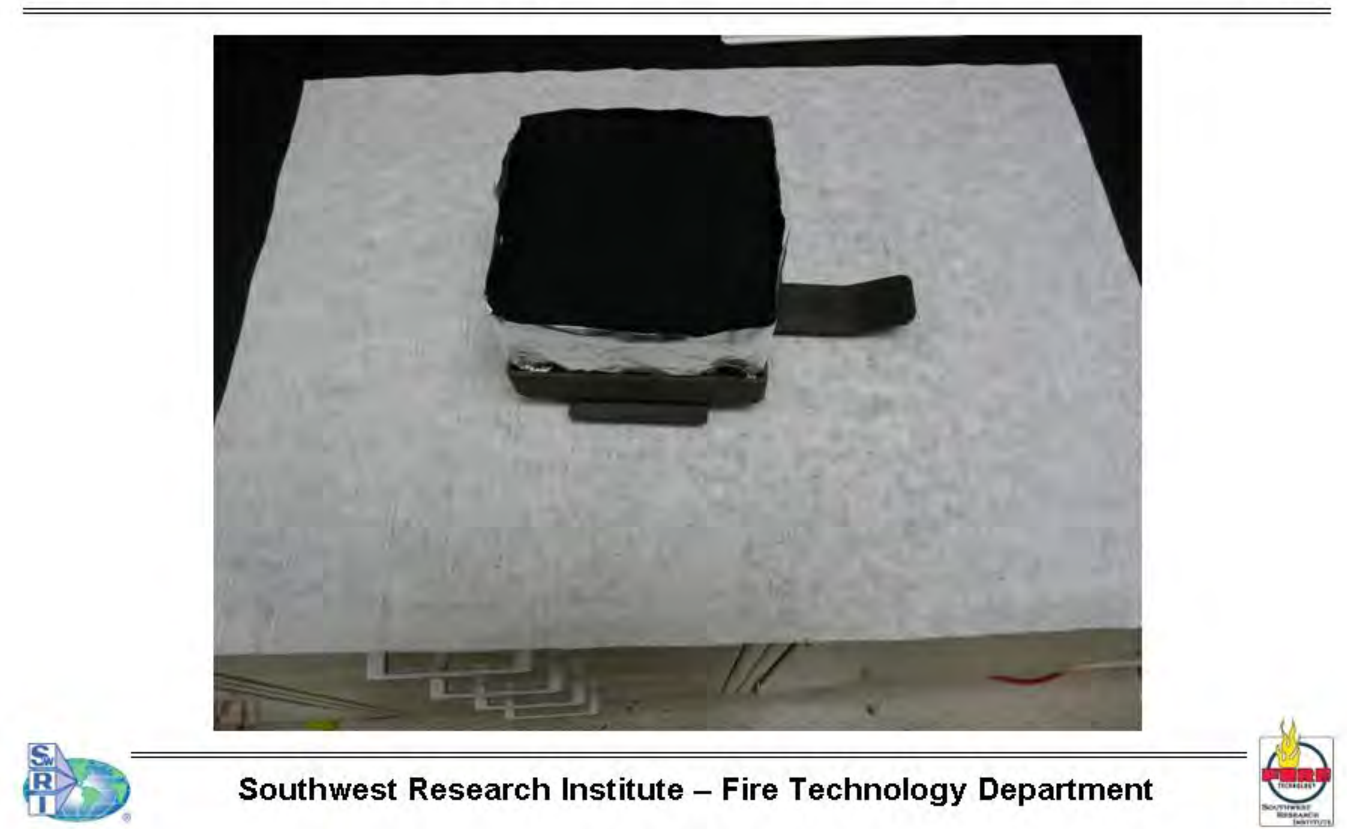




\section{ESTIMATING HRR OF FURNITURE CBUF I Model (1)}

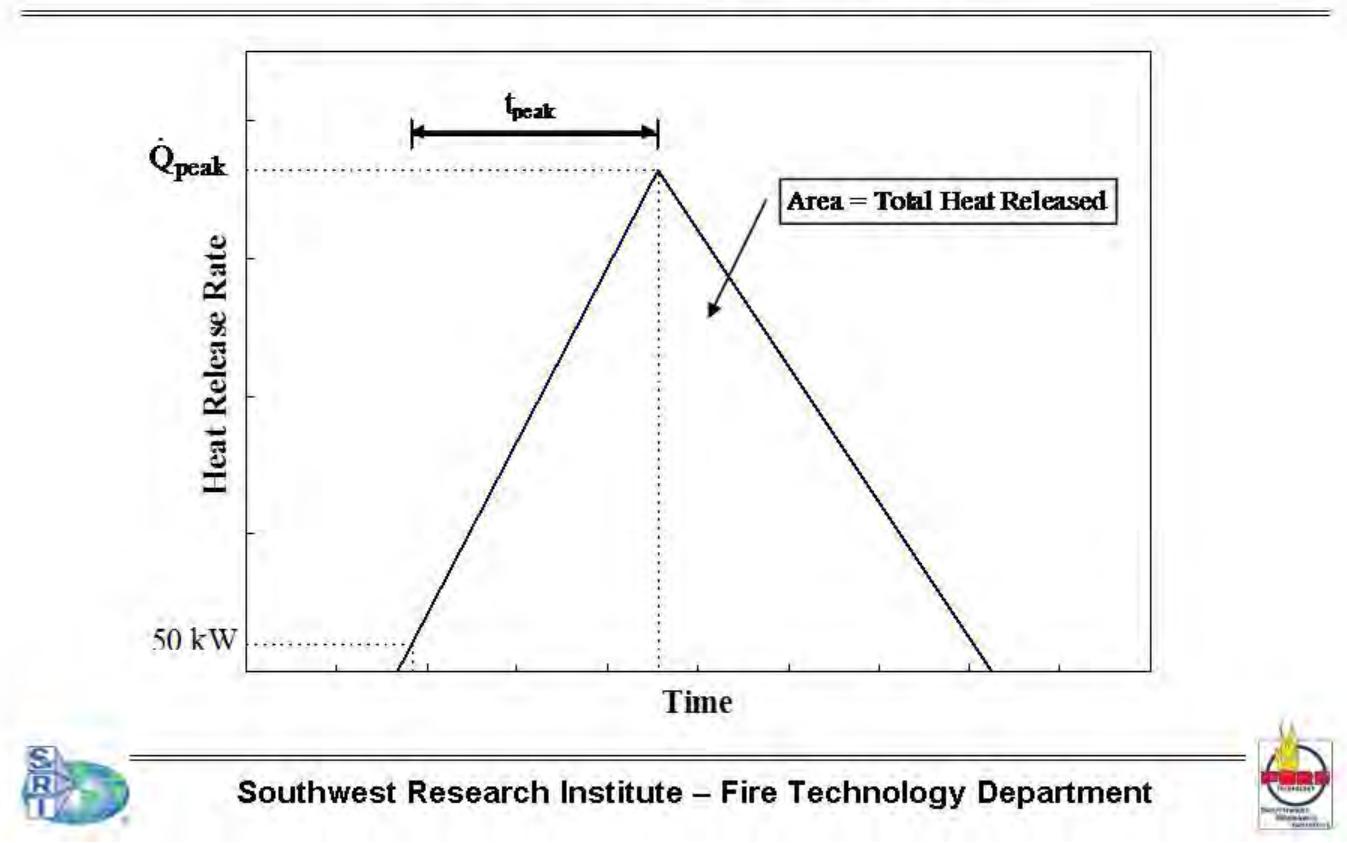

\section{ESTIMATING HRR OF FURNITURE CBUF I Model (2)}

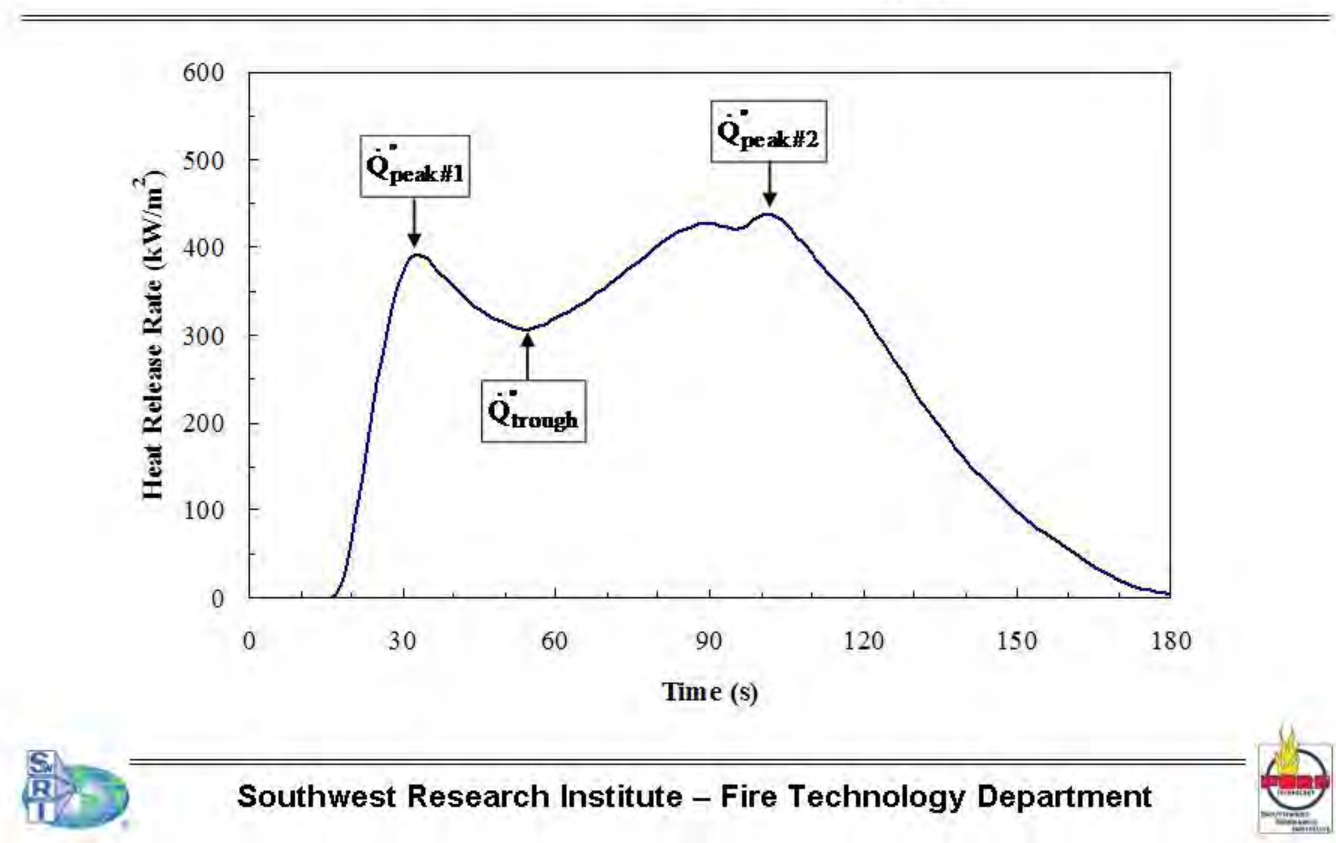




\section{ESTIMATING HRR OF FURNITURE Microscale Combustion Calorimeter (1)}

- ASTM D7309 MCC was designed by the FAA

- Specimen size: $1-10 \mathrm{mg}$

- Correlates well with other flammability tests

- Useful in developing fireresistant polymers

- Used at SwRI in support of product certification

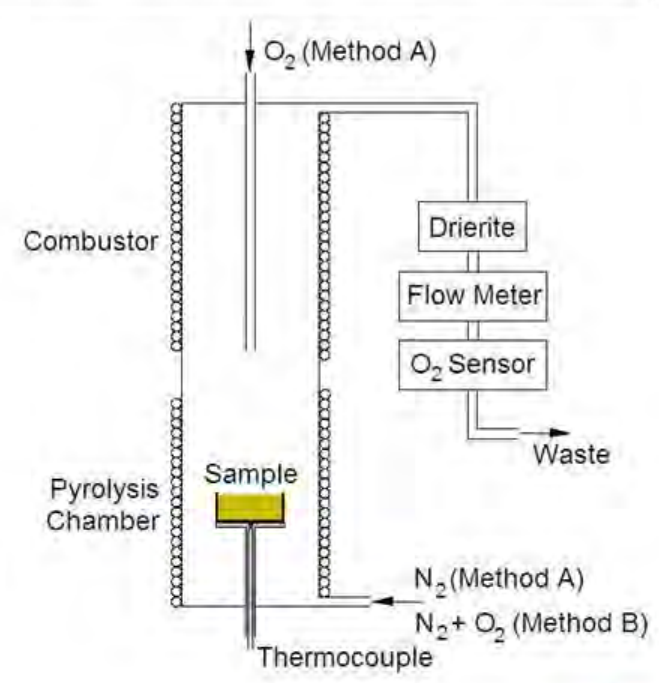

\section{ESTIMATING HRR OF FURNITURE Microscale Combustion Calorimeter (2)}
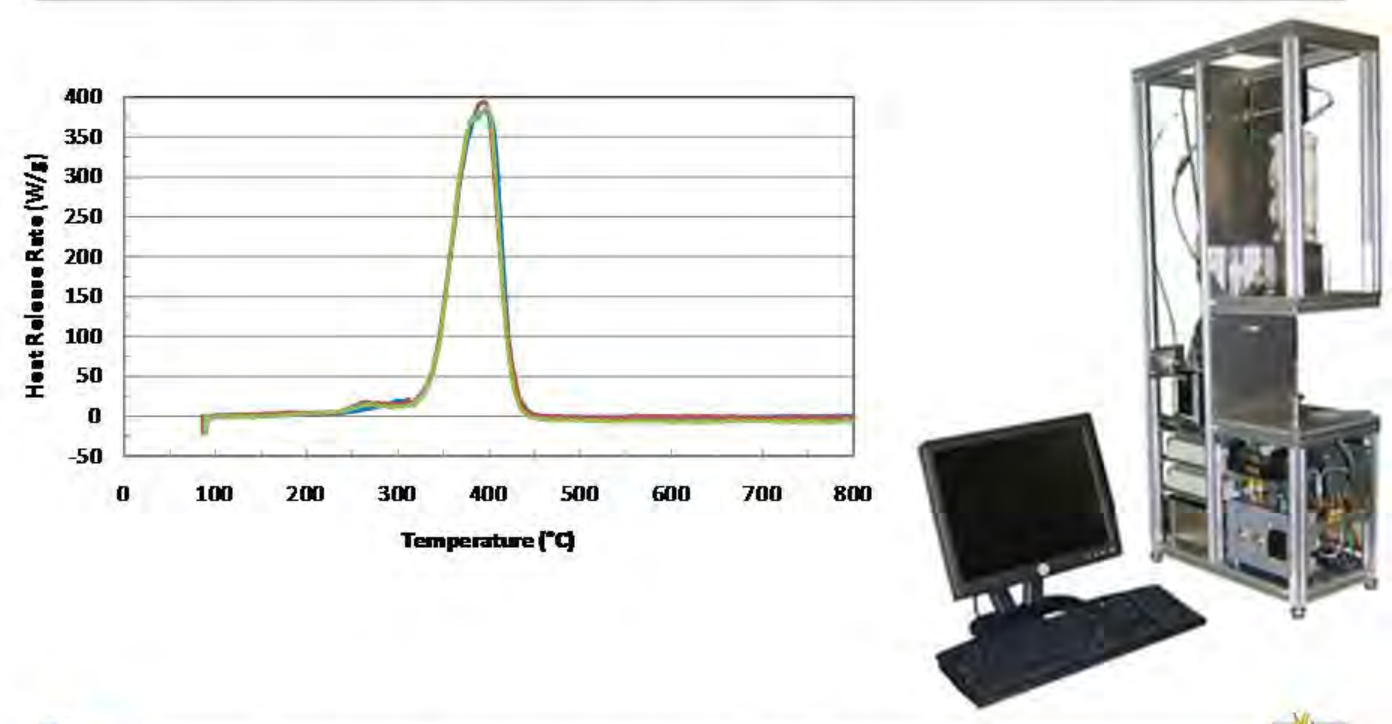

Southwest Research Institute - Fire Technology Department 


\section{ESTIMATING HRR OF FURNITURE Babrauskas' Model Predictions (1)}

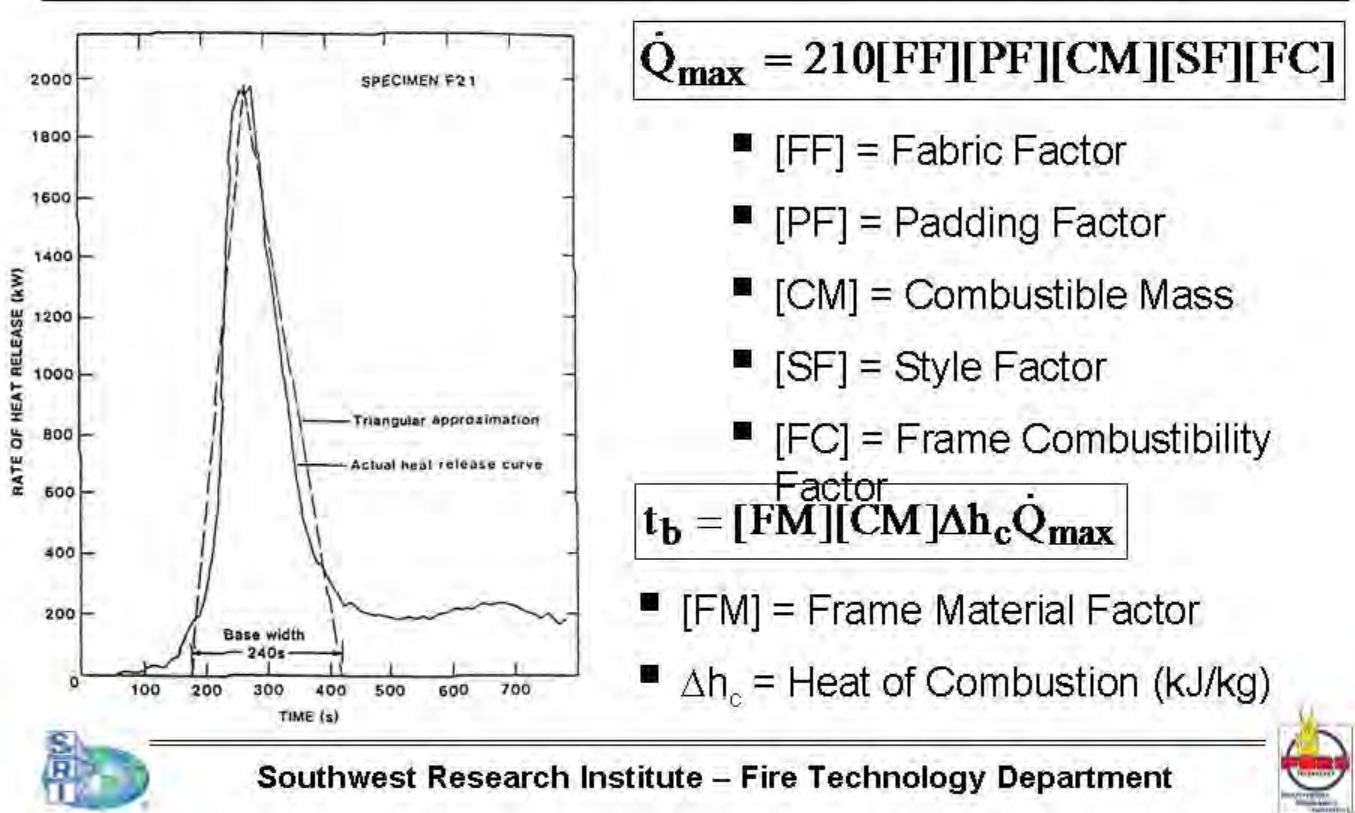

\section{RESEARCH PLAN Overview}

- Parametric Study of Upholstered Furniture Mockups

- Untreated vs. FR treated fabric (problems finding FR fabric)

- 5 padding materials (low and high density polyurethane foam, CAL TB 117 foam, BS 5852 crib \#5 foam, polyester fiber fill)

- 3 ignition sources (CAL TB 133, BS 5852 source 1, pool fire)

- 3 locations (seat, front bottom, back)

- Chairs and 1-, 2- and 3-seat sofa mockups were tested

- Test mockup materials in Cone Calorimeter and MCC

- Fine-tune existing models based on mockup data

- Evaluate predictive capability of improved models for used furniture (obtained 24 sets from SwRI employees) 


\section{RESEARCH PLAN \\ Example of Used Furniture Item}

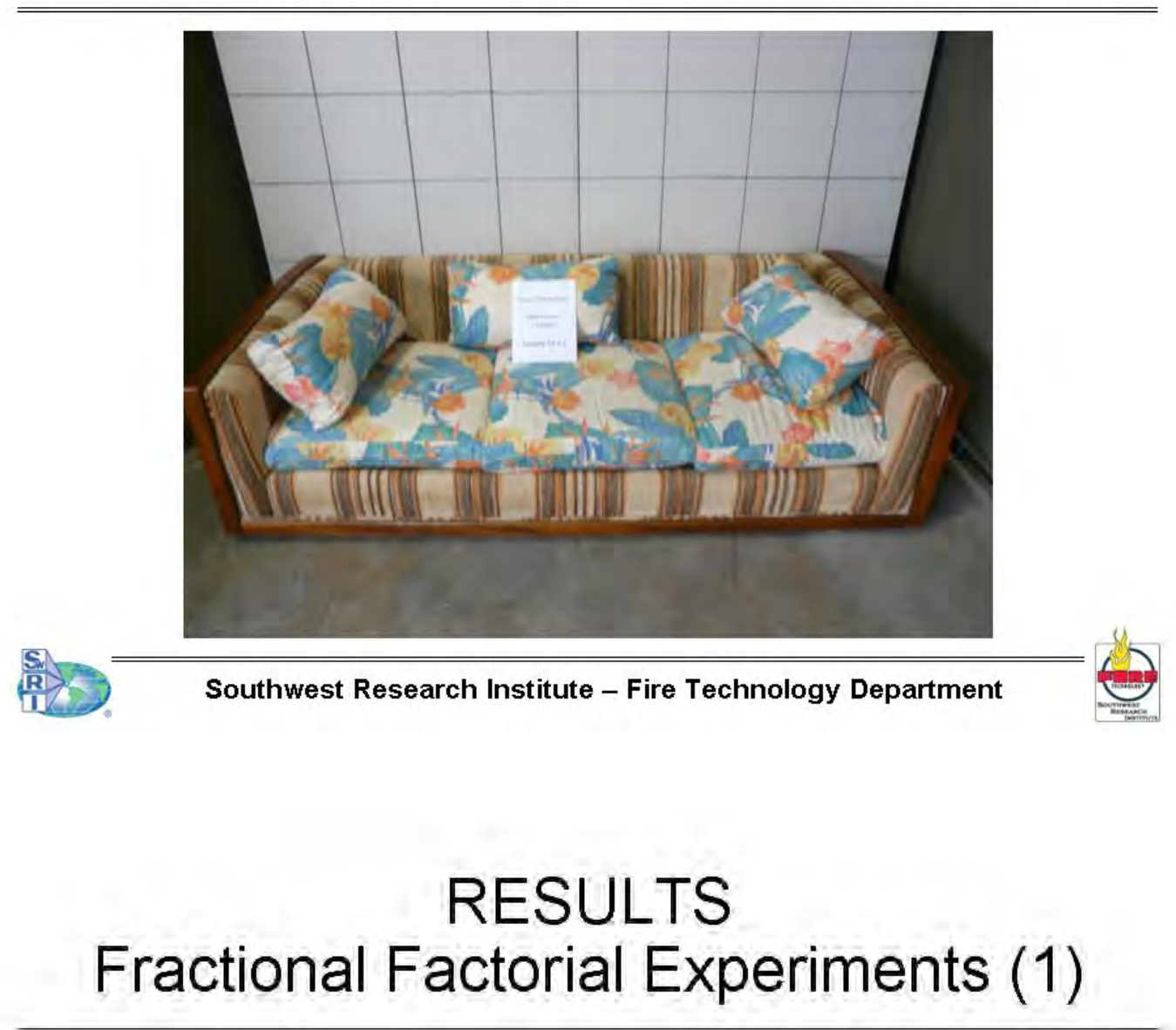

- 3 padding materials (non-FR cotton fabric in all tests)

- Low density polyurethane foam

- High density polyurethane foam

- CAL TB 117 polyurethane foam

- 3 ignition sources

- Large propane burner (CAL TB 133 or ASTM sand box burner)

- BS 5852 source 1 or 2

- Pool fire (2 or 4 oz of gasoline)

- 3 locations: seat, front bottom, back

- Nine duplicate room tests on one-seat and three-seat sofas (thirty-six tests in total) 


\section{RESULTS \\ Fractional Factorial Experiments (2)}

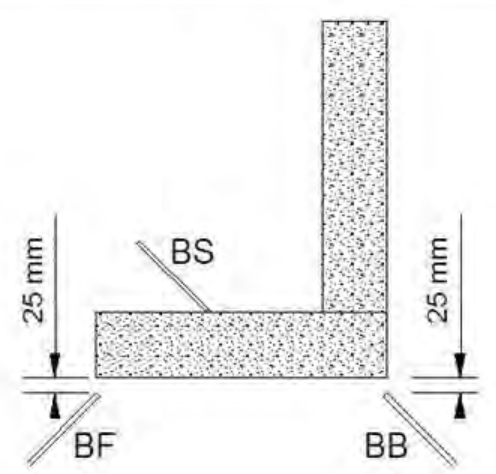

SIDE VIEW

SIDE VIEW
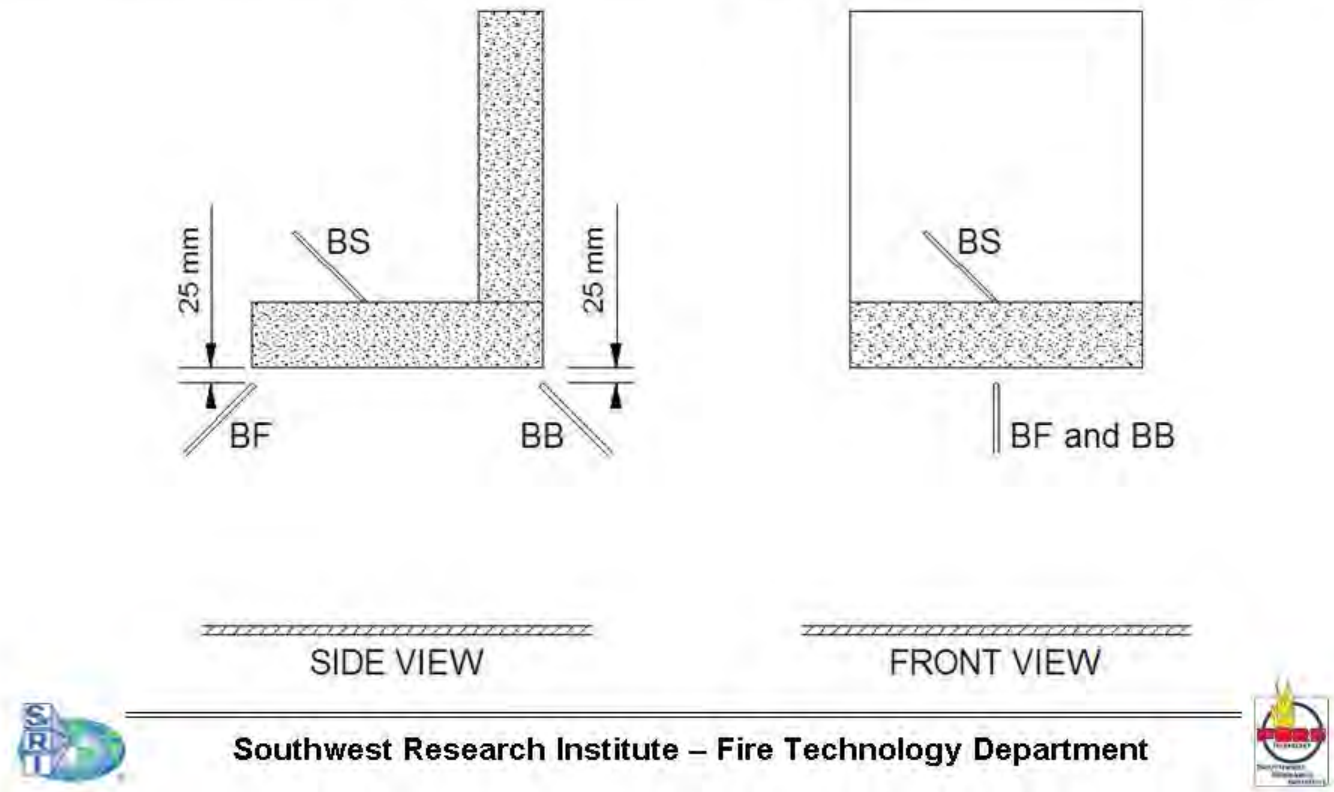

\section{RESULTS \\ Fractional Factorial Experiments (4)}

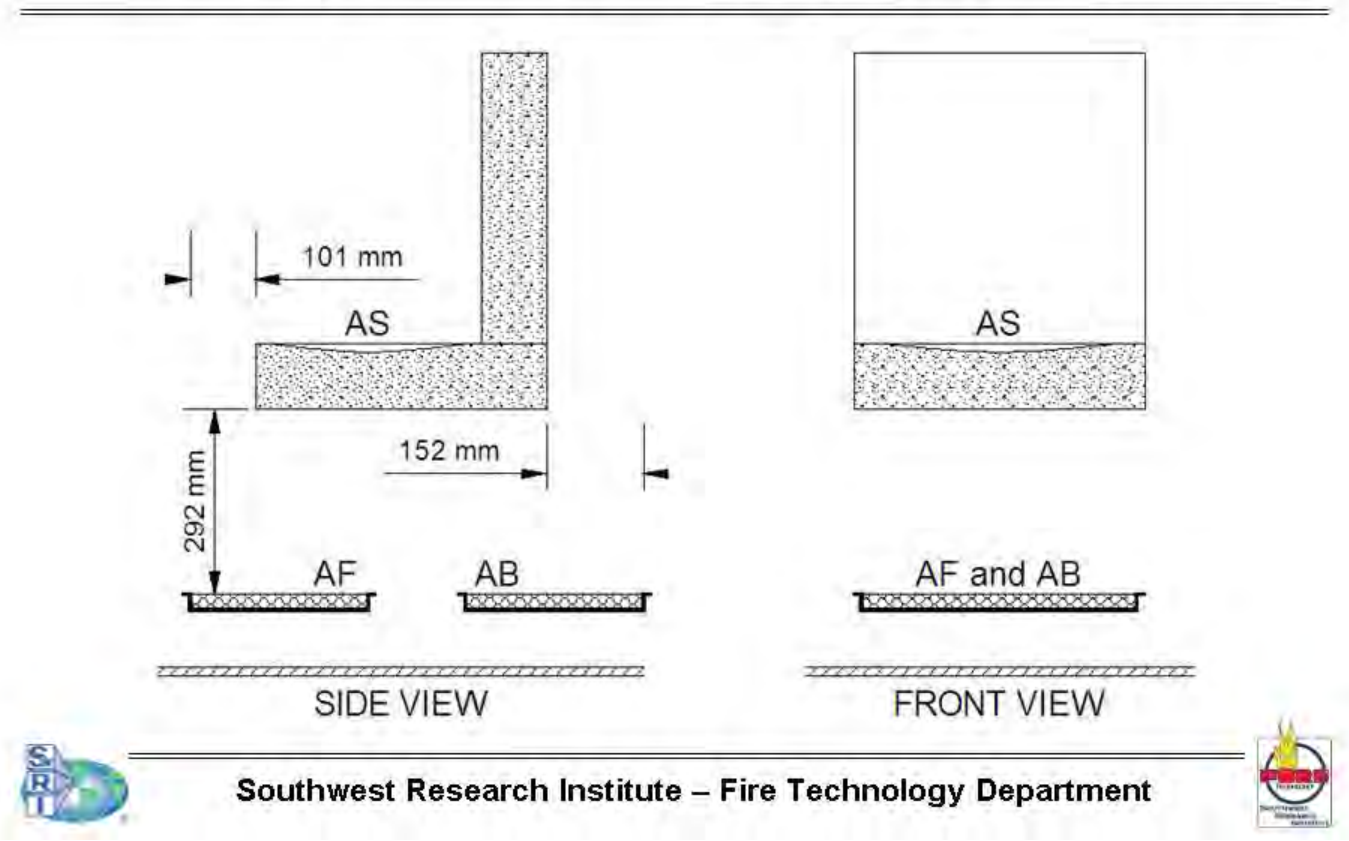




\section{RESULTS \\ Fractional Factorial Experiments (4)}
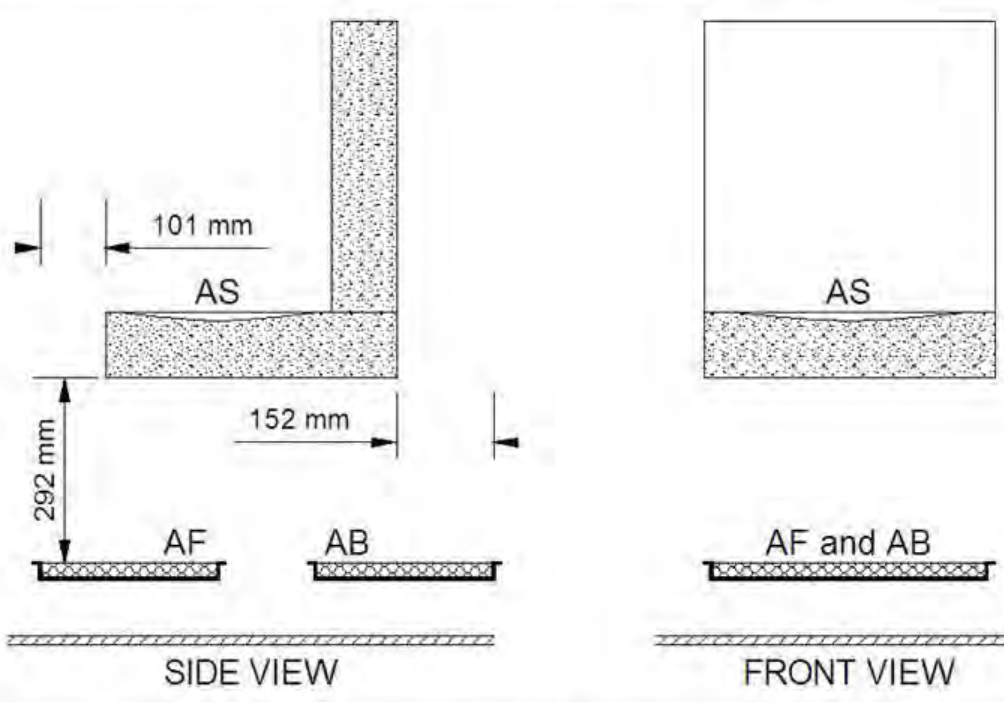

Southwest Research Institute - Fire Technology Department

\section{$A F$ and $A B$

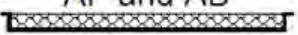

FRONT VIEW

\section{RESULTS \\ Fractional Factorial Experiments (5)}

- The HRR of a 3-seat sofa is very sensitive to the top surface location where the ignition source is applied

- The type of ignition source significantly affects the ignition delay $t_{0}$

- No significant difference between large burner and pool fire

- Small flame source results in a significant increase of $t_{0}$.

- Peak HRR is strongly affected by the padding material (significantly lower for CAL TB 117 foam)

- Back ignition generally resulted in a shorter ignition delay, but a slower fire growth rate and lower peak HRR 


\section{RESULTS Babrauskas' Model for Mockups}

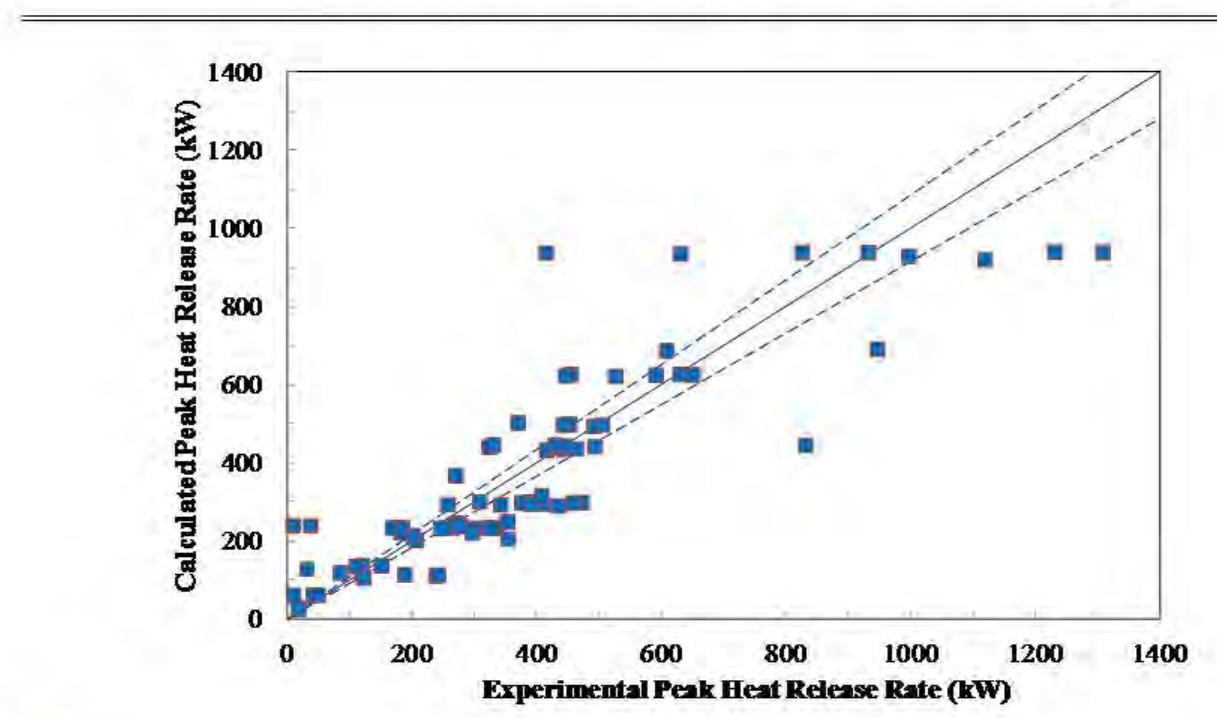

Southwest Research Institute - Fire Technology Department

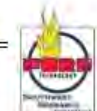

\section{RESULTS \\ Model Predictions for Test LRM123AF1}

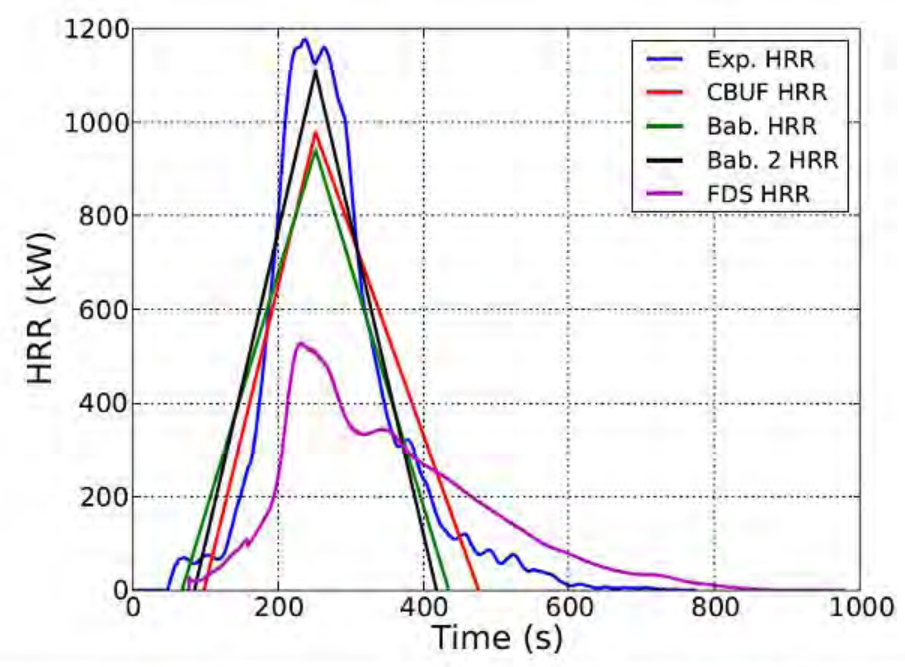

Southwest Research Institute - Fire Technology Department

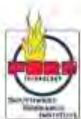




\section{RESULTS \\ CFAST Predictions for Test LRM123AF1}

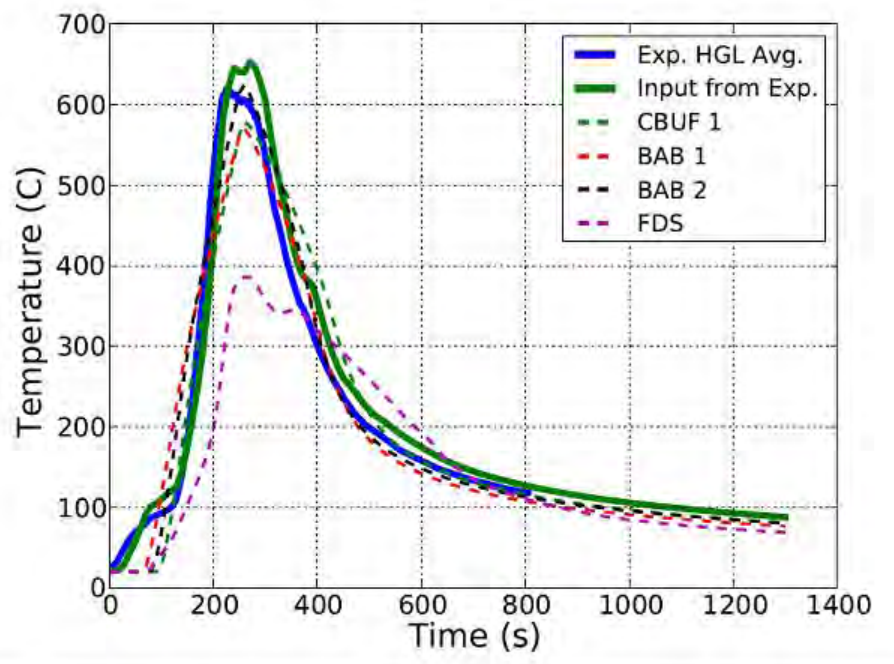

\section{RESULTS \\ Babrauskas' Model for Used Furniture}

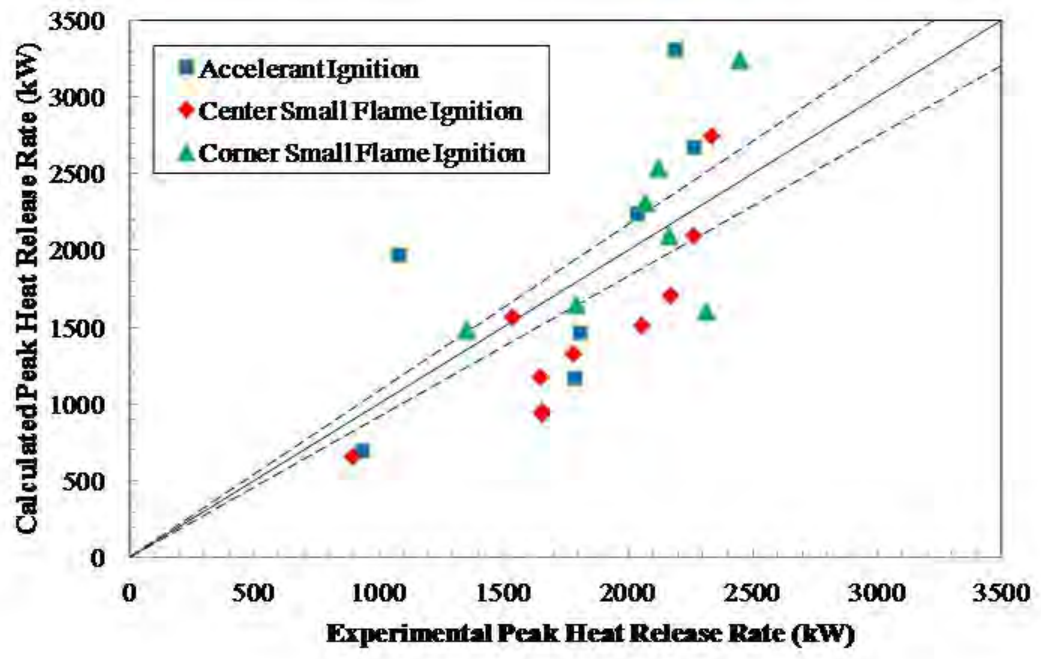

Southwest Research Institute - Fire Technology Department 


\section{SOME CONCLUSIONS (1)}

- Even if identical item(s) are available for furniture calorimeter testing, the measured HRR is subject to aleatory and, more importantly, epistemic uncertainty

- The use of FR treated foam appears to significantly delay ignition and reduce HRR in accidental fires

- In fires where the furniture is exposed to a severe ignition source the effect on ignition delay is negligible

- The HRR from a single item was generally not sufficient to reach flashover in a $12 \times 16 \times 9$ ' room with open door

- The used furniture generated large amounts of smoke

\section{SOME CONCLUSIONS (2)}

\begin{tabular}{||c|c|c|l|c|}
\hline & $\begin{array}{c}\text { Mass } \\
(\mathbf{k g})\end{array}$ & $\begin{array}{c}\text { Peak HRR } \\
(\mathbf{k W})\end{array}$ & & $\begin{array}{c}\text { Ignition Delay } \\
\text { (s) }\end{array}$ \\
\hline 1-Seat & $33.7 \pm 11.3$ & $1455 \pm 401$ & Accelerant & $71 \pm 55$ \\
\hline 2-Seat & $39.4 \pm 6.1$ & $1726 \pm 113$ & Small Flame Center & $435 \pm 214$ \\
\hline 3-Seat & $67.2 \pm 17.5$ & $2073 \pm 356$ & Small Flame Corner & $171 \pm 52$ \\
\hline
\end{tabular}




\section{QUESTIONS?}

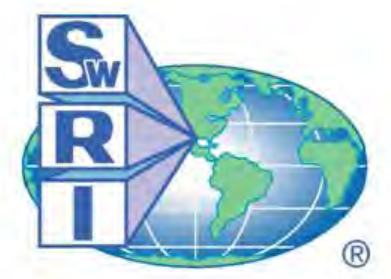

http://www.fire.swri.org 
APPENDIX D.5 Bradley Pabody, USFA

NFIRS Overview 


\section{The National Fire Incident Reporting System}

An Overview

\section{NFIRS \\ What is the National Fire Incident Reporting System?}

> Voluntary - 23,000 Departments Participate from all 50 states

$>$ Incident-based

- Locally driven - quality, completeness, content

$>$ More than 1.2 million fires reported for $\mathbf{2 0 1 0}$

$>22$ million total incidents reported for $\mathbf{2 0 1 0}$ 


\section{NFIRS Participation}

\section{Fire Departments Reporting Per Year 1980-2010}

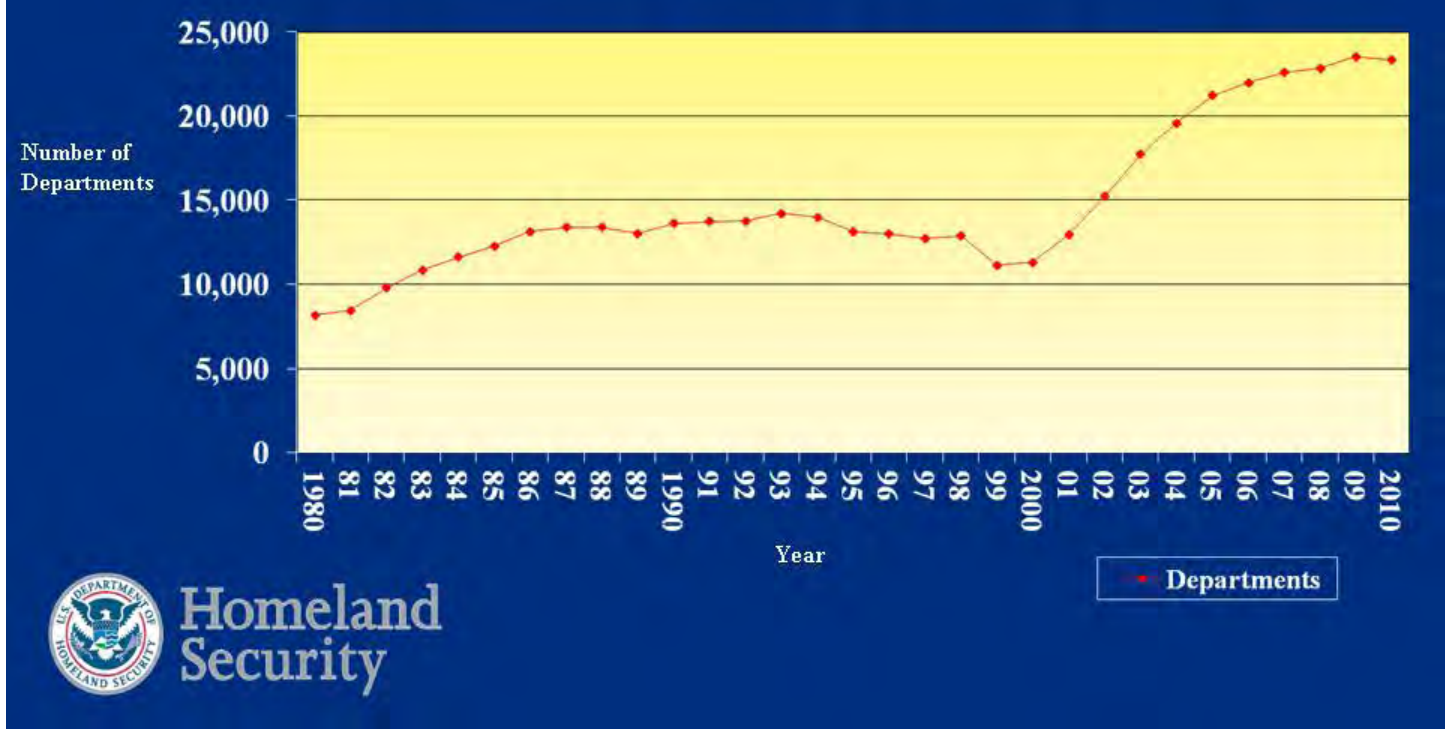

\section{Fire Incidents Reported Per Year 1980-2010}

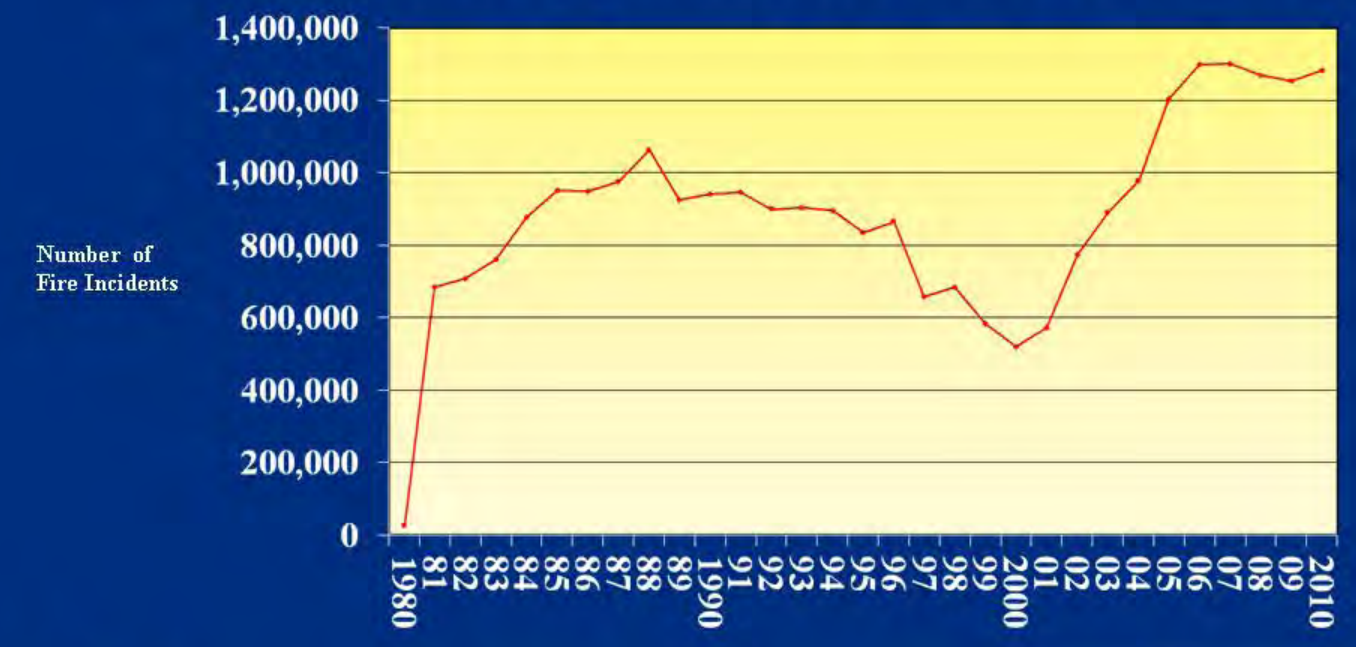

Homeland

Year

Fires

Security 


\section{NFIRS Background}

$>$ Initial National Fire Incident Reporting System was created in 1975

$>$ NFIRS Version 2.0, 1976

$>$ NFIRS Version 3.0, 1980

$>$ NFIRS Version 4.0, 1985

$>$ NFIRS Version 4.1, 1990

$>$ NFIRS Version 5.0, 1999

\section{How do we collect fire data?}

NFIRS data flow

Fire Departments

State Fire Offices

U.S. Fire Administration/

National Fire Data Center 


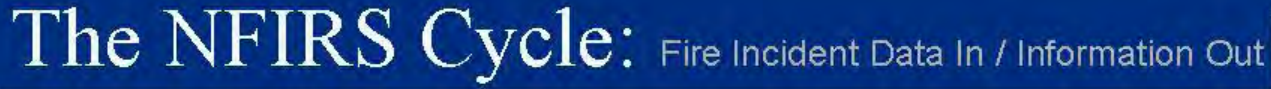

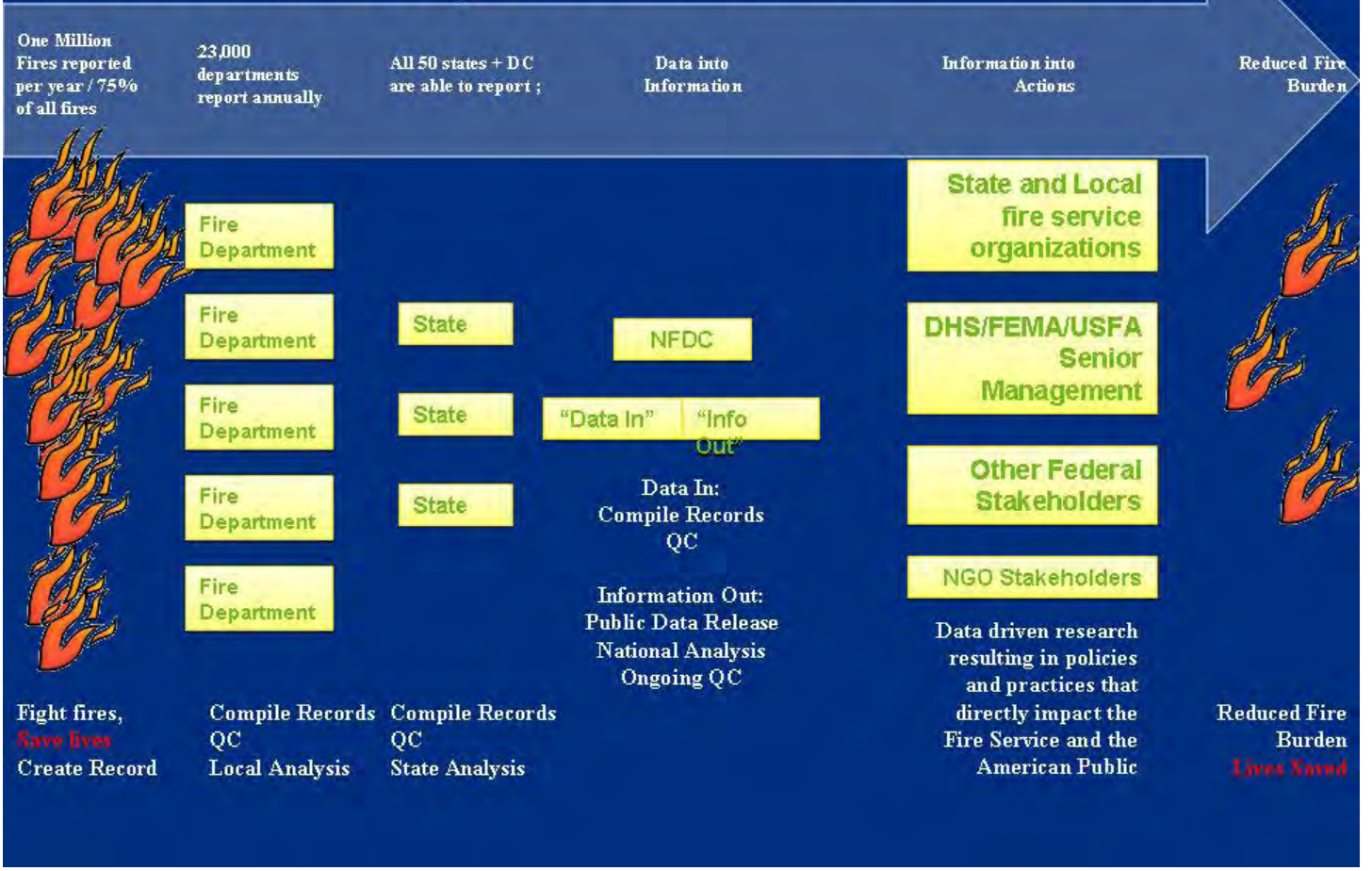

\section{NFIRS Modules}

$>$ The Basic Module (NFIRS-1) captures general information on every incident (or emergency call) to which the department responds.

$>$ The Fire Module (NFIRS-2) is used to describe each fire incident to which the department responds. For wildland fire incidents, the Wildland Module can be used instead of the Fire Module if that option is available by your state reporting authority.

$>$ The Structure Fire Module (NFIRS-3) is used to describe each structure fire to which the department responds. This module is used in conjunction with the Fire Module.

$>$ The Civilian Fire Casualy Module (NFIRS-4) is used to report injuries or deaths to civilians or other emergency personnel (e.g., police officers, non-fire

department/EMS personnel) that are related to a fire incident. This module is used in conjunction with the Fire Module and, if applicable, the Structure Fire Module. Nonfire-related injuries or deaths to civilians can be reported on the EMS Module. 


\section{NFIRS Modules}

$>$ The Fire Service Casualty Module (NFIRS-5) is used to report injuries and deaths of firefighters. The module can also be used to report the exposure of a firefighter to chemicals or biological agents at an incident where that exposure does not result in any symptoms at that time but that manifest themselves at a later date. This module may be used with any of the other modules

$>$ The EMS Module (NFIRS-6) is completed by fire departments that provide emergency medical services. The module is used to report all medical incidents where the department provided the primary patient care. This includes incidents where there were civilian fire-related casualties and a Civilian Fire Casualty Module was completed and where there were firefighter fire-related casualties and a Fire Service Casualty Module was completed. (This module does not serve as a patient care record, but it can be used in conjunction with the local requirements for patient care.)

\section{Homeland} Security

\section{NFIRS Modules}

$>$ The Hazardous Materials Module (NFIRS-7) is completed to report spills or releases of 55 gallons or more of hazardous materials or when special HazMat actions were taken. As appropriate, the module is used in conjunction with the Fire Module or other modules to provide detailed information about incidents involving hazardous materials.

$>$ The Wildland Fire Module (NFIRS-8) is completed to report incidents that involve wildland or vegetation fires. The module is used in lieu of the Fire Module for wildland fire incidents.

$>$ The Apparatus or Resources Module (NFIRS-9), a department-use module, is completed to report data specific to each piece of apparatus that responds to an incident. It includes information that can be used to calculate response time and time out of service. This module is not used if the Personnel Module is used. 


\section{NFIRS Modules}

$>$ The Personnel Module (NFIRS-10), a department-use module, is completed to report the same information as on the Apparatus or Resources Module, but it also provides for tracking the personnel associated with that apparatus.

$>$ The Arson Module (NFIRS-11) is completed to report additional information on fires that have been coded by the department as "intentionally set."

$>$ In addition to the 11 modules, a Supplemental Form (NFIRS-1S) can be used to report information on additional persons and entities involved in the incident and to collect additional special studies fields. This paper-only form extends the amount of information collected in the Basic Module.

\section{Homeland}

Security

\section{NFIRS Data Analysis}

$>$ National fire data analyses are done by USFA to answer questions about the frequency, causes, spread, and extinguishment of fires and on the causes and nature of injuries.

$>$ Information about the national fire problem is disseminated to the public via the USFA website and published reports and analyses. 


\section{Fire Statistics}

The USFA website contains statistics on fires that occur in the United States and analytical and topical reports that describe the national fire problem. Also included are statistics related to firefighters and fire departments.

http://www.usfa.dhs.gov/statistics

Homeland

Security

\section{NFIRS Enhancements}

In order to facilitate a modular approach to the NFIRS enhancement process, the work has been separated into the following five discrete phases:

- Data Entry Browser Interface. This feature provides for a totally web based data entry tool eliminating the need to download and install client software on the user's computer. Use of approved $3^{\text {rd }}$ party commercial software as an alternative will still be permitted. (planned release date: Spring, 2010)

- Data Warehouse $\&$ Mining. This feature will provide flexible and efficient ways of retrieving and exporting data. (planned release date: Spring, 2011)

\section{Homeland}

Security 
- New NFIRS Web Portal. This objective continues the modernization of the USFA solution by adding a web based portal, and implements a role based security model to give users single point access for the NFIRS data entry, report dashboards and access to administrative applications. While the individual applications would maintain a similar look and feel they will be encapsulated into a single location within the portal.

- Revision of the NFIRS Data Entry Applications. This objective provides a true integration of the portal with the Incident Reporting application as the core with the addition of a new rules engine.

- Enhanced User Interface. The final objective adds the remaining functionality to complete the NFIRS application. GIS will be incorporated into the Incident Reporting application as well as administrative applications to support system users.

\section{Homeland} Security

\section{NFIRS Enhancements}

Once complete, changes to the system will result in the following:

- Improved user experience through improvements to the user interface.

- Improved system performance.

- Overhaul of the USFA NFIRS 5.0 system software, applications and infrastructure.

- Addition of new or enhanced capabilities to USFA NFIRS 5.0 software.

- Brings NFIRS system software in line with Department of Homeland Security (DHS) and Federal Emergency Management Agency (FEMA) enterprise standards.

\section{Homeland}

Security 


\title{
Contact Information
}

\author{
Brad Pabody \\ United States Fire Administration \\ National Fire Data Center \\ 16825 South Seton Ave. \\ Emmitsburg, MD 21727 \\ (301) 447-1340 \\ brad.pabody@dhs.gov
}

Homeland

Security 


\section{APPENDIX D.6 John Hall, NFPA}

How NFPA Measures Fire Problems and Safety Strategies with Special Attention to Upholstered Furniture 


\section{How NFPA Measures Fire Problems and Safety Strategies With Special Attention to Upholstered Furniture}

John Hall

National Fire Protection Association

NIST Workshop on Contribution of Upholstered Furniture to Fire Losses

March 2012

\section{Overview}

- Always start with NFIRS national estimates

- Data elements related to prevention

- Data elements related to fire growth

- Options when NFIRS isn't enough 


\section{NFIRS National Estimates}

- NFIRS provides details

$>$ Voluntary at federal level

$>$ Not a statistical sample

- NFPA's fire department survey is a statistical sample of summary data

- NFIRS percentages are used with NFPA projections

- See 1989 Fire Technology article by Hall and Harwood for rules

[D How Fires Get Counted
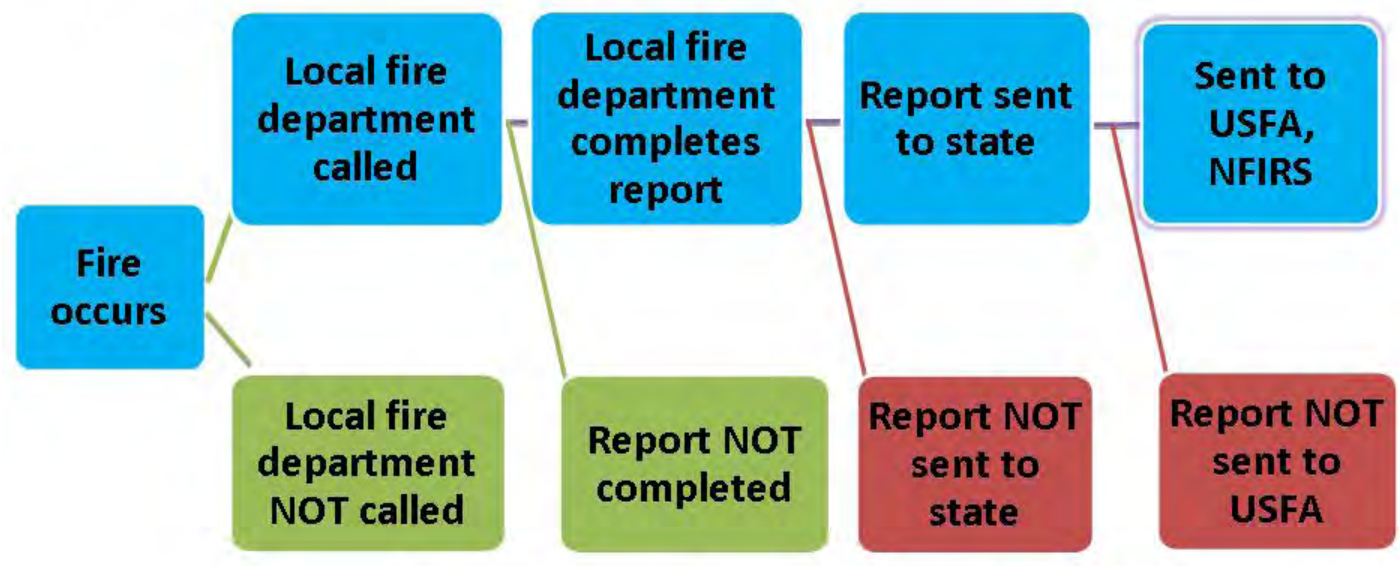

Not included in statistics

Not included in

NFIRS; possibly

in NFPA survey 


\section{NFIRS National Estimates Analysis Choices}

- What level of detail in incident type and property use to use in doing calculations

$>$ Residential structure vs. home structure

- How to treat confined structure fires

- Separate treatment of very large incidents

- Using death certificates or insured loss estimates rather than NFPA survey as a basis for scaling up NFIRS

\section{Data Elements Related to Prevention}

- Six data elements with details of ignition

- "Cause" - primarily to identify intentional

- Area of origin - which room or space

- Heat source and equipment involved in ignition

- What provided the heat for ignition?

- Item first ignited and Type of material first ignited

- What provided the first fuel?

- Upholstered furniture is item first ignited 21 


\section{Prevention Data Elements Analysis Choices}

- How do you handle unknowns?

NFPA proportionally allocates unknowns for any data element but takes account of skip patterns

- Which fires do you consider to be unknowns?

$>$ For item first ignited, unknowns are UU or blank; 00 is considered unclassified

- Are certain fires considered outside scope (e.g., CPSC's non-addressable fires)?

$>$ NFPA does not exclude intentional fires and fires started by playing with heat source; those issues are addressed when you estimate the leverage of a particular strategy

\section{Data Elements Related to Prevention}

- Home fire problem starting with ignition of upholstered furniture, 2006-2010 average

- 6,700 reported structure fires per year $>2 \%$ of total

- 480 associated civilian deaths per year $>19 \%$ of total; largest share for any item first ignited

- 840 associated civilian injuries per year $7 \%$ of total

- \$427 million per year in direct property loss $>6 \%$ of total 


\section{Data Elements Related to Prevention}

-What material is being ignited?

- Fabric made of cotton, blend, rayon or wool

$>72 \%$ of fires, $76 \%$ of deaths; $2005-2009$ averages

- Unclassified fabric, textile or fur

$>14 \%$ of fires, $15 \%$ of deaths

- Plastic

$>2 \%$ of fires, $0 \%$ of deaths

- Unclassified type of material

$>2 \%$ of fires, $2 \%$ of deaths

- Plastic-coated fabric

$>1 \%$ of fires, $0 \%$ of deaths

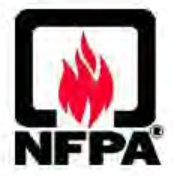

\section{Data Elements Related to Prevention}

- How is the upholstered furniture ignited?

- Smoking material (lighted tobacco product) $>28 \%$ of fires, $58 \%$ of deaths

- Candle $>10 \%$ of fires, $6 \%$ of deaths

- Hot ember or ash $>10 \%$ of fires, $7 \%$ of deaths

- Unclassified hot or smoldering object $>9 \%$ of fires, $4 \%$ of deaths

- Arcing

$>8 \%$ of fires, $7 \%$ of deaths 


\section{Data Elements Related to Prevention}

- How is the upholstered furniture ignited? (continued)

- Heat from operating equipment $>8 \%$ of fires, $5 \%$ of deaths

- Lighter $>8 \%$ of fires, $5 \%$ of deaths

- Unclassified heat from powered equipment $>5 \%$ of fires, $2 \%$ of deaths

- Unclassified heat source $>4 \%$ of fires, $2 \%$ of deaths

- Match $>3 \%$ of fires, $1 \%$ of deaths

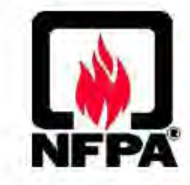

\section{Data Elements Related to Prevention}

- How is the upholstered furniture ignited? (continued)

- Intentional ignitions are $13 \%$ of fires, $6 \%$ of deaths

- Playing fires are $8 \%$ of fires, $5 \%$ of deaths

-When fires start with equipment as heat source, largest shares of total fires are:

$>$ Heating equipment ( $9 \%$ of fires, $7 \%$ of deaths)

$>$ Electrical distribution or lighting equipment ( $9 \%$ of fires, $11 \%$ of deaths) 


\section{Data Elements Related to Fire Growth}

- How large is the final extent of flame?

- Confined to object of origin $-24 \%$ of fires, $6 \%$ of deaths

- Confined to room of origin but not confined to object of origin $-34 \%$ of fires, $25 \%$ of deaths

- Beyond room of origin (our best indicator of a fire that reached flashover) $-42 \%$ of fires, $69 \%$ of deaths

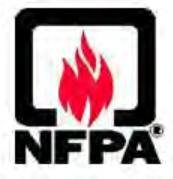

\section{Data Elements Related to Fire Growth}

- How often is upholstered furniture the principal contributor to fire growth?

- In NFIRS version 5.0 (1999 to present), the relevant data element is Item Contributing Most to Flame Spread

- Firefighters can skip this data element if

$>$ No significant flame spread

$>$ No flame spread beyond item first ignited

$>$ Cannot determine flame spread

- Check box is used if this item is the same as the Item First lgnited 


\section{Data Elements \\ Related to Fire Growth}

- How often is upholstered furniture the principal contributor to fire growth?

- In early NFIRS (1980 to 1983), the most relevant data element was Most Significant Factor Contributing to Flame Travel

- Some choices are burnable items.

- Other choices are failed or defeated barriers or avenues of fire spread without barriers

- Other data elements (not all used in NFIRS) were for item or type of material generating most significant flame or smoke

\section{Data Elements Related to Fire Growth}

- Flame spread and flame travel are not the same as fire growth

- The names of the data elements suggest an interest in flame spread along a surface or through a space

- As opposed to fire growth due to involvement of a larger fraction of the volume or mass of a major fuel item

- These data elements may not provide a strong estimate of fires where upholstered furniture contributes as the primary secondary item ignited, but we have nothing better. 


\section{Data Elements Related to Fire Growth}

- Items most often first ignited when flame is not confined to room of origin and upholstered furniture is the item contributing most to flame spread

- Upholstered furniture

$>60 \%$ of fires, $72 \%$ of deaths

- Unclassified furniture or utensil

$>6 \%$ of fires, $1 \%$ of deaths

- Mattress or bedding

$>4 \%$ of fires, $3 \%$ of deaths

- Wire or cable insulation

$>4 \%$ of fires, $5 \%$ of deaths

- Floor covering

$>3 \%$ of fires, $4 \%$ of deaths

\section{Data Elements Related to Fire Growth}

- Items most often first ignited when flame is not confined to room of origin and upholstered furniture is the item contributing most to flame spread (continued)

- Unclassified item

$>2 \%$ of fires, $0 \%$ of deaths

- Papers

$>2 \%$ of fires, $4 \%$ of deaths

- Multiple items

$>2 \%$ of fires, $1 \%$ of deaths

- Interior wall covering

$>2 \%$ of fires, $1 \%$ of deaths

- Clothing

$>2 \%$ of fires, $2 \%$ of deaths 


\section{Data Elements Related to Fire Growth}

- Items most often first ignited when flame IS confined to room of origin and upholstered furniture is the item contributing most to flame spread

- Upholstered furniture

$>68 \%$ of fires, $77 \%$ of deaths OR

$>58 \%$ of fires, $66 \%$ of deaths if unknowns are cases of no flame spread

- Unclassified furniture or utensil

$>6 \%$ of fires, $1 \%$ of deaths OR $5 \%$ of fires, $1 \%$ of deaths

- Wire or cable insulation

$>4 \%$ of fires, $0 \%$ of deaths OR $4 \%$ of fires, $0 \%$ of deaths

- Mattress or bedding

$>3 \%$ of fires, $2 \%$ of deaths OR $3 \%$ of fires, $2 \%$ of deaths

- Floor covering

$>2 \%$ of fires, $1 \%$ of deaths OR $2 \%$ of fires, $1 \%$ of deaths

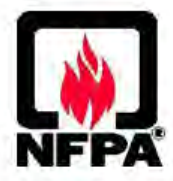

\section{Options When NFIRS Isn't Enough}

-What can't you get from NFIRS alone?

- Details of the type and composition of upholstered furniture

- Location of point of ignition on the furniture

- High-credibility estimates of fires where upholstered furniture is the primary fuel package involved but not the first fuel package

- Detailed scenarios that show when upholstered furniture is ignited and how important it is to the course of the fire 


\section{Options When NFIRS Isn't Enough}

-What are your options?

- Try to add detail to NFIRS. STOP! The data collectors will not accept such a large additional data burden - and they probably lack the resources to routinely provide such detail anyway.

- Use a completely different database that has the needed detail. STOP! Any such database e.g., documented investigations or incidents involved in court cases - is almost guaranteed to be statistically unrepresentative.

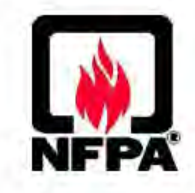

\section{Options When NFIRS Isn't Enough}

-What are your options?

- Use the NFIRS special study option. MAYBE

- If you work through local fire departments, be sure you don't ask for details they cannot reasonably be expected to collect.

- Probably better to conduct a special study through CPSC. They have done this before.

- Consider collecting samples from the involved upholstered furniture, so you can get details without overburdening field data collectors. 


\section{Options When NFIRS Isn't Enough}

-What are your options?

- Build a probabilistic model. YES!

- For example estimate percentage $\left(p_{i}\right)$ of upholstered furniture in the national inventory having certain specified characteristics

- Using lab data, estimate relative ease of ignition $(\mathrm{q})$ for upholstered furniture with different characteristics

- Then $p_{i} q_{i} / \Sigma p_{j} q_{j}$ is a derived estimate of the percentage of ypholstered furniture fires having characteristics designated $i$

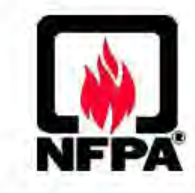

\section{Options When NFIRS Isn't Enough}

-What are your options?

- Build a probabilistic model. Example \#2

- Estimate the number of home structure fires and deaths per year that extend beyond the room of origin AND do not start with ignition of upholstered furniture. Do the same for fires confined to room of origin but beyond object.

- Maybe also limit to areas of origin where upholstered furniture is commonly found OR eliminate areas of origin where upholstered furniture is not found (e.g., concealed wall space). 


\section{Options When NFIRS Isn't Enough}

- Modeling option Example \#2 (continued)

- Estimate the percentage of fires with those specs where upholstered furniture was the Item Contributing Most to Flame Spread

- Break down the estimates to distinguish different items first ignited

- And maybe different igniting heat sources.

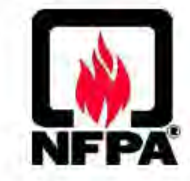

\section{Options When NFIRS Isn't Enough}

- Modeling option Example \#2 (continued)

- Obtain a sample of relevant fires with narratives. Or use your special study of upholstered furniture fires with more details.

- For each first item ignited, use narratives to fill in estimated details on what the first item typically was and where it was located.

- Now you can construct and weight scenarios for size and characteristics of the fire problem involving upholstered furniture as main fuel package but not first fuel package. 


\section{Options When NFIRS Isn't Enough}

- Modeling option Example \#2 (continued)

- Think you're done now? What about...

- The alternative avenues of fire growth that may become primary if upholstered furniture fire performance has been improved.

- You will need some lab work, possibly some physical modeling, to describe consequences for your scenarios with modified furniture

- And that includes modeling whether deaths still occur as they will if occupant locations and fire conditions are not changed enough.

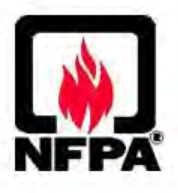

\section{Options When NFIRS Isn't Enough}

- Starter list for alternative avenues: Items contributing most to flame spread when flame is not confined to room of origin and upholstered furniture is item first ignited

- Upholstered furniture $>70 \%$ of fires, $71 \%$ of deaths

- Unclassified furniture or utensil $>6 \%$ of fires, $6 \%$ of deaths

- Structural member or framing

$>5 \%$ of fires, $3 \%$ of deaths

- Interior wall covering

$>4 \%$ of fires, $6 \%$ of deaths

- Unclassified structural component or finish

$>3 \%$ of fires, $3 \%$ of deaths 


\section{Implications for the Workshop Topics}

- For fires with flame beyond room of origin, upholstered furniture as secondary fuel package appears to add $69 \%$ to number of such fires with upholstered furniture as item first ignited

- And to add $39 \%$ to number of fire deaths

- Unless you think unclassified furniture is mostly upholstered furniture, in which case the mark-up drops to $52 \%$ for fires and $36 \%$ for deaths

- For fires with flame confined to room but beyond object of origin, secondary ignitions add $48 \%$ to fires and $31 \%$ to deaths, if unknowns are nospread fires, not including unclassified furniture

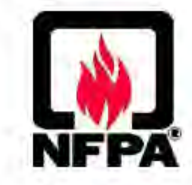

\section{Implications for the Workshop Topics}

- All this is relative to total item first ignited upholstered furniture fires.

- If you exclude smoldering ignitions, the add-on percentages are much greater

- If you also exclude what CPSC calls nonaddressable fires, the add-on percentages are much, much greater

- But remember that these secondary ignitions are no longer small open flame ignitions. Mitigation rather than prevention would presumably be the strategy of choice. 


\section{Implications for the Workshop Topics}

- In less statistical terms...

- Secondary ignitions add significantly to item first ignited upholstered furniture fires

- Just how significantly is subject to a fair degree of variation in estimates

- Which might be reduced through additional analysis and some probabilistic modeling

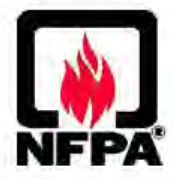

\section{Implications for the Workshop Topics}

- Estimating how much those fires and losses might be reduced by better upholstered furniture flaming fire performance would likely involve:

- Probabilistic modeling

- Physical modeling

- New lab data

- Stats from existing fire data

- Stats from special studies

- Basically, everything we have and can get 


\title{
For More Information
}

- Contact info

\author{
John Hall \\ NFPA \\ 1 Batterymarch Park \\ Quincy, MA 02169-7471 \\ (617) $984-7460$ \\ jhall@nfpa.org
}




\section{APPENDIX D.7 David Butry, NIST}

The Use of NFIRS in Economic Analysis 


\title{
The Use of NFIRS in Economic Analysis
}

\author{
Workshop on Quantifying the Contribution of \\ Flaming Residential Upholstered Furniture to \\ Fire Losses in the United States
}

March 23-23 2012

\author{
David T. Butry
}

Applied Economics Office

Engineering Laboratory

NIST

\section{Fundamental Economic Challenge}

- Minimize the sum of firerelated costs plus losses (or net value change)

- Costs are inputs to prevent or mitigated fire losses

- E.g., Investments spent on fire service, fire protection in constructed facilities, smoke alarms

- Losses are incurred because of (unwanted) fires

- E.g., Economic value of property damage, fatalities, business interruptions

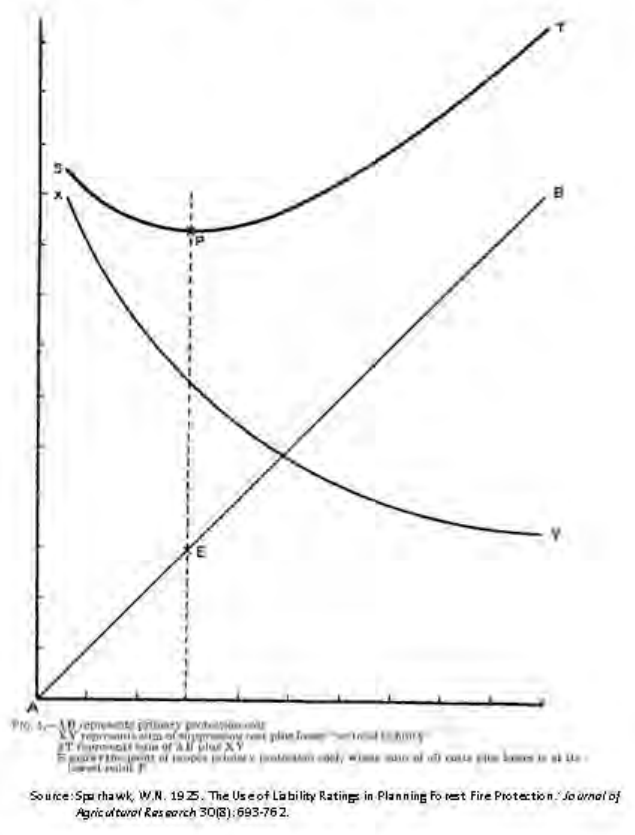




\section{$\operatorname{Min}(\mathrm{C}+\mathrm{L})$}

- In the economic problem, levels of investments into fire protection and mitigation are chosen ('solved') to obtain the minimum

- Greater spending on costs results in lower losses

- Of course, it requires an understanding of how costs affect losses

- A tradeoff occurs from substituting costs for losses

- At the minimum (optimum), an additional $\$ 1$ invested into fire protection and mitigation results in an additional reduction of loss of $<\$ 1$

- Beyond the minimum, 'the cure is worse than the disease' (economically)

- Under-investments can (does) occur

- When the benefits of fire protection and mitigation are not fully realized

- E.g., When all the benefits aren't (can't be) measured

- When benefits are not internalized

- When those who make the investment are not the (full) beneficiary

\section{Common Economic Themes}

- Risk Analysis

- Uncertainty \& Risk Preferences

- Benefit-Cost Analysis

- Cost-Effectiveness

- Return on Investment

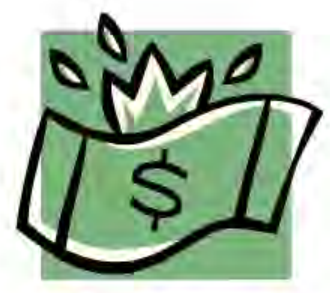

- Loss Estimation

$\Rightarrow$ All require some understanding of the fire problem (needed are data on costs and losses) 


\section{Where Does NFIRS Fit In?}

- Made up of various modules describing the fire incident

- Basic

- Fire

- Structure

- Civilian fire casualty

- Fire service casualty

- EMS

- Hazardous materials

- Wildland fire

- Apparatus or resources

- Personnel

- Arson

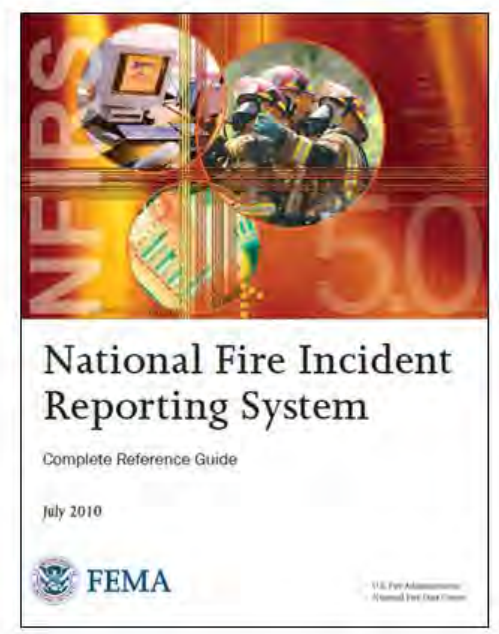

\section{Ignition Specifics}

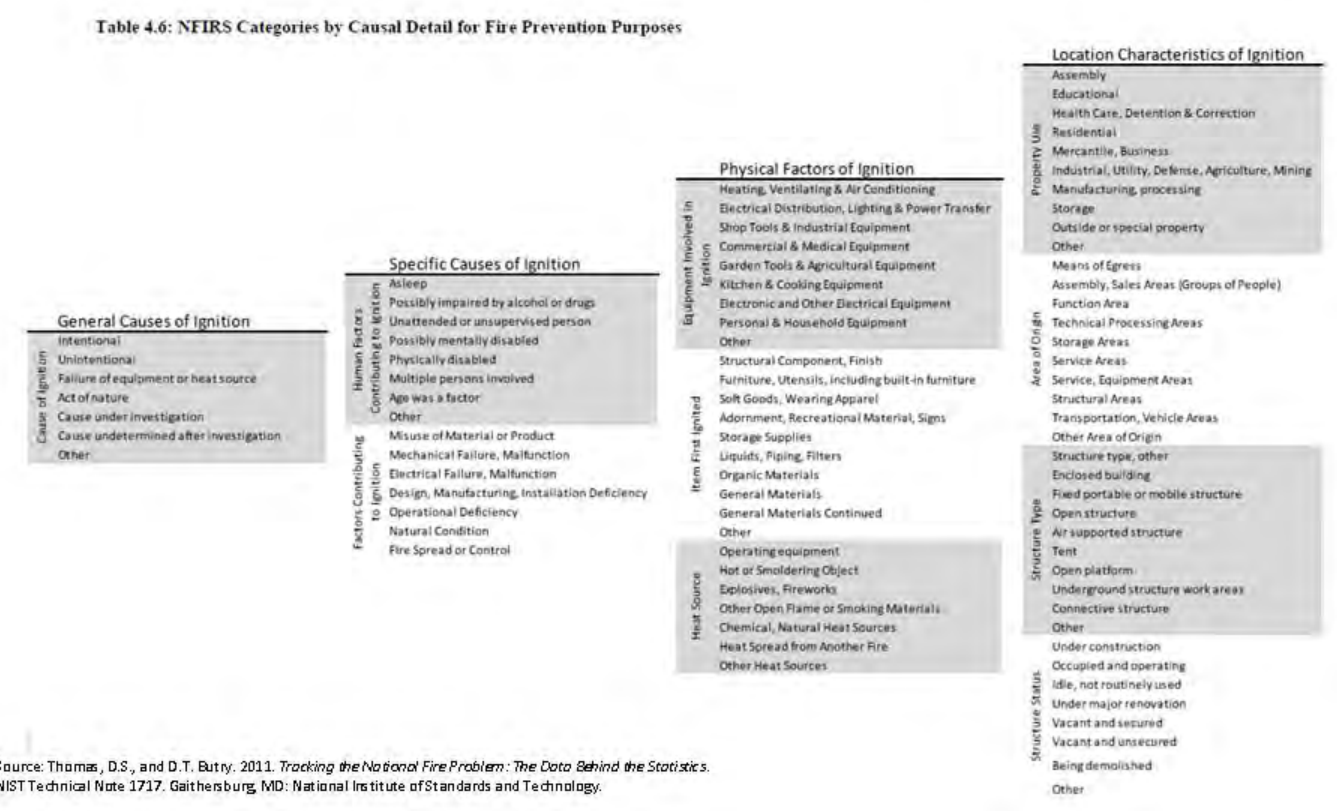




\section{Some Uses of NFIRS Data}

- Measure components of fire risk (probability $x$ consequence)

- Likelihood of occurrence

- Fatalities, injuries, and property damage

- Understand factors related to ignition

- E.g., Item first ignited

- Understand factors related to losses

- E.g., Presence of a smoke alarm

- However, NFIRS doesn't provide (as) much related to fire protection and mitigation costs.

\section{Using NFIRS Data for Economic Analysis}

\section{(A Quick NIST Example)}

- Objective: to measure the performance of residential fire sprinklers in one- and two-family homes

- Focus on fatalities averted

- Convert estimated physical performance into 'cost of life saved'

- Challenge: to measure performance while controlling for 'confounders'

- Smoke alarm technology

- Distance to fire department

- Structure age

- Family income

- Family age

- ...

- NFIRS fire incidence data was used to control for differences between sprinklered and non-sprinklered fire incidents

- Basic finding: sprinklers reduce fire-related fatalities even when controlling for the benefits provided by smoke alarm technologies and differences in housing and family characteristics 


\section{RUF \& NFIRS}

- Where is upholstered furniture tracked in NFIRS?

- Fire Module: Item First Ignited (code 21)

- Structure Module: Item Contributing Most to Flame Spread (code 21)

- Used when item first ignited was not the item contributing most to flame spread.

- How well is it tracked?

- Item First lgnited is a required field

- $|F|$ is reported $91 \%$ of time for non-confined residential fire incidents (2002-2009)

- RUF $|F|$ fires accounted for $2 \%$ of all fires

- Item Contributing Most to Flame Spread is not a required field

- Accounted for $28 \%$ of all non-confined residential fire incidents (2002-2009)

- RUF ICMFS fires accounted for $1 \%$ of all fires

\section{NFIRS RUF Incidents by Year}

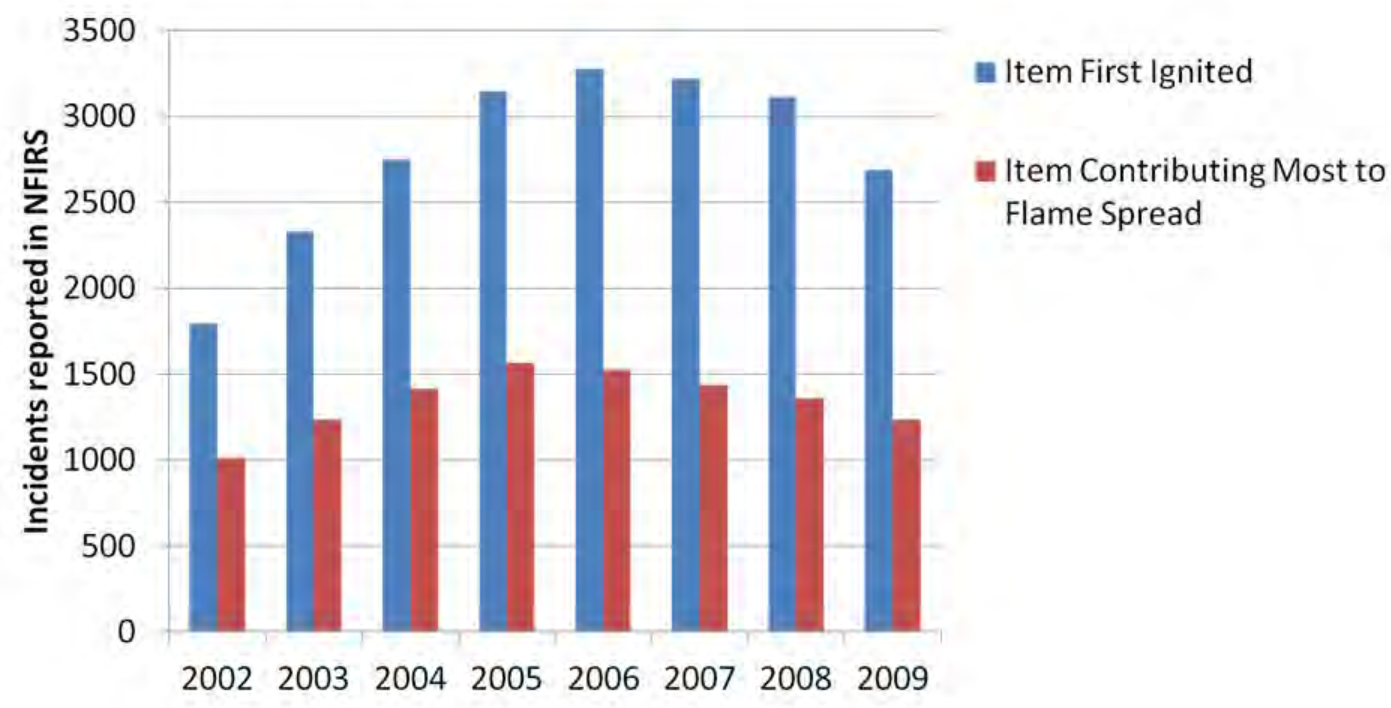




\section{RUF Flame Spread Comparison}

\begin{tabular}{|l|c|c|c|}
\hline & $\begin{array}{c}\text { None } \\
\text { (Object) }\end{array}$ & Room & Beyond Room \\
\hline RUF Fires & & & \\
\hline Item First Ignited & $27.2 \%$ & $32.6 \%$ & $40.2 \%$ \\
& $(6,074)$ & $(7,286)$ & $(8,964)$ \\
\hline $\begin{array}{l}\text { Item Contributing Most } \\
\text { to Flame Spread }\end{array}$ & $4.0 \%$ & $42.6 \%$ & $53.4 \%$ \\
\hline All Residential Fires & $(430)$ & $(4,592)$ & $(5,759)$ \\
\hline Item First Ignited & $30.6 \%$ & $28.9 \%$ & $40.4 \%$ \\
\hline $\begin{array}{l}\text { Item Contributing Most } \\
\text { to Flame Spread }\end{array}$ & $(296,078)$ & $(279,509)$ & $(390,849)$ \\
\hline
\end{tabular}

Notes: (1) Item Contributing Most to Flame Spread is NOT Item First I gnited

(2) From 2002-2009 there were 1,064,600 NFIRS-reported non-confined residential structure fires

\section{RUF National Estimates}

(Quick and Dirty)

\begin{tabular}{|c|c|c|c|c|c|c|c|c|c|}
\hline & 2002 & 2003 & 2004 & 2005 & 2006 & 2007 & 2008 & 2009 & Total \\
\hline Fires & 7,888 & 6,475 & 6,454 & 6,119 & 6,266 & 5,773 & 5,278 & 4,380 & 48,632 \\
\hline Fatalities & 361 & 372 & 397 & 345 & 297 & 334 & 285 & 220 & 2,610 \\
\hline Injuries & 985 & 957 & 879 & 985 & 854 & 755 & 850 & 776 & 7,041 \\
\hline $\begin{array}{l}\text { Property } \\
\text { Damage } \\
\text { (Ș million) }\end{array}$ & 246 & 245 & 237 & 283 & 477 & 237 & 274 & 230 & 2,228 \\
\hline
\end{tabular}

Notes: (1) Combined upholstered furniture fires as reported by item First ignited (21) and item Contributing Most to Fiame Spread (21)

(2) Fatalities and injuries are for civilian only

(3) Property damage includes property and content loss 


\section{Data Questions}

- Do Item First Ignited and Item Contributing Most to Flame Spread account for all (most) of the fires involving RUF?

- Do other ways exist to identify fires involving RUF?

- Is it difficult to determine if RUF was involved?

- Is under-reporting likely?

- Are fires that spread beyond the room of origin 'special' or 'different' than those that don't?

- Are there factors that affect both flame spread and the likelihood RUF is involved?

- Are 'bad' fires more likely to contain a Item Contributing Most to Flame Spread?

\section{Potential Economic Analyses}

- Report national RUF fire estimates (numbers, fatalities, injuries, and property damage)

- Pros: straightforward

- Cons: ignores potential confounding effects from other factors

- Estimate RUF 'treatment' effect using statistical methods

- Pros: Can 'deal with' confounding effects,

Provides 'causal' effect,

Creates a better understanding of RUF risks

- Cons: Requires a greater understanding of fire

behavior and the role of RUF and correlated factors,

Need to identify a baseline (counterfactual-RUF fire compared to what?),

Won't (directly) provide 'national estimates' 
APPENDIX E-NFIRS Coding Forms 


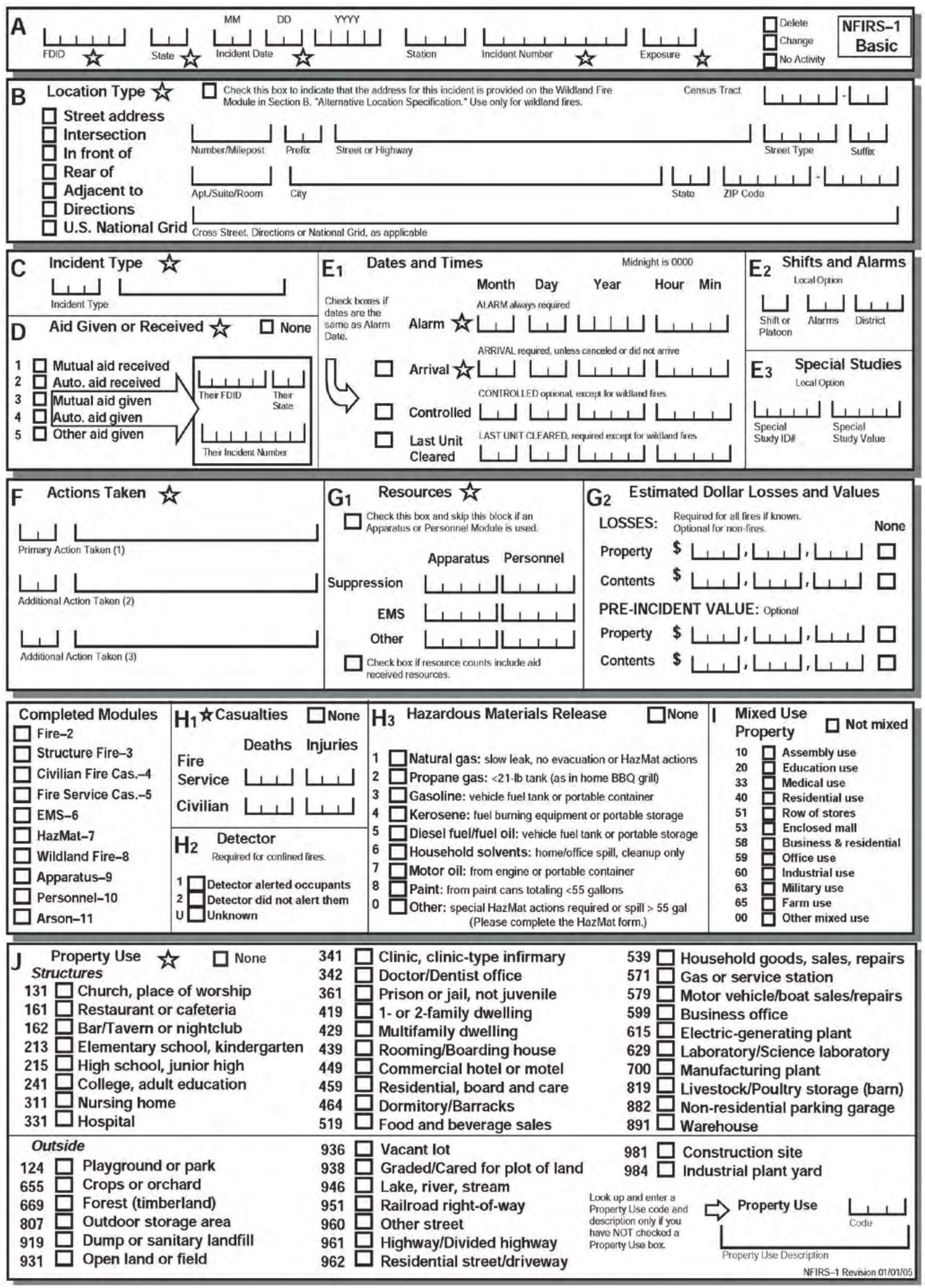




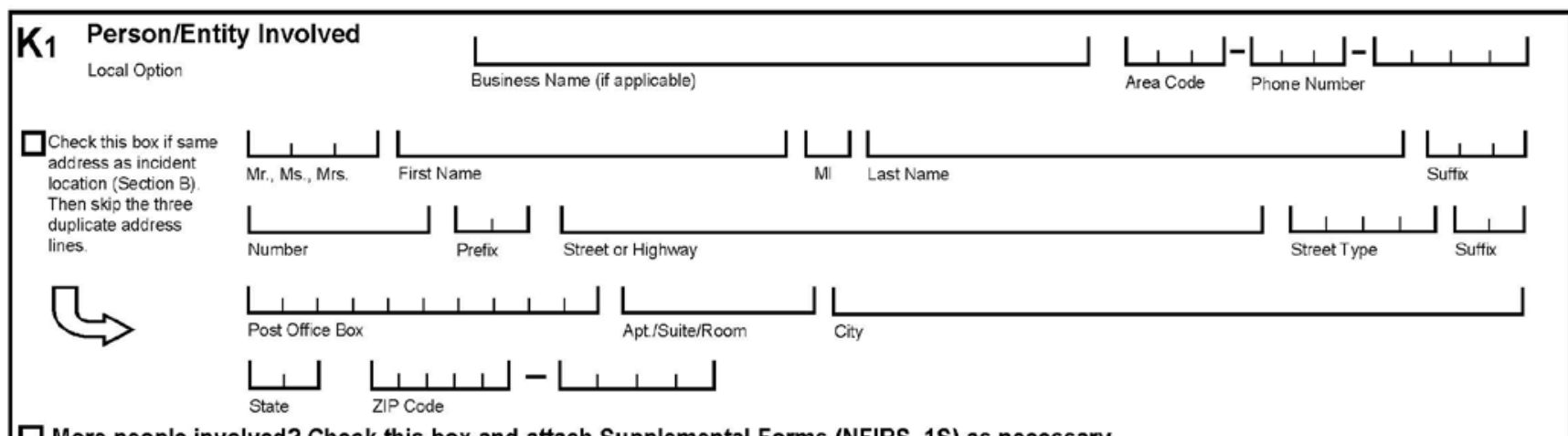

$\square$ More people involved? Check this box and attach Supplemental Forms (NFIRS-1S) as necessary.
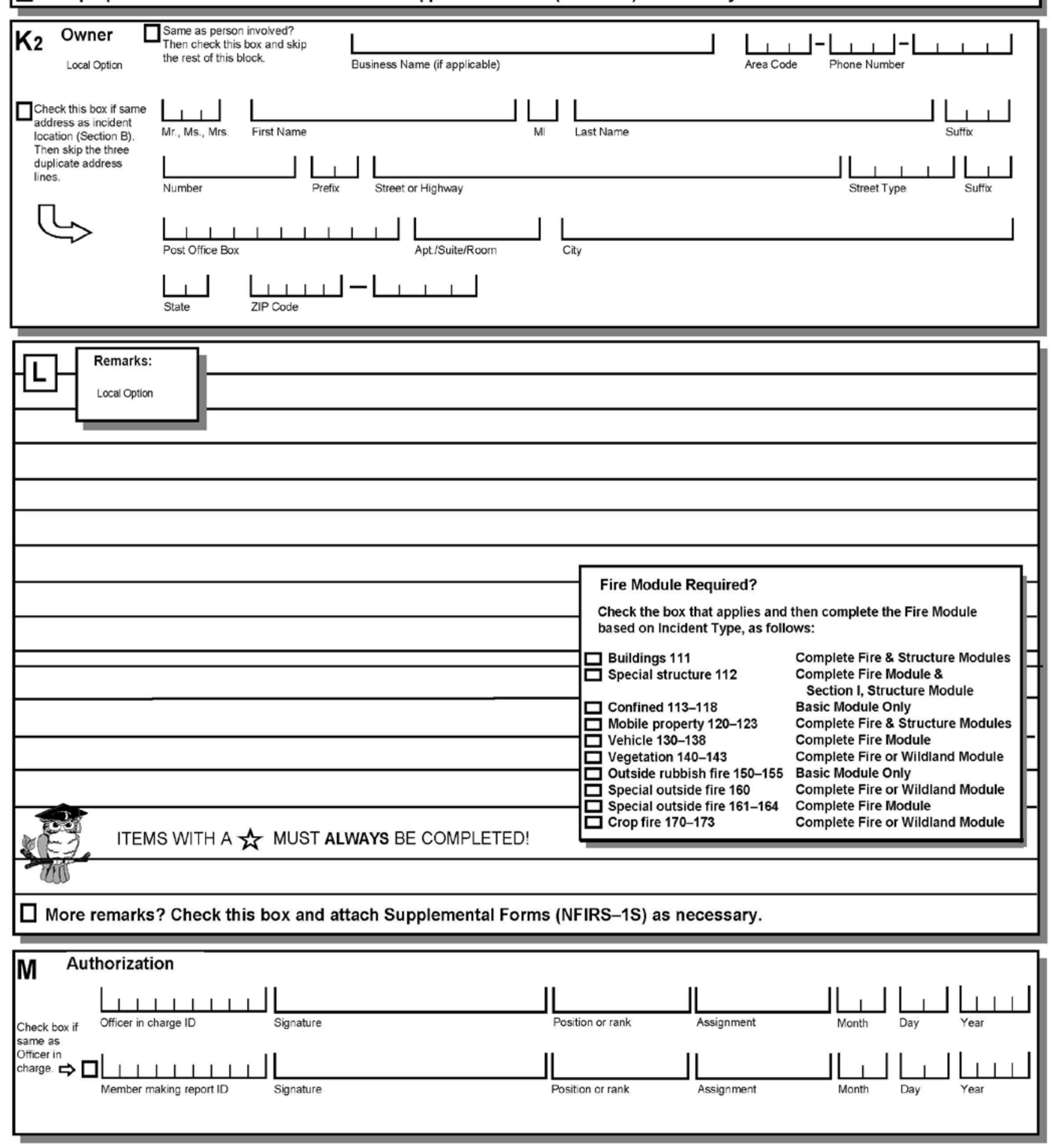


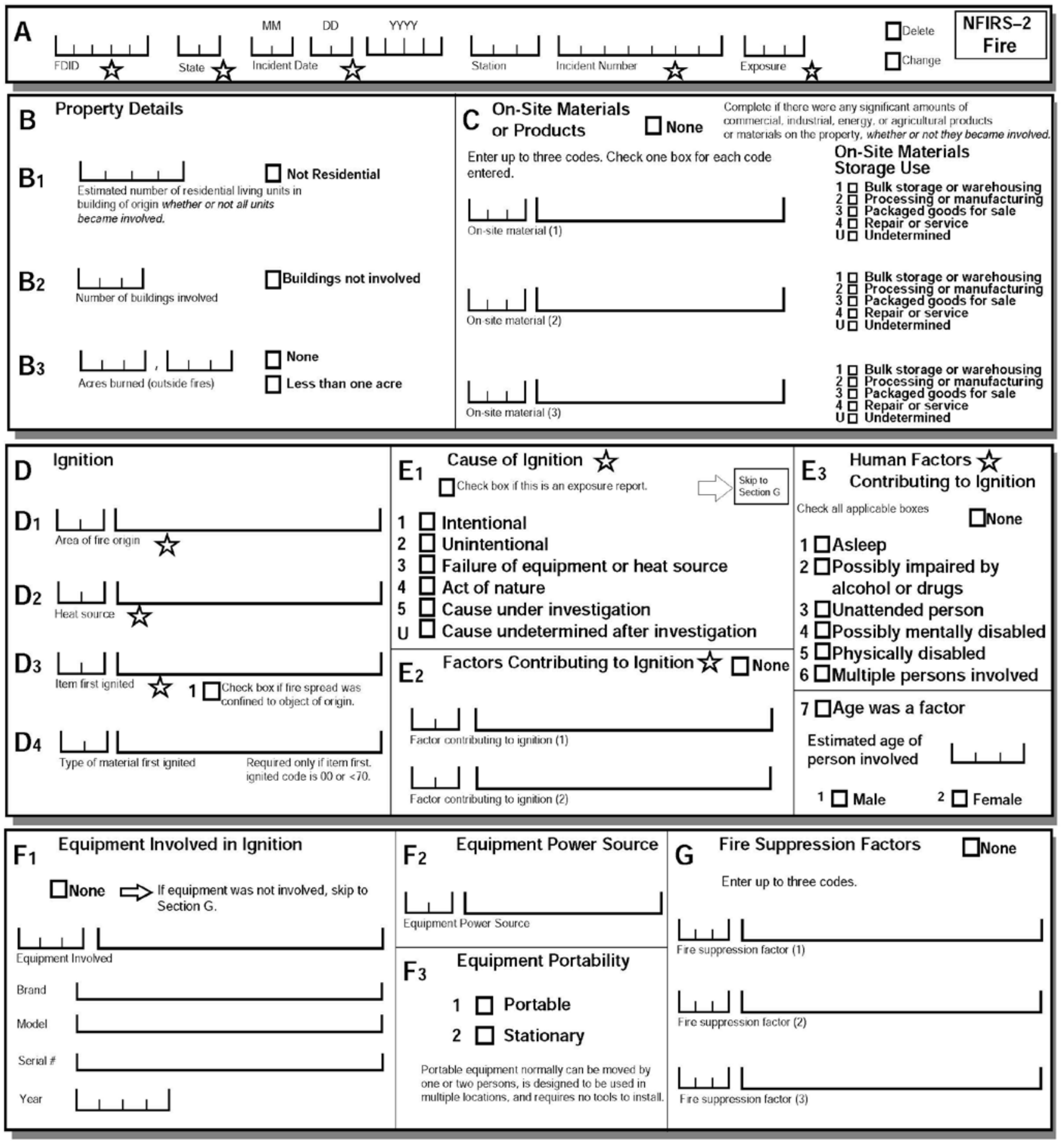

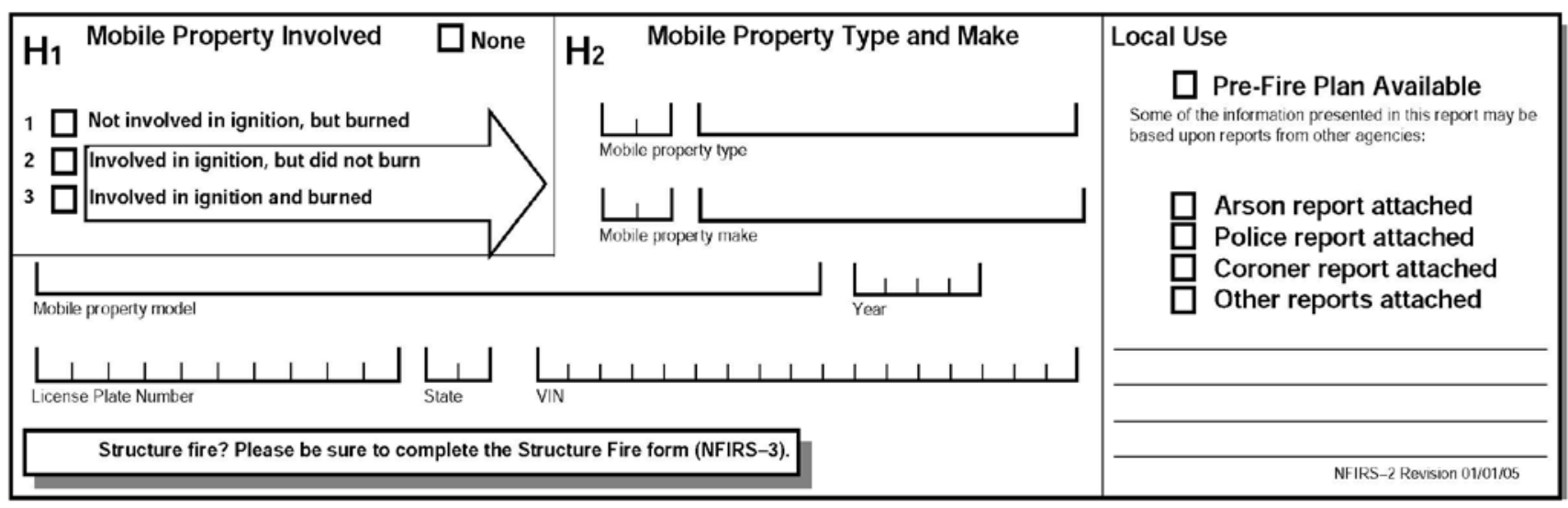




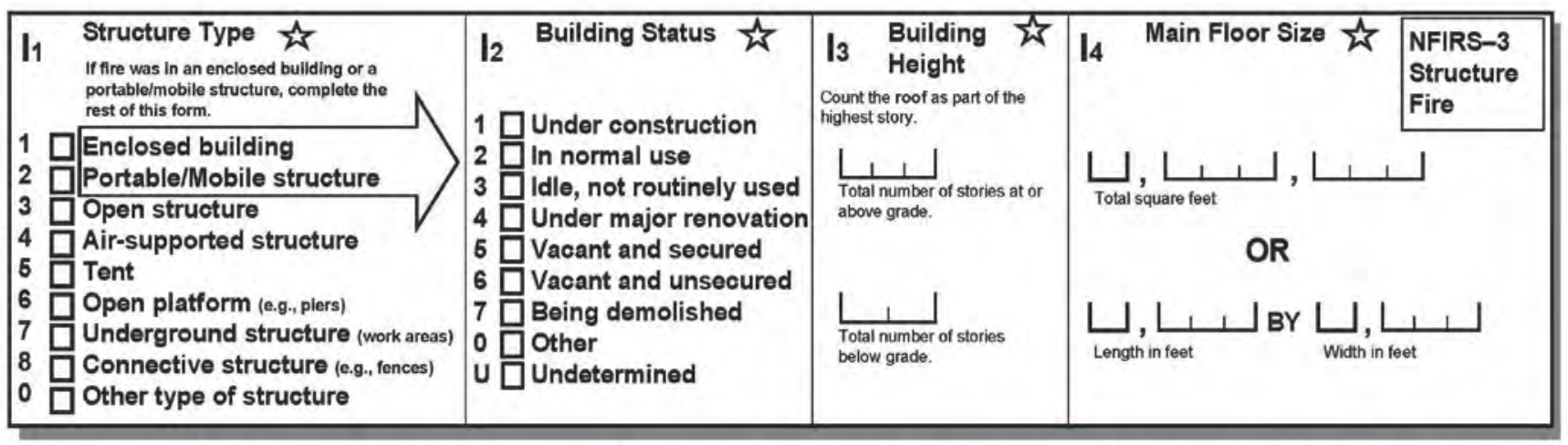

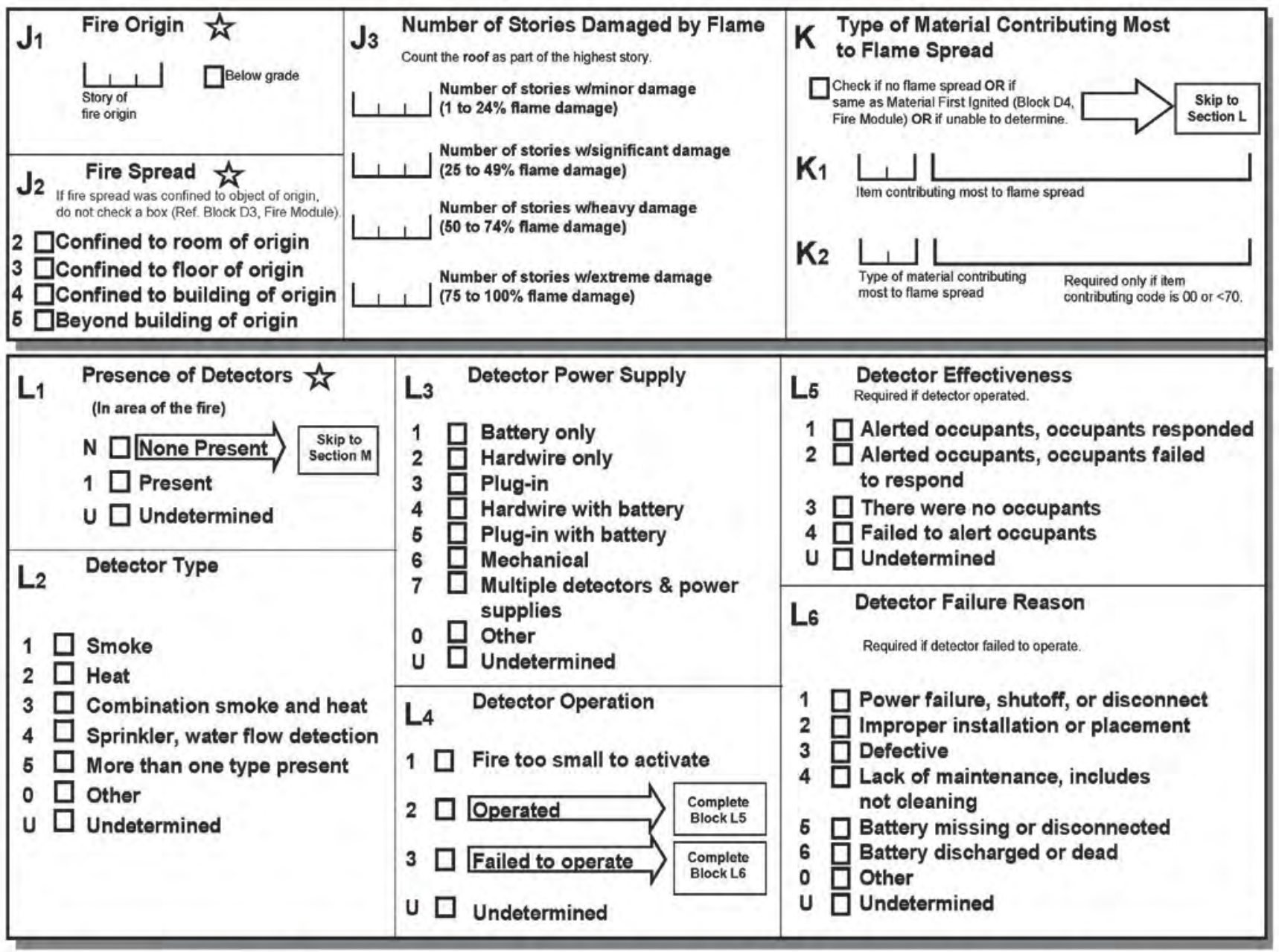

\begin{tabular}{|c|c|c|c|}
\hline \multicolumn{2}{|c|}{ 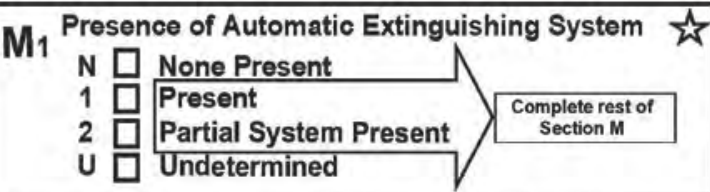 } & \multirow{2}{*}{$\begin{array}{|ll|}M_{3} \quad \begin{array}{l}\text { Operation of Automatic } \\
\text { Extinguishing System }\end{array} \\
\text { Required if fire was within designed range. } \\
1 \text { Operated/effective (go to M4) } \\
2 \text { Operated/Not effective (go to M4) } \\
3 \text { Oire too small to activate } \\
4 \text { Failed to operate (go to M5) } \\
0 \\
\mathrm{U}\end{array}$} & \multirow{3}{*}{ 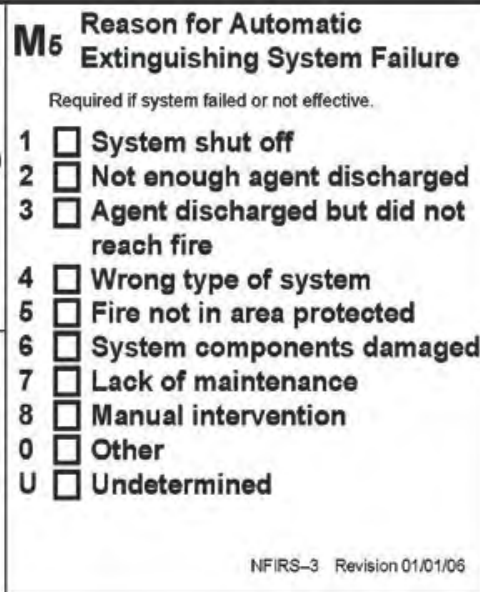 } \\
\hline \multirow{2}{*}{\multicolumn{2}{|c|}{ 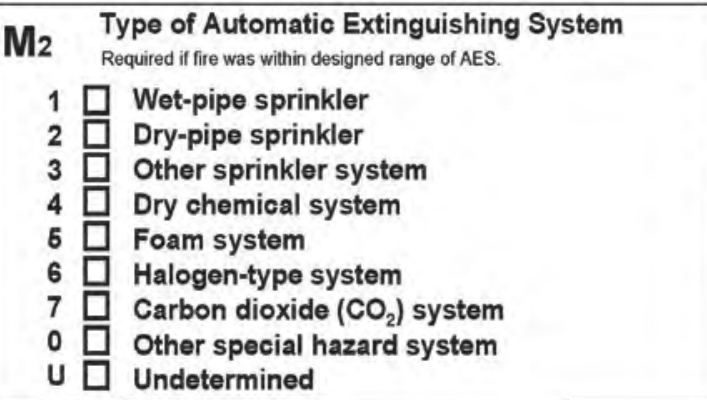 }} & & \\
\hline & & M4 $\begin{array}{l}\text { Number } \\
\text { Heads }\end{array}$ & \\
\hline
\end{tabular}




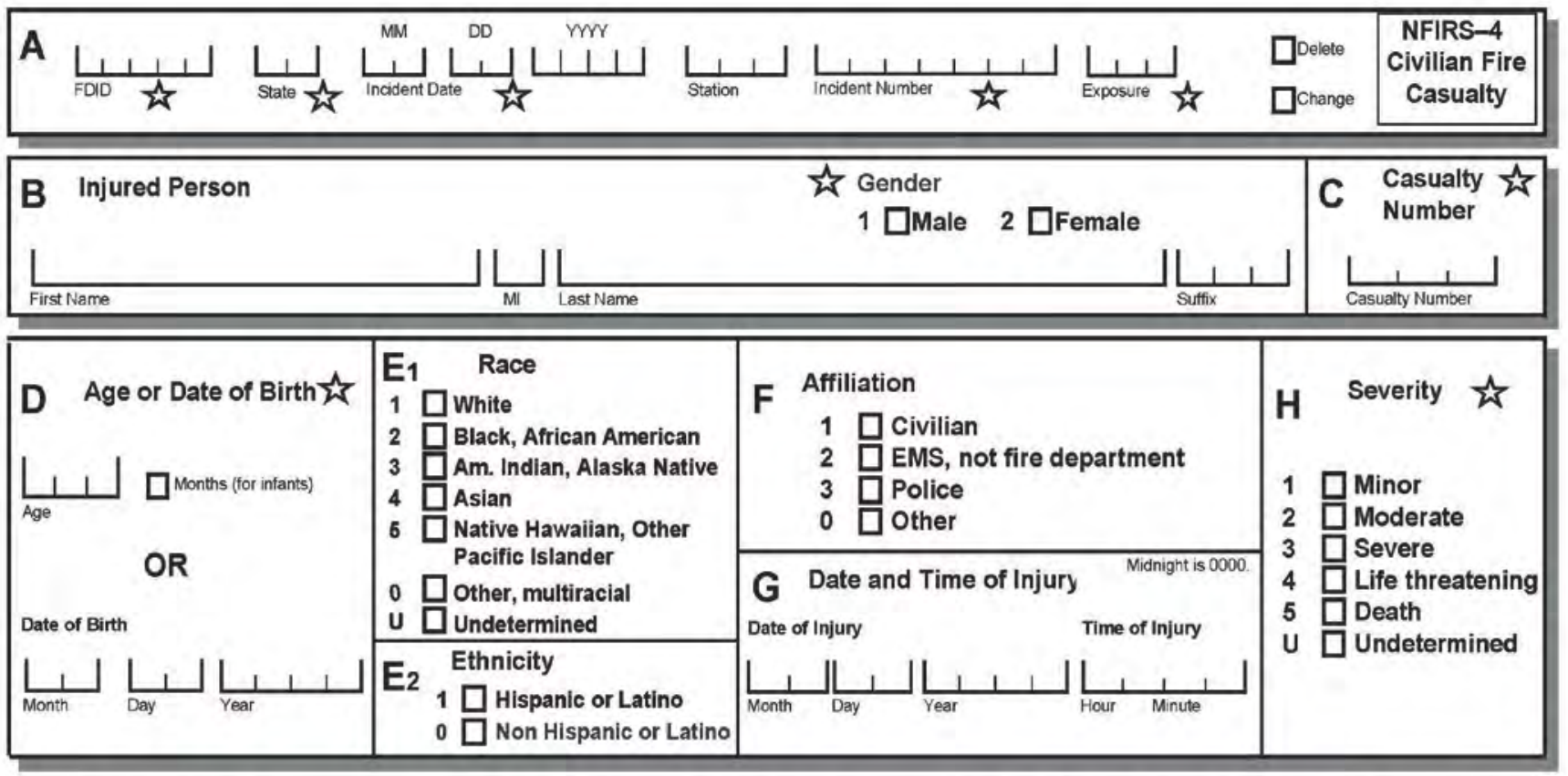

\begin{tabular}{|c|c|c|c|}
\hline $\begin{array}{ll}\text { I } & \text { Cause of Injury } \\
1 & \square \text { Exposed to fire products including flame } \\
2 & \text { heat, smoke, and gas } \\
3 & \text { Exposed to toxic fumes other than smoke } \\
4 & \text { Jumped in escape attempt } \\
5 & \text { Fell, slipped, or tripped } \\
6 & \text { Caught or trapped } \\
6 & \text { Structural collapse } \\
7 & \square \text { Struck by or contact with object } \\
8 & \square \text { Overexertion or strain } \\
9 & \square \text { Multiple causes } \\
0 & \square \text { Other } \\
\mathrm{U} & \square \text { Undetermined }\end{array}$ & $\begin{array}{ll}\text { J } & \begin{array}{l}\text { Human Factors } \\
\text { Contributing to Injury }\end{array} \\
\text { Check all applicable boxes } \\
1 & \square \text { Asleep } \\
2 & \square \text { Unconscious } \\
3 & \square \text { Possibly impaired by alcohol } \\
4 & \square \text { Possibly impaired by other drug } \\
5 & \square \text { Possibly mentally disabled } \\
6 & \square \text { Physically disabled } \\
7 & \square \text { Physically restrained } \\
8 & \square \text { Unattended person }\end{array}$ & $\begin{array}{l}\text { Factors Contributing } \\
\text { to Injury }\end{array}$ & $\square$ None \\
\hline
\end{tabular}

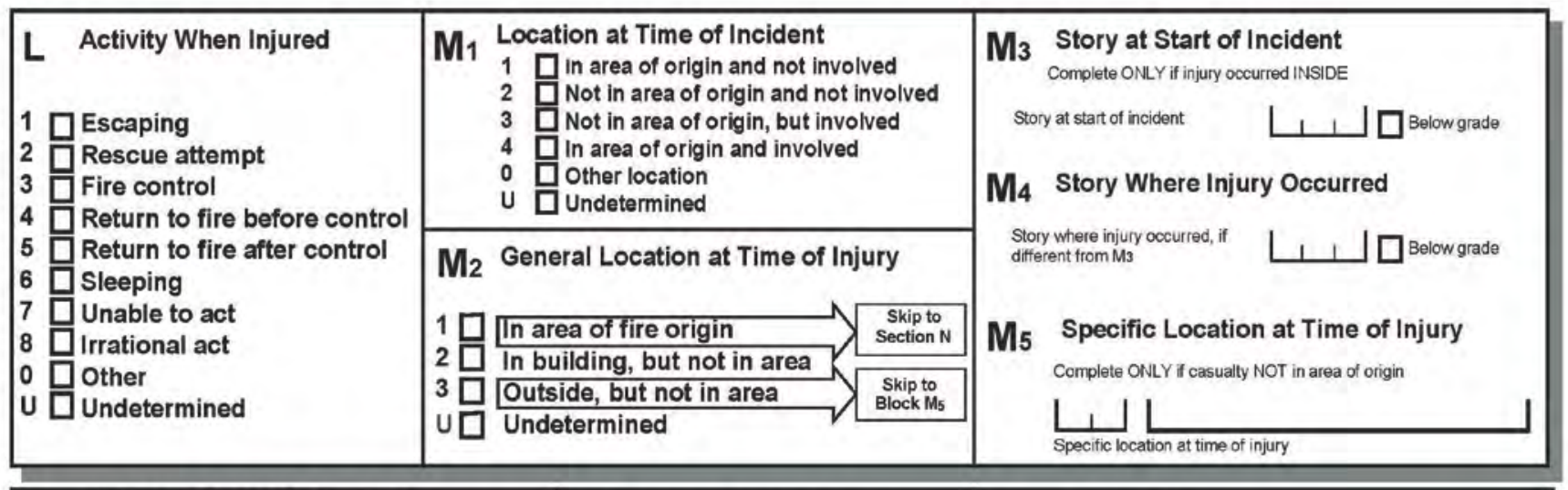

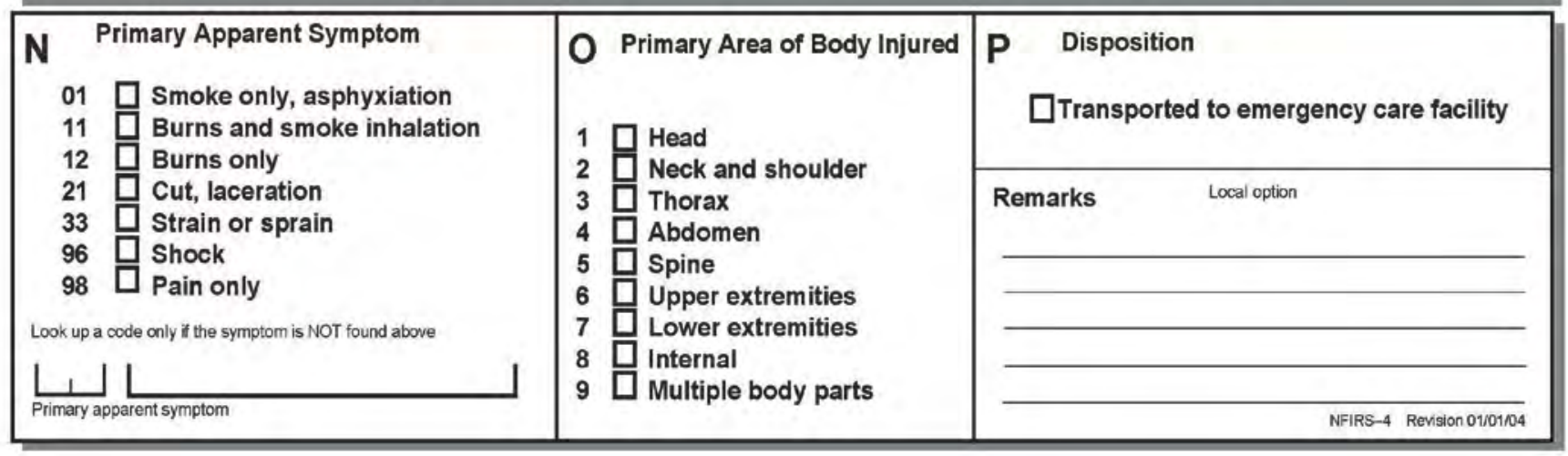




\begin{tabular}{|c|c|c|c|c|c|c|}
\hline$A$ & $\frac{11 \perp 11}{\text { FDID }}$ & 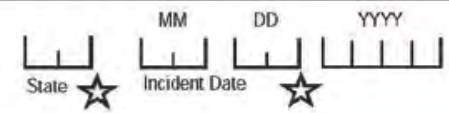 & 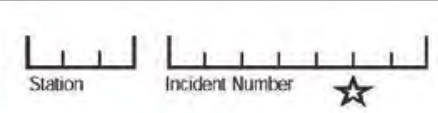 & $\frac{11}{L_{\text {Exposure }}^{1}}$ & $\begin{array}{l}\square^{\text {Delete }} \\
\square^{\text {change }}\end{array}$ & $\begin{array}{c}\text { NFIRS-5 } \\
\text { Fire Service } \\
\text { Casualty }\end{array}$ \\
\hline
\end{tabular}

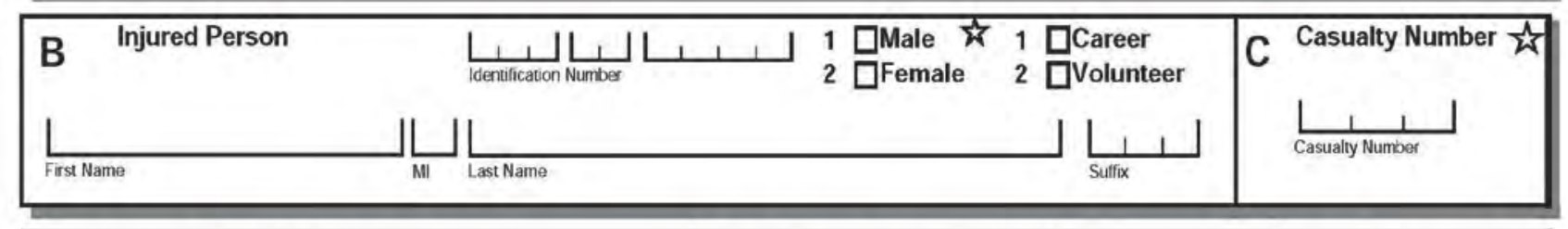

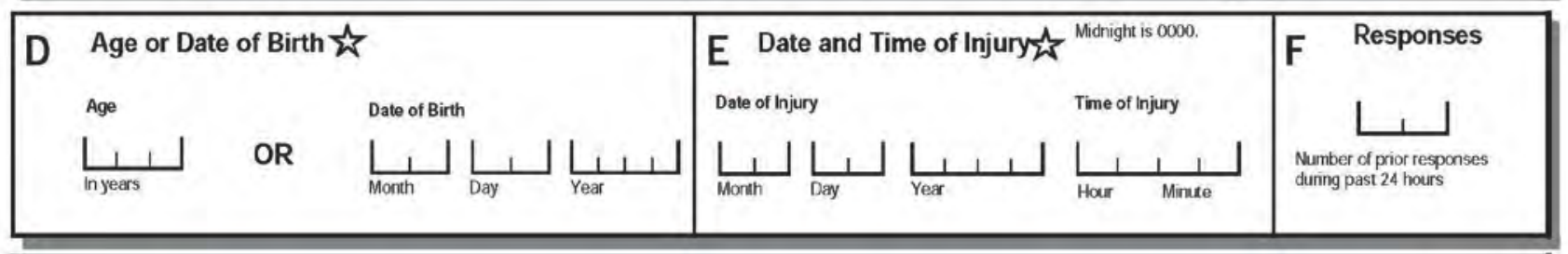

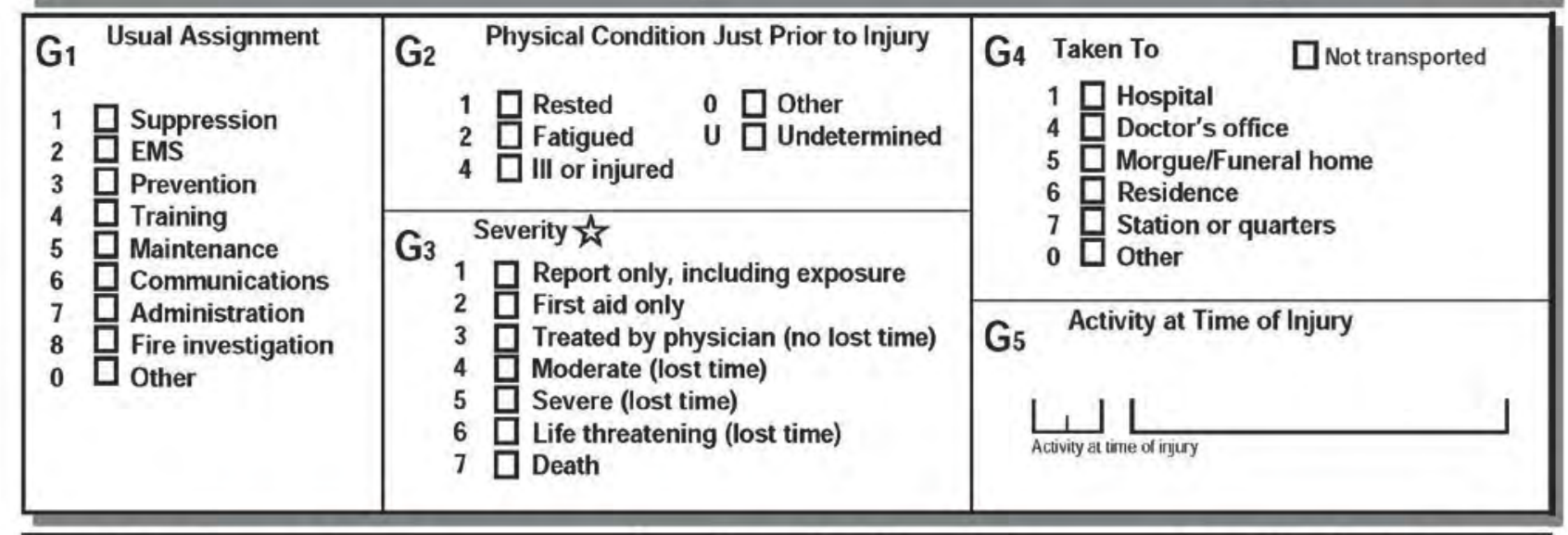

\begin{tabular}{|c|c|c|c|c|}
\hline $\mathrm{H}_{1}$ & Primary Apparent Symptom & 11 & Cause of Firefighter Injury & I3 $\begin{array}{l}\text { Object Involved } \\
\text { in Injury }\end{array}$ \\
\hline $\mathrm{H}_{2}$ & Primary Part of Body Injured $\quad \square$ None & $I_{2}$ & Factor Contributing to Injury $\square$ None & $L_{\text {Object involved in injury }}$ \\
\hline
\end{tabular}

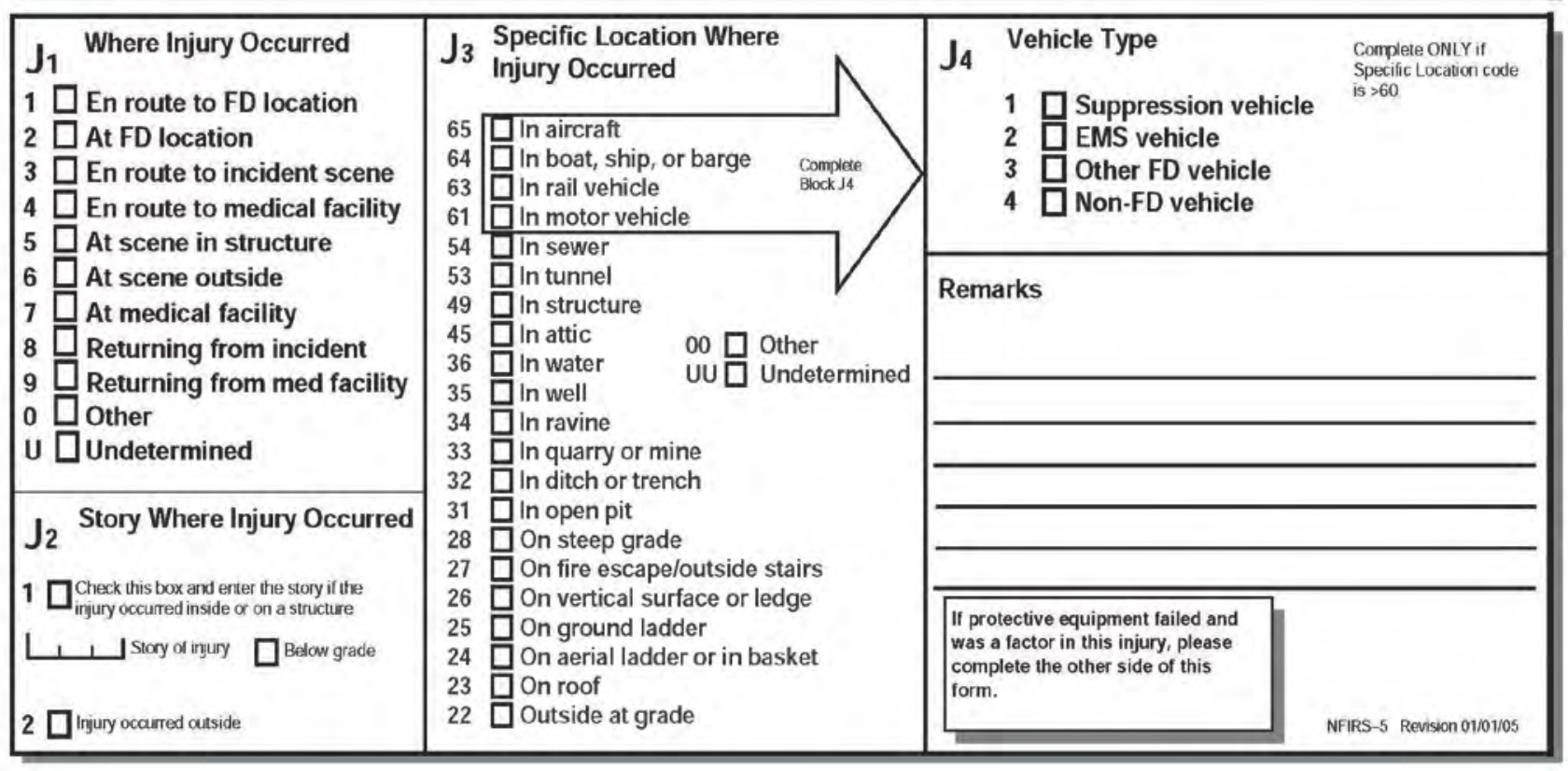




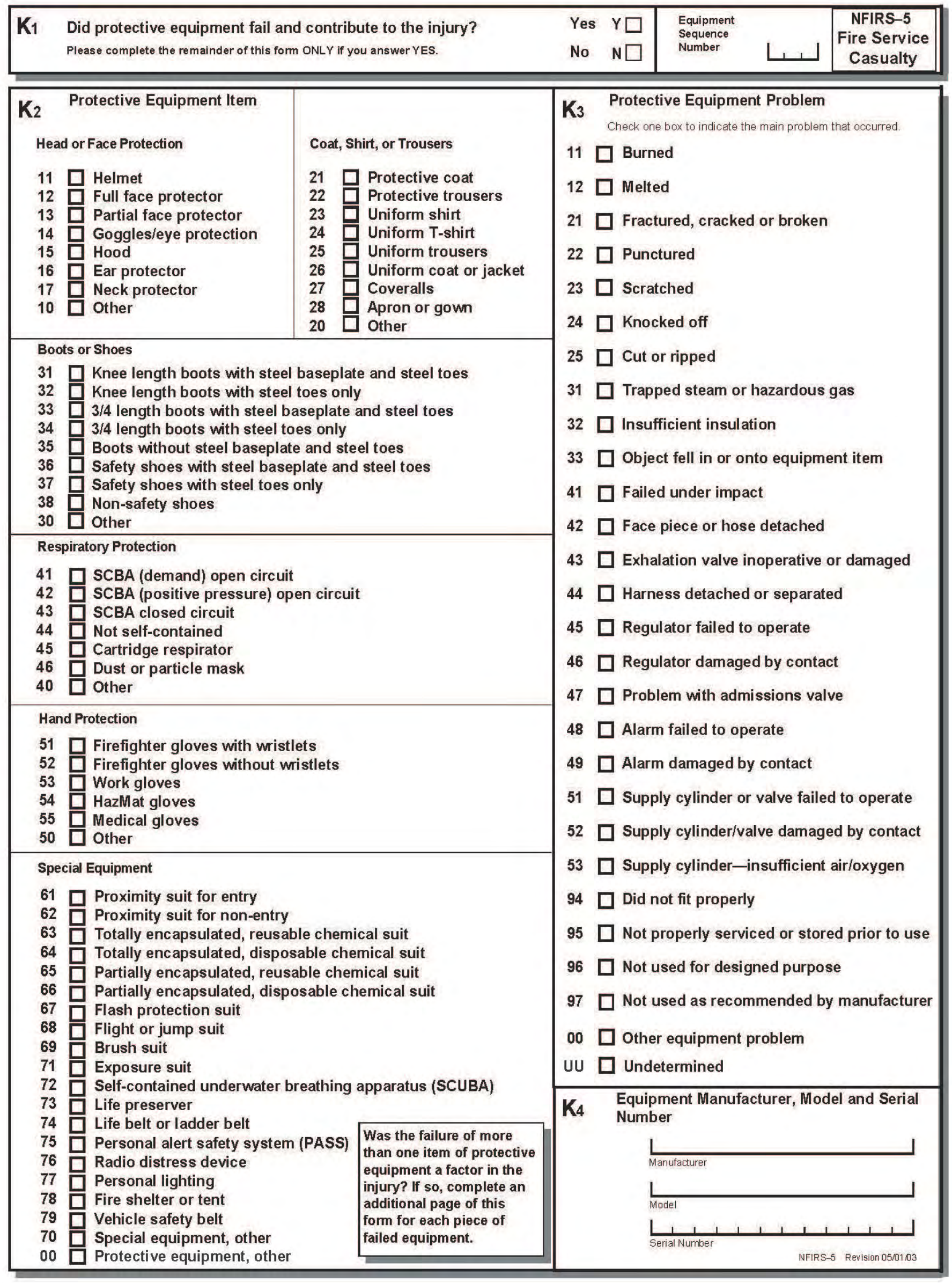




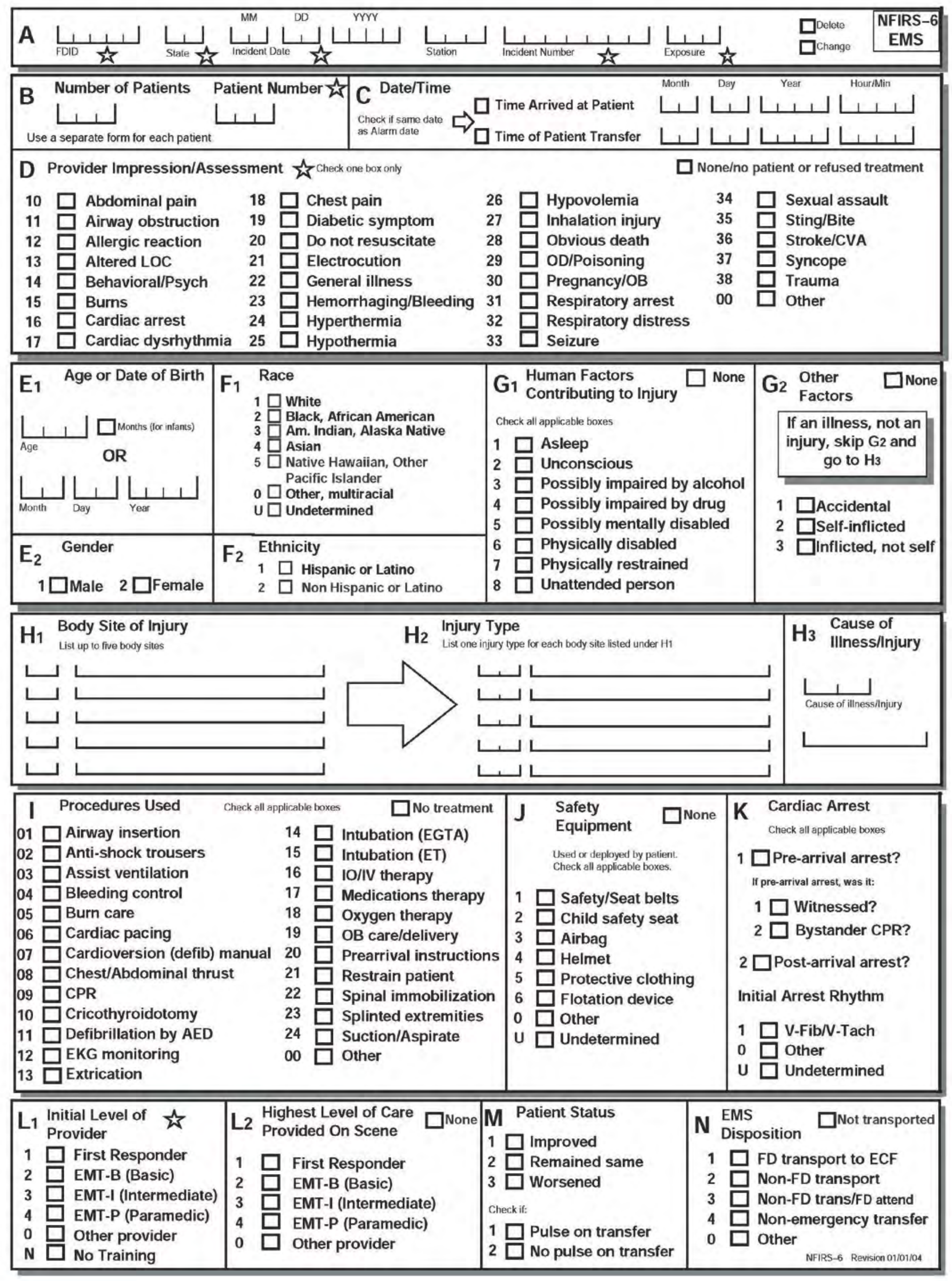




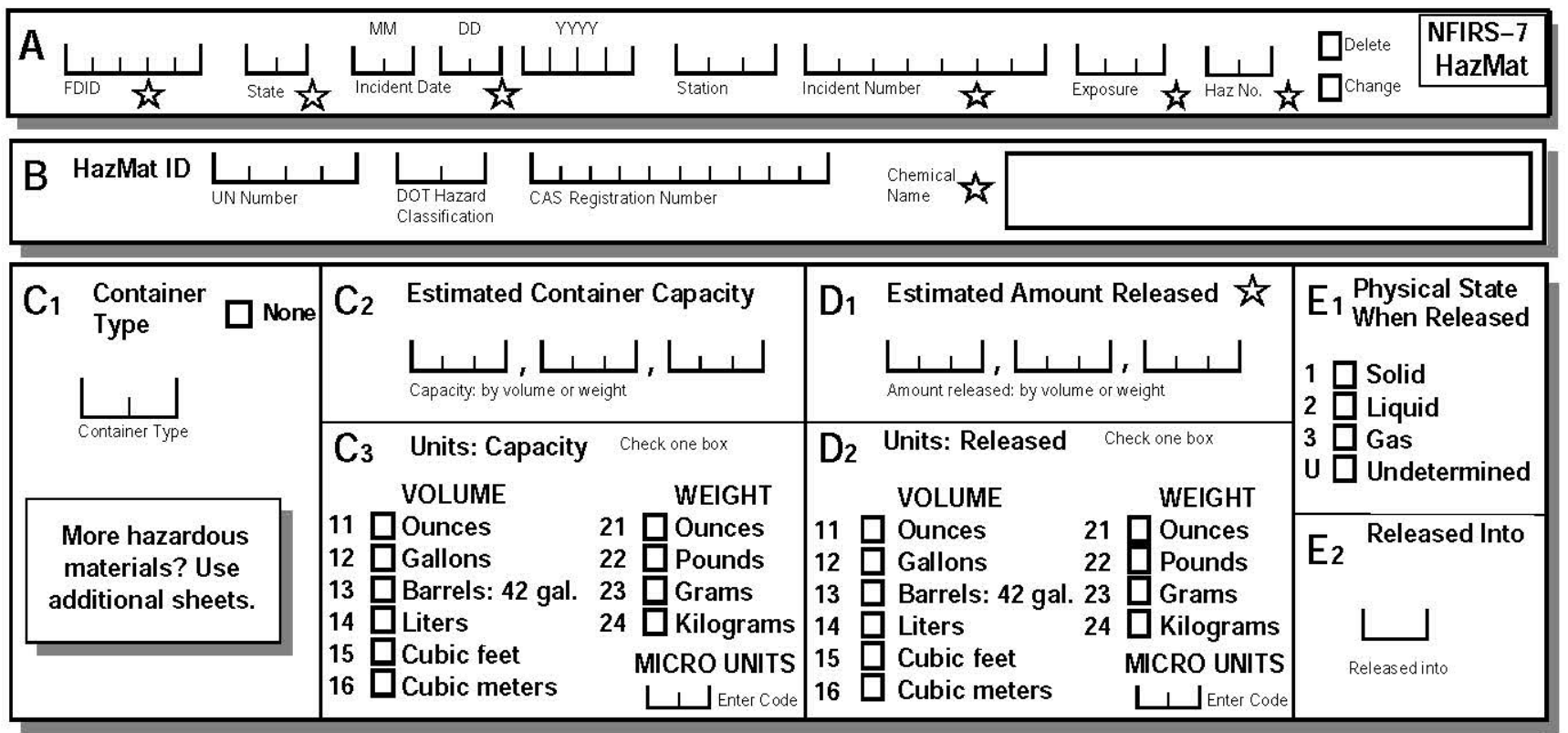

\begin{tabular}{|c|c|c|c|}
\hline $\begin{array}{l}\text { Complete the remainder } \\
\text { of this form only for the } \\
\text { first hazardous material } \\
\text { involved in this incident. }\end{array}$ & $\begin{aligned} F_{2} & \text { Population Density } \\
1 & \square \text { Urban } \\
2 & \square \text { Suburban } \\
3 & \square \text { Rural }\end{aligned}$ & 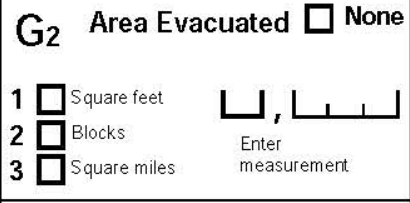 & $\begin{array}{l}\text { HazMat Actions Taken } \\
\text { Enter up to three actions taken }\end{array}$ \\
\hline $\begin{array}{l}\text { F1 Released From } \\
\text { Check all applicable boxes }\end{array}$ & G1 Area Affected & G3 $\begin{array}{l}\text { Estimated Number of } \\
\text { People Evacuated }\end{array}$ & Additional action taken (2) \\
\hline$\square$ Below grade & $1 \square$ Square feet & 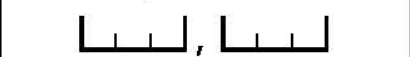 & Additional action taken (3) \\
\hline${ }^{1 \square}$ Inside/on structure & 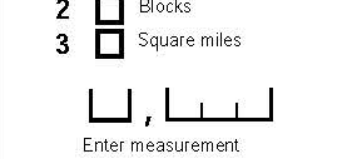 & $\begin{array}{c}\text { G4 } \begin{array}{l}\text { Estimated Number of } \\
\text { Buildings Evacuated }\end{array} \\
\square, \downarrow \perp \perp \perp \text { None }\end{array}$ & $\begin{array}{l}\text { I If fire or explosion is involved with a } \\
\text { release, which occurred first? } \\
1 \square \text { Ignition U } \square \text { Undetermined } \\
2 \square \text { Release }\end{array}$ \\
\hline
\end{tabular}

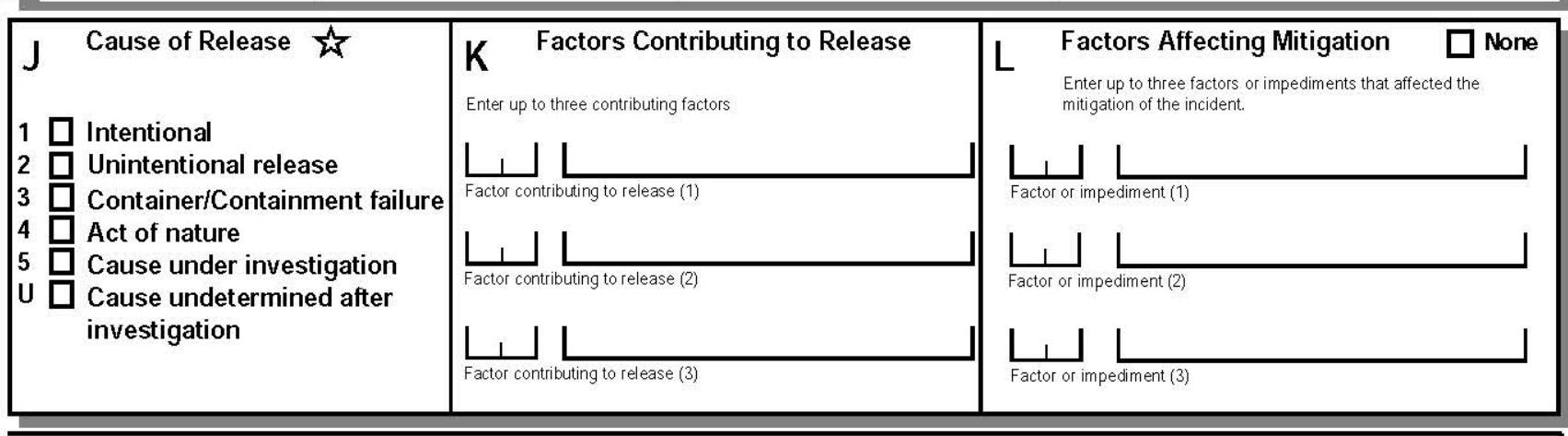

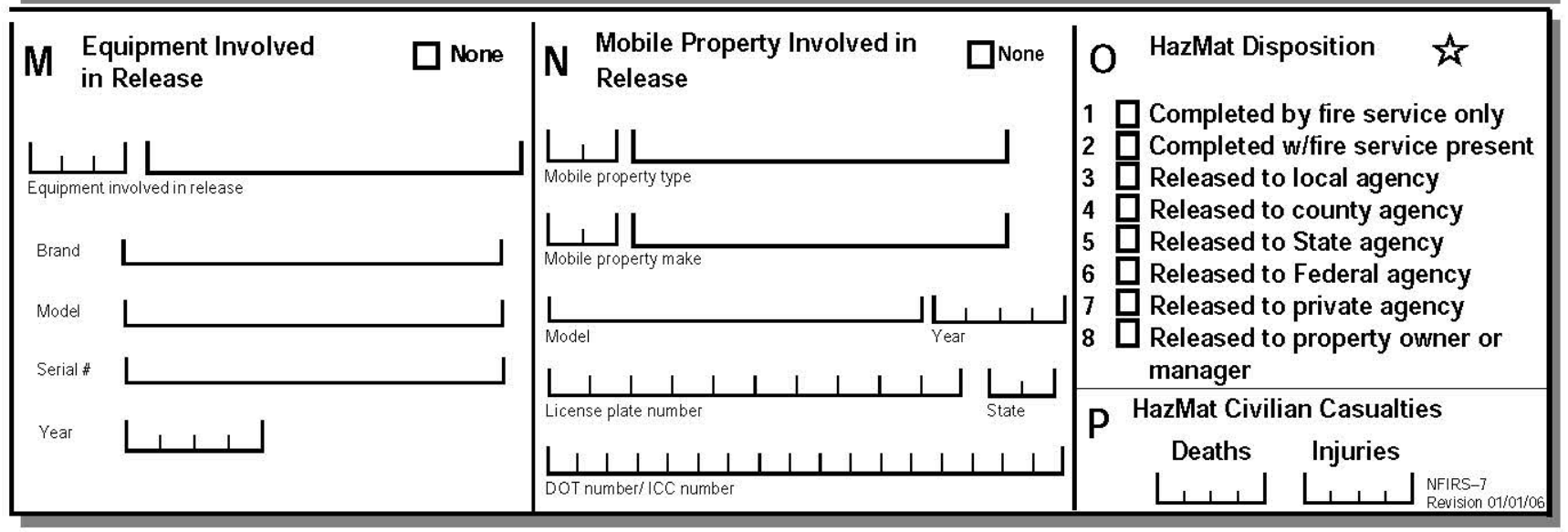




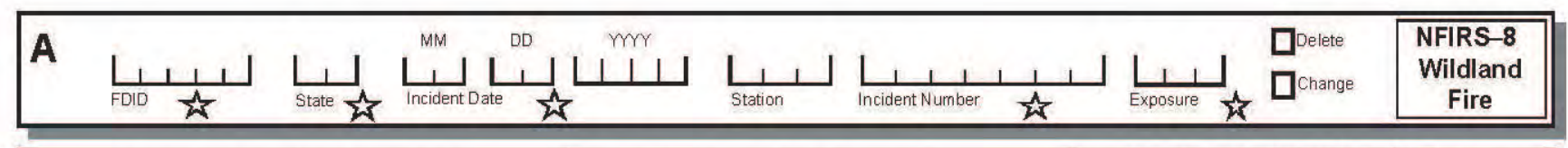

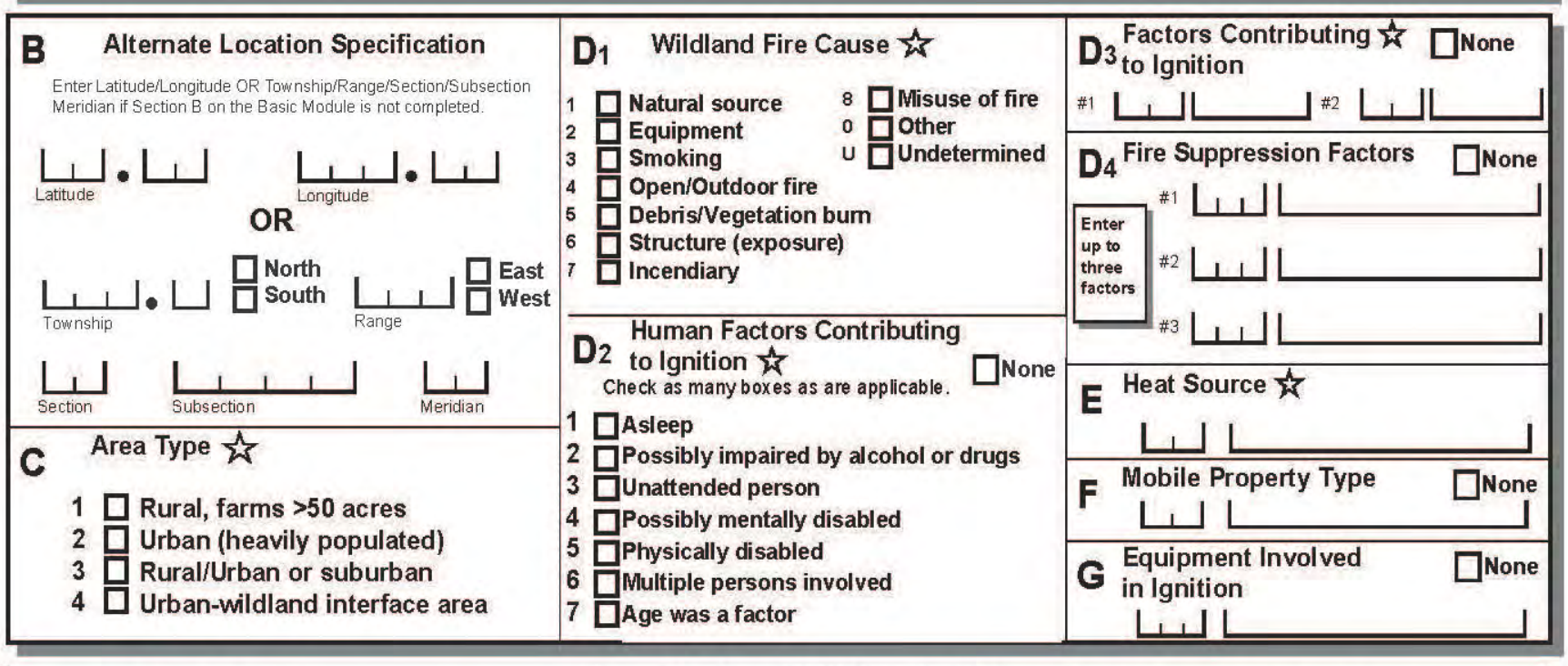

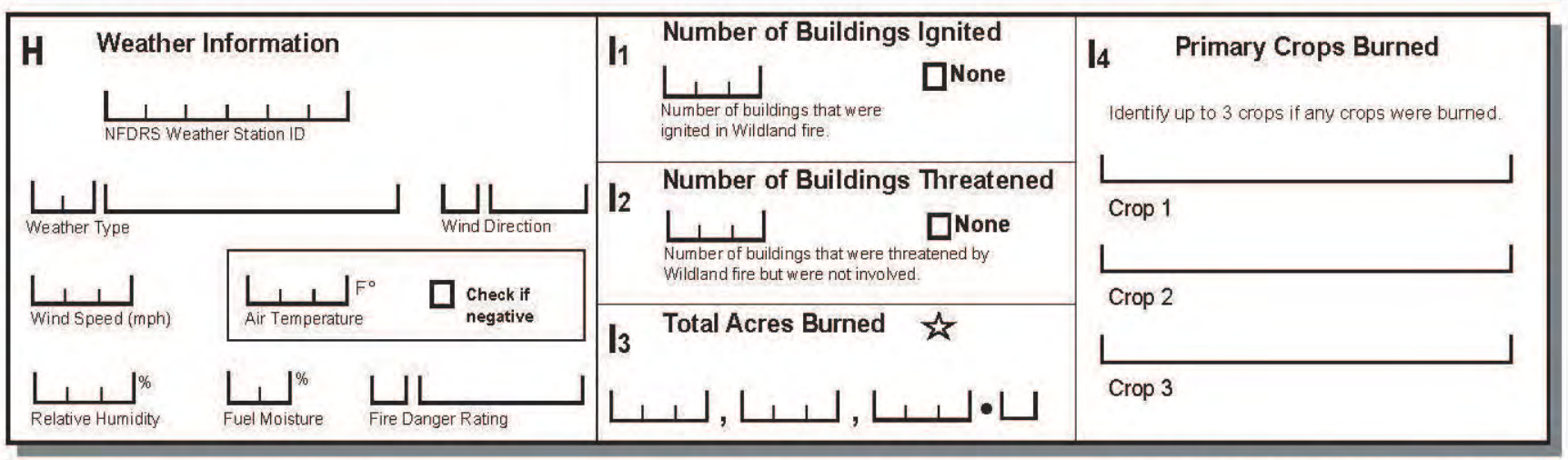

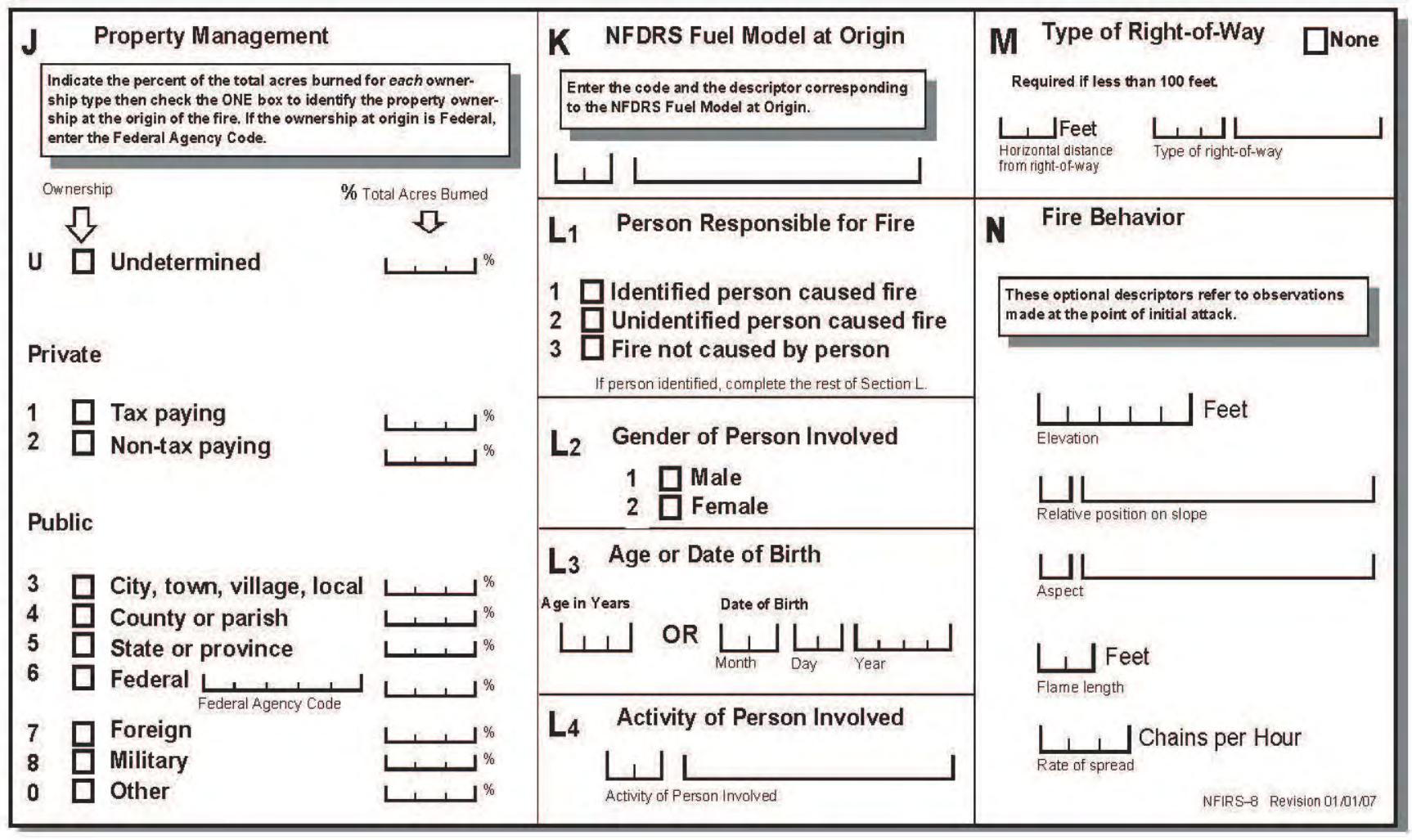




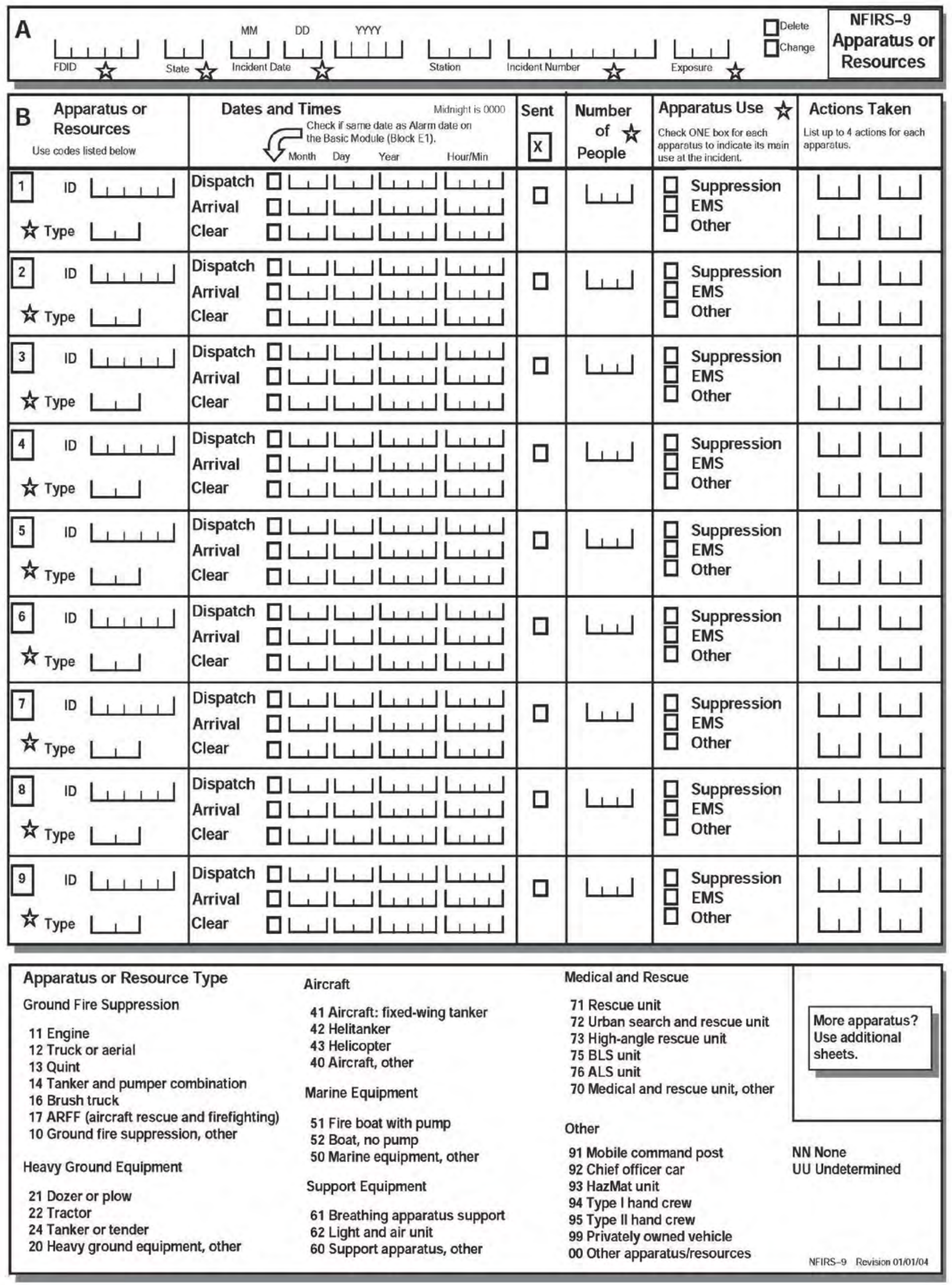




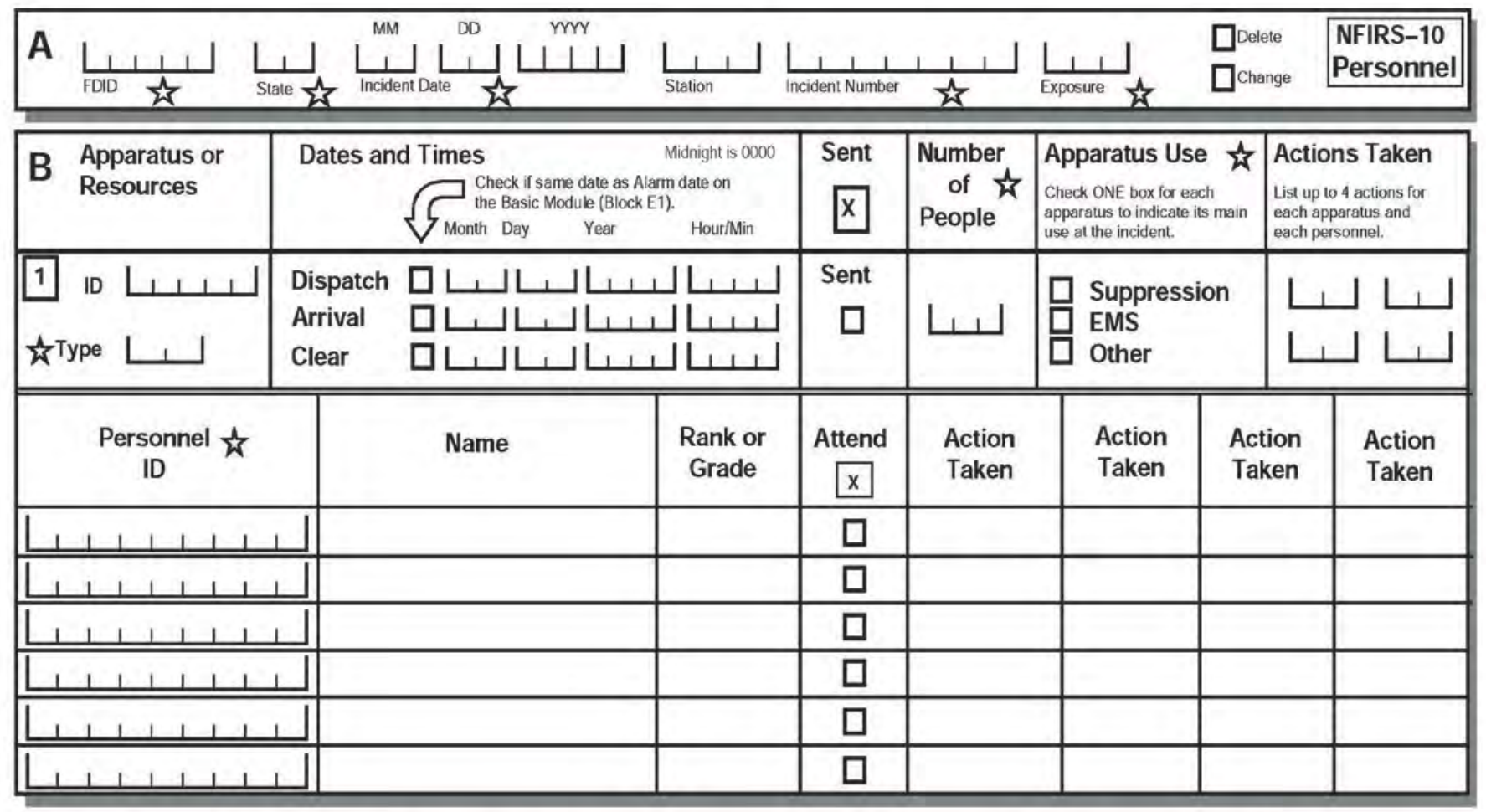

\begin{tabular}{|c|c|c|c|c|c|c|c|c|}
\hline 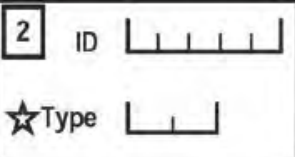 & $\begin{array}{l}\text { Dispatch } \\
\text { Arrival } \\
\text { Clear }\end{array}$ & 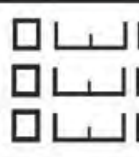 & 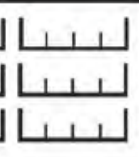 & $\begin{array}{c}\text { Sent } \\
\square\end{array}$ & لـــا لـا & 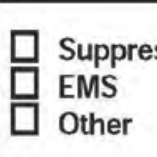 & & لــا لـ لـ لـ لــا \\
\hline $\begin{array}{l}\text { Personnel } \underset{\text { id }}{\text { ID }} \\
\text {. }\end{array}$ & & Name & $\begin{array}{l}\text { Rank or } \\
\text { Grade }\end{array}$ & $\begin{array}{l}\text { Attend } \\
x\end{array}$ & $\begin{array}{l}\text { Action } \\
\text { Taken }\end{array}$ & $\begin{array}{l}\text { Action } \\
\text { Taken }\end{array}$ & $\begin{array}{l}\text { Action } \\
\text { Taken }\end{array}$ & $\begin{array}{l}\text { Action } \\
\text { Taken }\end{array}$ \\
\hline $5,1,1,1,1,1$ & & & & $\square$ & & & & \\
\hline $5+1+1,1+1$ & & & & $\square$ & & & & \\
\hline 51111111 & & & & $\bar{\square}$ & & & & \\
\hline 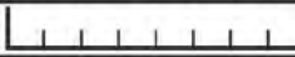 & & & & $\bar{\square}$ & & & & \\
\hline 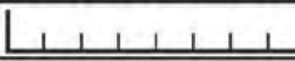 & & & & $\square$ & & & & \\
\hline+ & & & & 口 & & & & \\
\hline
\end{tabular}

\begin{tabular}{|c|c|c|c|c|c|c|c|c|}
\hline 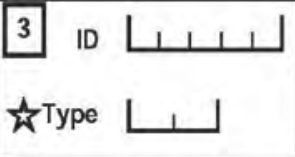 & $\begin{array}{l}\text { Dispatch } \\
\text { Arrival } \\
\text { Clear }\end{array}$ & 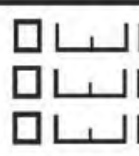 & 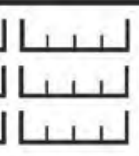 & $\begin{array}{c}\text { Sent } \\
\square\end{array}$ & لــــا لـا & $\begin{array}{l}\text { Suppre } \\
\text { EMS } \\
\text { Other }\end{array}$ & & لــــا \\
\hline $\begin{array}{l}\text { Personnel } \downarrow \\
\text { ID }\end{array}$ & & Name & $\begin{array}{l}\text { Rank or } \\
\text { Grade }\end{array}$ & $\begin{array}{c}\text { Attend } \\
\square\end{array}$ & $\begin{array}{l}\text { Action } \\
\text { Taken }\end{array}$ & $\begin{array}{l}\text { Action } \\
\text { Taken }\end{array}$ & $\begin{array}{l}\text { Action } \\
\text { Taken }\end{array}$ & $\begin{array}{l}\text { Action } \\
\text { Taken }\end{array}$ \\
\hline 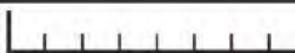 & & & & $\square$ & & & & \\
\hline$\square, 1,1,1,11$ & & & & $\square$ & & & & \\
\hline $\begin{array}{llllllll} & 1 & 1 & 1 & 1 & 1\end{array}$ & & & & $\bar{\square}$ & & & & \\
\hline $\begin{array}{llllllll} & 1 & 1 & 1 & 1 & 1 & 1 & 1\end{array}$ & & & & $\square$ & & & & \\
\hline 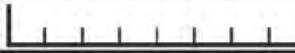 & & & & $\square$ & & & & \\
\hline$L, 1,1,1,1$ & & & & $\square$ & & & & \\
\hline
\end{tabular}




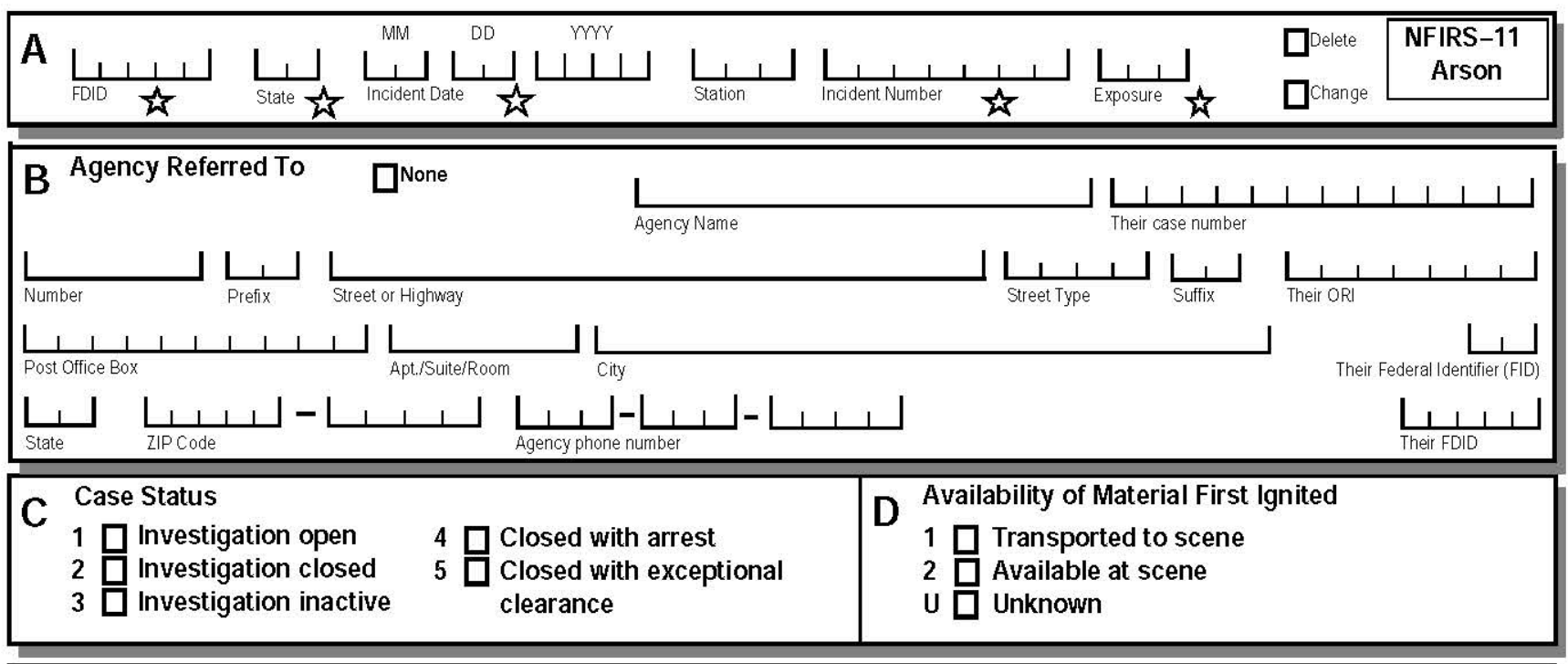

\begin{tabular}{|c|c|c|c|c|c|c|c|}
\hline \multirow{2}{*}{$\mathbf{E}$} & \multicolumn{2}{|c|}{ Suspected Motivation Factors } & \multirow[t]{2}{*}{ Check up to three factors } & \multirow{2}{*}{\multicolumn{2}{|c|}{$42 \square$ Vanity/Recognition }} & \multirow{2}{*}{54} & \multirow{3}{*}{$\begin{array}{l}\text { Burglary } \\
\text { Homicide concealment }\end{array}$} \\
\hline & & & & & & & \\
\hline 11 & $\square$ Extortion & 22 & Hate crime & 43 & Thrills & 61 & \\
\hline 12 & $\square$ Labor unrest & 23[ & Institutional & 44 & Attention/Sympathy & 62 & Burglary concealment \\
\hline 13 & Insurance fraud & 24[ & Societal & 45 & Sexual excitement & 63 & Auto theft concealment \\
\hline 14 & $\square$ Intimidation & 31[ & Protest & 51 & Domicide & 64 & Destroy records/evidence \\
\hline 15 & $\square$ void contract/lease & 32[ & Civil unrest & 52 & Suicide & 00 & Other suspected motivation \\
\hline 21 & $\square$ Personal & 41[ & Fireplay/Curiosity & 53 & $\square$ Domestic violence & UU & $\square$ Unknown motivation \\
\hline
\end{tabular}

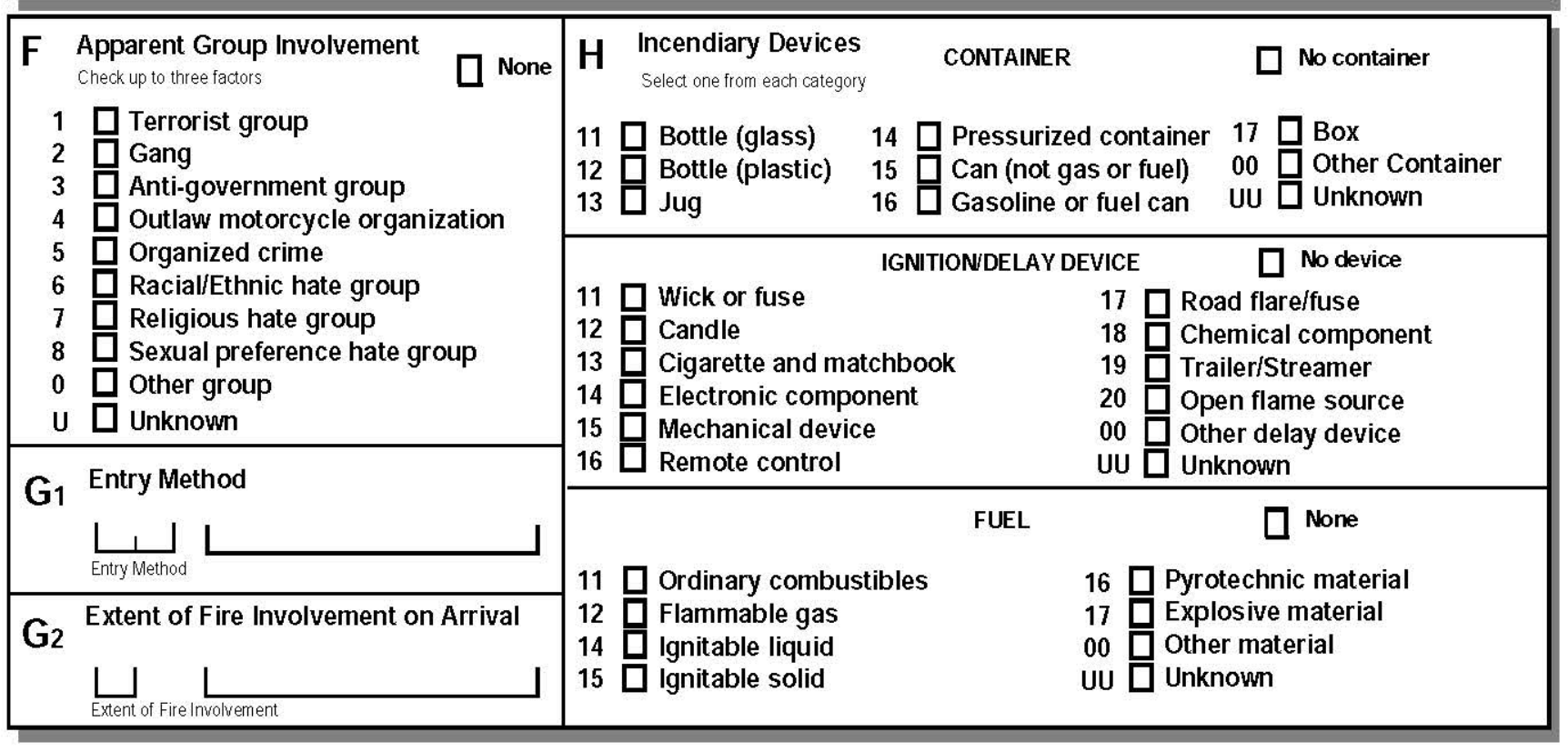

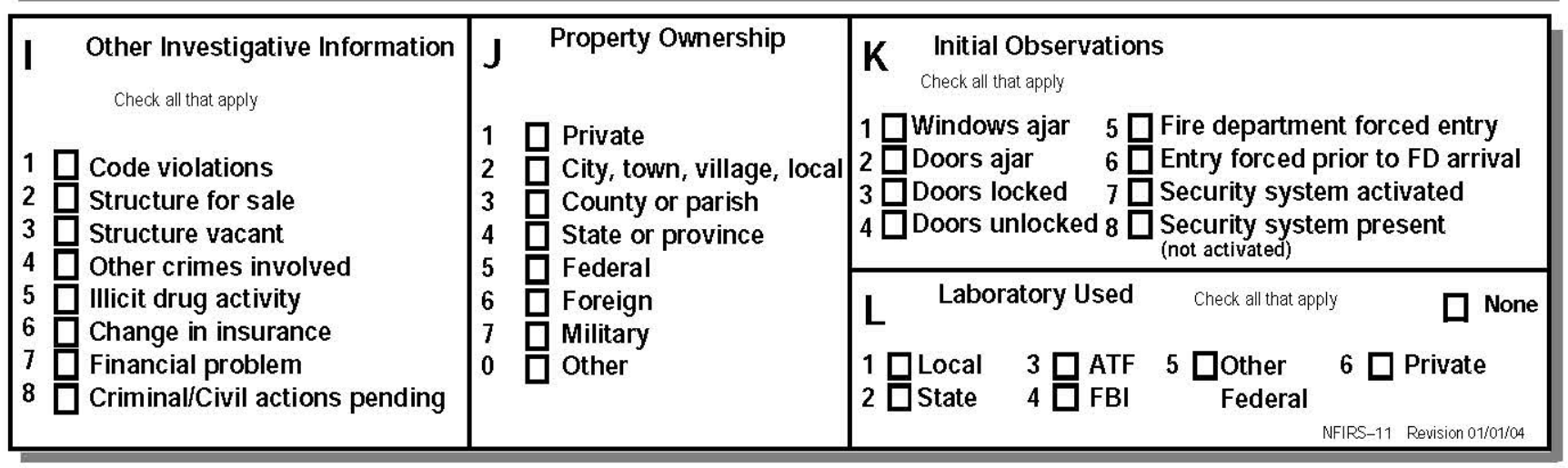




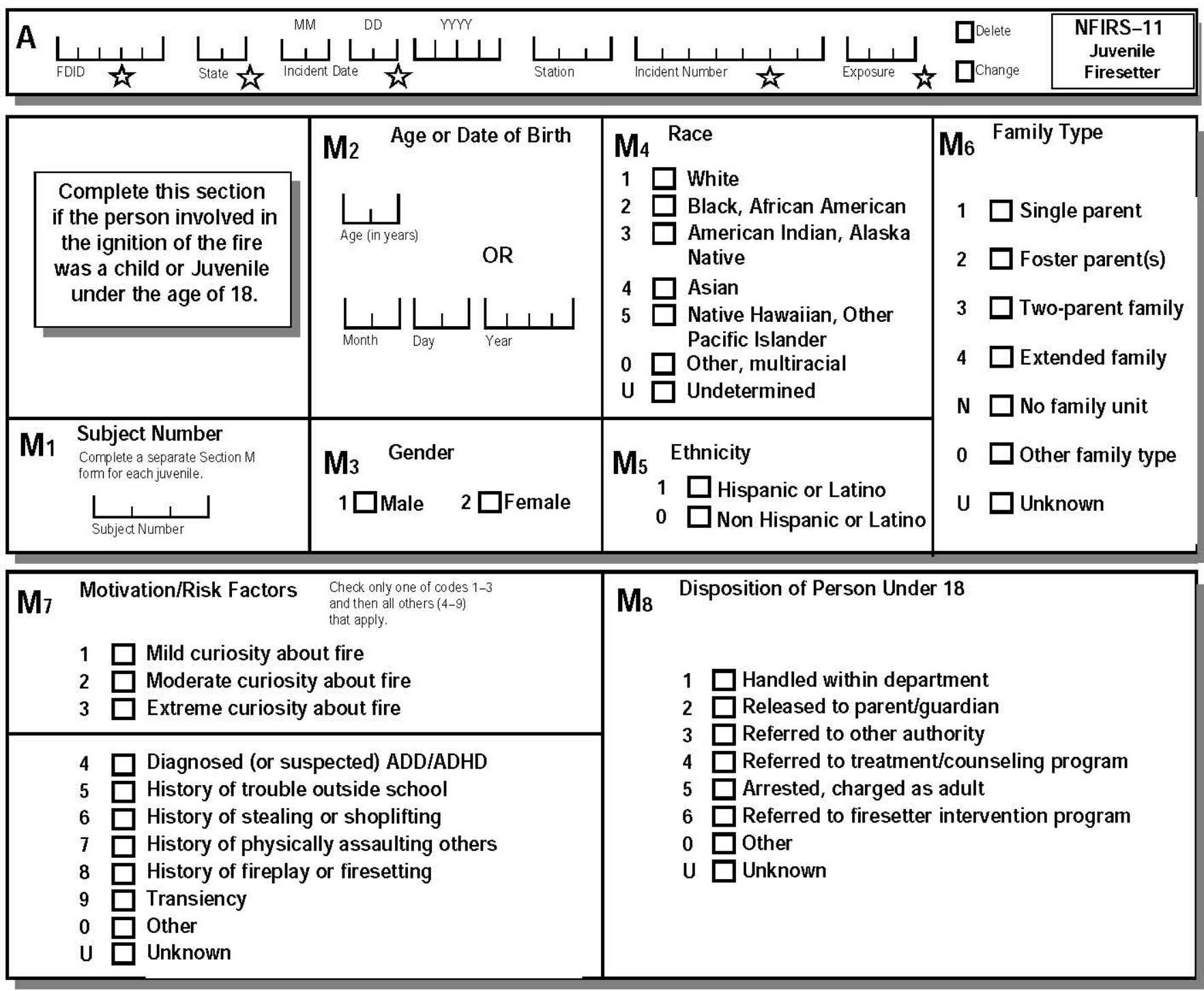

\begin{tabular}{|l|}
\hline $\mathbf{N}$ Remarks (local use) \\
\hline \\
\hline \\
\hline \\
\hline \\
\hline \\
\hline \\
\hline \\
\hline \\
\hline
\end{tabular}




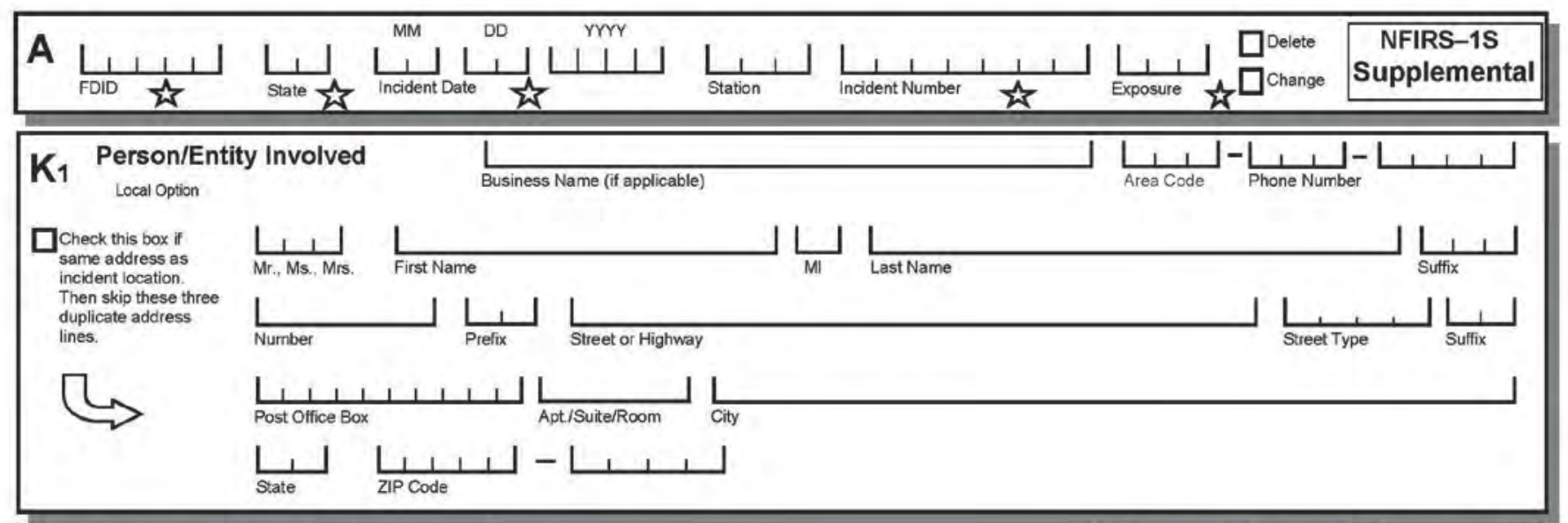

K1 Person/Entity Involved
Local Option

K1 Person/Entity Involved
Local Option

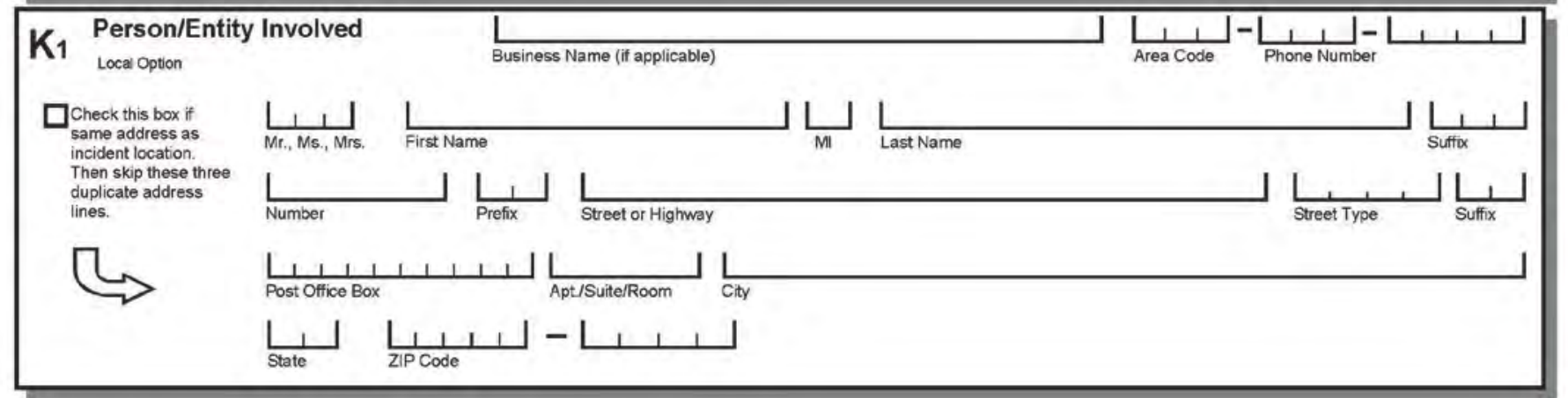

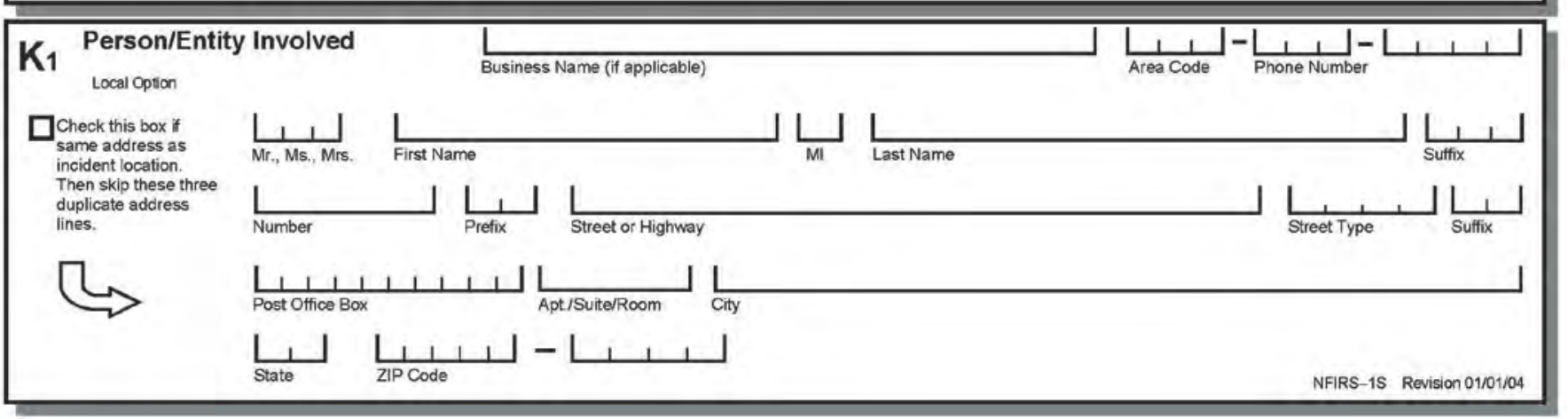




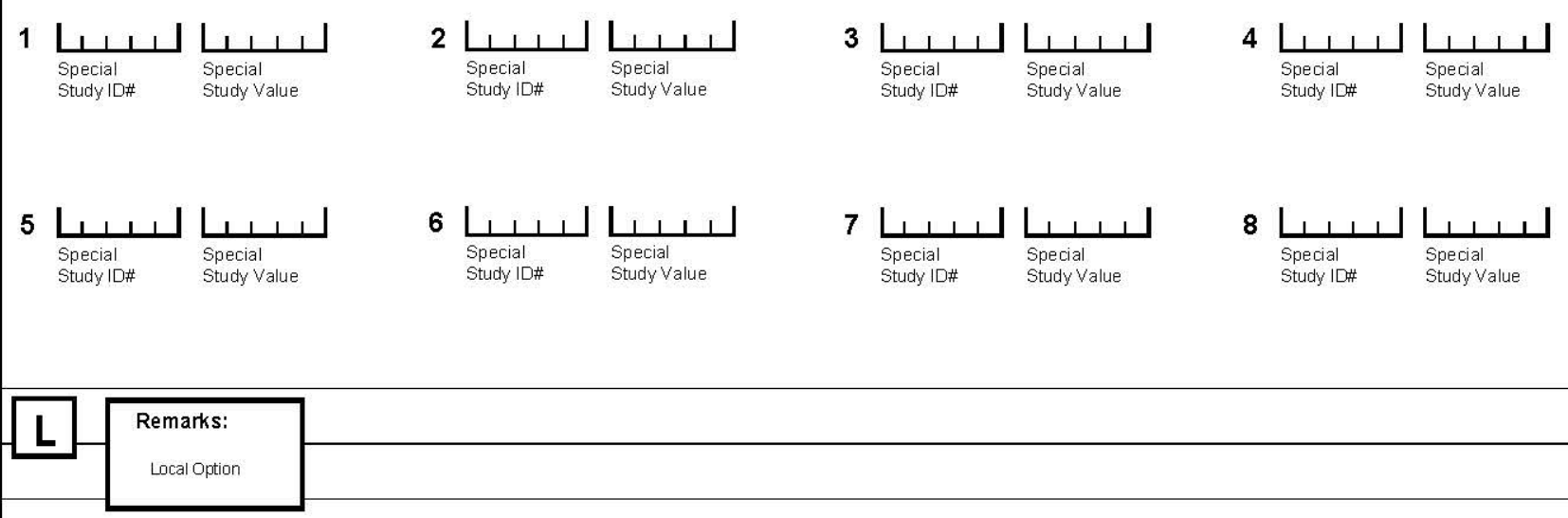


APPENDIX F-Summary of First-Day Presentations and Discussion 
- Recent studies confirm potential for rapid fire growth to cause significant fire losses in residences

- Time for RUF fueled fires to develop are on the same order as those required for fire departments to be notified and respond (implications for fire losses and fire fighter safety)

- Consensus that losses due to smoldering only RUF are small and nearly negligible (losses occur following transition to flaming)

- Statistics suggest that flaming ignition of RUF occurs in a number of ways and in total represent a significant but not dominant source of fire losses

- Direct measures are not available describing RUF as second (or higher) item ignited, but there may be approaches for estimating losses due to these ignitions

- There is justification for breaking down statistics into losses inside the room for fire origin and outside the room of fire origin

- Statistics describing the role of RUF inside the room of fire origin are somewhat limited due to a lack of information concerning fire growth within the room (events between ignition and fire leaving room are not well captured)

- Statistics concerning role of RUF on losses external to the room of fire origin appear to have a firmer foundation

- Approaches for filling in some data gaps and uncertainties were suggested.

- Targeted special studies using one page data sheet

- Informal questioning of people filling out INFIRS form to clarify how coding is being performed in the field

- There is a continuing need for characterizing number and characteristics of RUF in residence

- Prevention versus mitigation 